Portland State University

PDXScholar

Fall 12-18-2015

\title{
The Effects of an Overnight Environmental Science Education Program on Students' Attendance Rate Change for Middle School Years
}

Jennifer Elizabeth Basham

Portland State University

Follow this and additional works at: https://pdxscholar.library.pdx.edu/open_access_etds

Part of the Educational Leadership Commons, Junior High, Intermediate, Middle School Education and Teaching Commons, and the Science and Mathematics Education Commons Let us know how access to this document benefits you.

\section{Recommended Citation}

Basham, Jennifer Elizabeth, "The Effects of an Overnight Environmental Science Education Program on Students' Attendance Rate Change for Middle School Years" (2015). Dissertations and Theses. Paper 2730.

https://doi.org/10.15760/etd.2726

This Thesis is brought to you for free and open access. It has been accepted for inclusion in Dissertations and Theses by an authorized administrator of PDXScholar. Please contact us if we can make this document more accessible: pdxscholar@pdx.edu. 
The Effects of an Overnight Environmental Science Education Program on Students’ Attendance Rate Change for Middle School Years

by

Jennifer Elizabeth Basham

A thesis submitted in partial fulfillment of the requirements for the degree of

\author{
Master of Science \\ in \\ Educational Leadership and Policy
}

Thesis Committee:

Sybil Kelley, Chair

Heather Burns

Moti Hara

Daniel Prince

Portland State University

2015 


\title{
THE EFFECTS OF AN OVERNIGHT ENVIRONMENTAL PROGRAM
}

\author{
Abstract \\ Programs that engage middle students in participatory, real-world, and hands-on \\ field based instruction can be a powerful asset to the educational experiences for \\ students; motivating and inspiring some to appreciate and value school in a different way. \\ Overnight environmental science programs have a unique opportunity to support students \\ by creating experiences where students can participate in learning in vastly different ways \\ from what they may engage with in the traditional 4-walled classroom, while \\ concurrently developing a relationship with the natural world. Decreasing educational \\ budgets and increased need to substantiate educational programs in terms of their impact \\ on students has added pressure for overnight environmental science programs to validate \\ their impact through quantitative means. Utilizing overnight environmental science \\ education program attendance records and merging them with school district data relating \\ to attendance, this study investigates the impact of one such overnight environmental \\ science program on students' attendance rate change. Analyzing the secondary data using \\ multiple linear regressions modeling, researchers explored how the overnight \\ environmental program impacted student attendance rate change and how it varied by \\ demographic characteristics to understand if and how the program addresses school \\ district and educational policy reform targets.
}




\section{THE EFFECTS OF AN OVERNIGHT ENVIRONMENTAL PROGRAM}

\section{Acknowledgements}

There are a number of people to whom I need to offer my deepest gratitude. First I must thank the funders of this project: the Gray Family Foundation, Goodman Foundation, and the Institute for Sustainable Solutions. The extensive nature of this project could not have occurred without your generous support. I would also like to thank the participating districts in our study. Your continued involvement in the Multnomah Education Service District Outdoor School program and willingness to be a part of this research was invaluable. I must also recognize my thesis committee for their continued encouragement and incredible guidance to foster this project to the end. Special thanks to Sybil Kelley for always listening and envisioning this project with me, Heather Burns for being a grounded presence and inspiration, Moti Hara for your expertise and guidance with the statistical analysis, and Daniel Prince for believing in me and entrusting me with this giant project. Karen Finch, thank you for your dedication and time assembling the data for the project. A special thanks goes to my husband for your unending support and understanding while I grappled with this enormous project. To my peers, friends, and family for your compassion and patience. Finally, thanks to all of the phenomenal staff and educators who teach, inspire, mentor, and foster memorable and transformational experiences for students at the MESD Outdoor School. 


\section{THE EFFECTS OF AN OVERNIGHT ENVIRONMENTAL PROGRAM}

\section{Table of Contents}

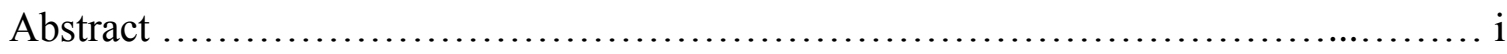

Acknowledgements...................................................... ii

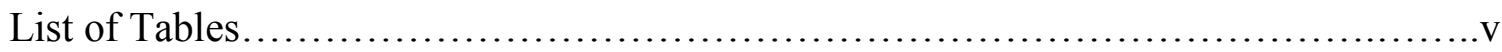

List of Figures...........................................................

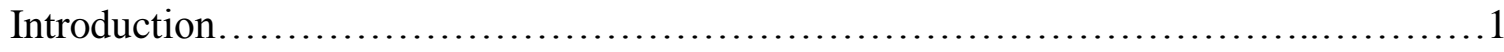

Review of Literature ..........................................................

Methods................................................................. 19

Results.................................................................... 33

Discussion...................................................................

Conclusion............................................................. 59

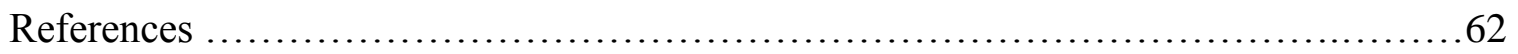

Appendix

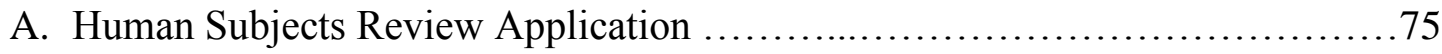

B. Human Subjects Review Approval...................................... 101

C. Example District Request for Study Participation (PPS) …................103

D. Portland Public School District Informed Consent.......................... 137

E. Reynolds School District Informed Consent.............................139

F. David Douglas School District Informed Consent....................... 145

G. Parkrose School District Informed Consent.............................. 151 
THE EFFECTS OF AN OVERNIGHT ENVIRONMENTAL PROGRAM

\section{List of Tables}

Table 1

Sixth Grade Student Demographic Based on Year they Attended the Outdoor School

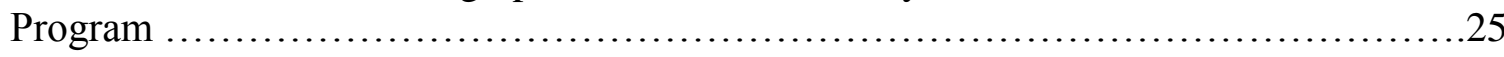

Table 2

Multiple Regression for Attendance Change from $5^{\text {th }}$ to $7^{\text {th }}$ Grade for Students Attending Outdoor School Program........................................... 35

Table 3

Multiple Regression for Attendance Change from $5^{\text {th }}$ to $7^{\text {th }}$ Grade for Students Attending Outdoor School Program by Year Attended..

Table 4

Multiple Regression for Attendance Change from $5^{\text {th }}$ to $7^{\text {th }}$ Grade for Students Attending Outdoor School Program by District Attended

Table 5

Multiple Regression for Attendance Change from $5^{\text {th }}$ to $7^{\text {th }}$ Grade for Students Attending Outdoor School Program by Year and District Attended. 


\section{THE EFFECTS OF AN OVERNIGHT ENVIRONMENTAL PROGRAM}

\section{List of Figures}

Figure 1

Number of Days Districts Participated in MESD Outdoor School

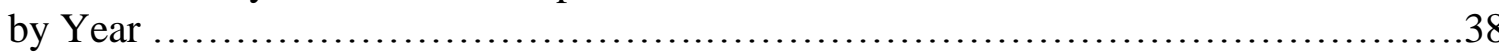




\section{THE EFFECTS OF AN OVERNIGHT ENVIRONMENTAL PROGRAM}

\section{Introduction}

The educational system within the United States has changed drastically over the past few decades. School leaders and policy makers have expressed deep concern for our nation's youth citing a troubling phenomenon of increased high school dropout, chronic absences, and disengaged students (Hart Buehler, Tapogna, \& Chang, 2012; Garcia-Reid, Reid, \& Peterson, 2005; Lieberman, 2013). Emphasis on high stakes testing coupled with higher levels of accountability have stretched the capacity of classrooms to build a knowledgeable and engaged citizenry that can solve the environmental and social problems of the future (Stapp, 1969). Furthermore, highly structured schedules, lack of access to natural areas, and the lure of technology have led to a myriad of social problems including increased obesity, less active lifestyles, and detachment from the environment (Louv, 2007; Williams \& Brown, 2012; Orr, 2010). With many problems facing our communities, society often looks to education to solve them.

A few problems that are explicitly related to schools are the problems of high school dropout and absenteeism. This is a disturbing problem for our society because for some demographics of students the dropout rates are upwards of 50\% (Rodríguez \& Conchas, 2009). Furthermore, studies have shown that the level of education a person has can predict future job opportunities and income (Baum, Ma, \& Payea, 2013). Current studies have shown that many of our nation's high school students are ill prepared to enter the workforce (Marx \& Harris, 2006) or have dropped out entirely. Arguably, one of the leading causes of high school dropout is chronic absenteeism (Hart Buehler, 


\section{THE EFFECTS OF AN OVERNIGHT ENVIRONMENTAL PROGRAM}

Tapogna, \& Chang, 2012). Moreover, absenteeism has been shown to have a huge influence on academic achievement because if students are not engaged in the learning environment, they miss out on valuable learning time (Basch, 2011; McDermott, Mordell, \& Stoltzfus, 2001). Although there are a multitude of factors that influence attendance, some studies have suggested that cultivating school environments where students can see the relevance of the content to their lives, are motivated to learn, and feel successful can be a powerful and salient experience leading to positive engagement within the classroom (Skinner, Chi, \& The Learning-Gardens Educational Assessment Group, 2011).

School programs that focus on engaging students in hands-on, field based scientific inquiry create positive opportunities that enhance the learning experience for children and allow them to participate in authentic, meaningful, and real-world applications of science (Mabie \& Baker, 1996), which could lead to increased engagement. Unfortunately, in many elementary schools, an extreme focus placed on literacy and math due to high-stakes standardized tests has pushed science education to the back burner (Hamilton, Stecher, Marsh, McCombs, \& Robyn, 2007). New emphasis placed on science, technology, engineering and mathematical (STEM) learning within the classroom is one step toward fixing this curriculum deficiency. However multiple barriers still exist in order to truly implement a robust curriculum that includes in-class instruction, outdoor field activities, and positive youth development skills (DettemannEasler \& Pease, 1999). 


\section{THE EFFECTS OF AN OVERNIGHT ENVIRONMENTAL PROGRAM}

The challenges schools face in implementing a curriculum that engages and excites students, while providing a solid foundation of skills and knowledge, are demanding at best. Furthermore, the educational system's success is measured by how well schools and students do on achievement tests (Marx \& Harris, 2006). Consequently, this shift in priorities is problematic in that it often favors subjects tested-reading and math — and neglects subjects of science and social studies (Hamilton et al., 2007). Providing students with rich and diverse experiences, both in and outside of the classroom, can contribute to a well-rounded student (Williams \& Brown, 2012). Overnight environmental science programming as a means to connect or reconnect disenchanted students to learning shows potential as a solution to our attendance problem.

Understanding how to connect students to the learning environment has been researched extensively. Over the past decade or more, much literature has focused on problems facing our educational systems such as the achievement gap (Evans, 2005; Gardner, 2007; Lieberman, Hoody, \& State Education and Environment Roundtable [SEER]., 1998), attendance (Eaton, Brener, \& Kann, 2008; Gottfried, 2010; Hart Buehler et al., 2012), engagement (Fisher, Frey, \& Lapp, 2011), motivation (Hardré, Davis, \& Sullivan, 2008; Skinner, Kindermann, \& Furrer, 2009), and the influence of policy shifts in education (Marx \& Harris, 2006; Samuel \& Suh, 2012). Another area of inquiry for many educational researchers has been the effect of the classroom environment and teaching strategies on student learning (Fazio \& Karrow, 2013). In the area of 


\section{THE EFFECTS OF AN OVERNIGHT ENVIRONMENTAL PROGRAM}

environmental education many studies have been conducted to understand how environmental education influences achievement (Bartosh, Tudor, Ferguson, \& Taylor, 2006; Lieberman et al., 1998), attitudes and beliefs about the environment (Bradley, Waliczek, \& Zajicek, 1999), and how environmental education programs support school learning through increased engagement and motivation in school settings (Skinner et al., 2011). Our research builds on current research about how environmental education programs support and foster connections schools and specifically links environmental science program outcomes with attendance.

This research explores the following questions: do overnight environmental science programs have a positive impact on students' attendance rate in school? If so, where are the largest gains? Additionally, does the impact of these programs differ depending on a student's economic, ethnic, and/or racial characteristics? If so, how? This study draws from the Social-Determination Theory (Bandura, 1997) to guide our assumption that overnight environmental science programs can nurture engagement and motivation in the classroom, leading to positive increases in attendance rate changes for the participants who attend the Multnomah Education Service District Outdoor School program (Skinner et al., 2011).

While overnight environmental science programs often cultivate a student's ecological awareness in addition to scientific application and knowledge gain (Simmons, 2000), schools can find it difficult to justify these experiences outside of the classroom due to the cost and, more importantly, the lack of quantifiable evidence of the impact on 


\section{THE EFFECTS OF AN OVERNIGHT ENVIRONMENTAL PROGRAM}

student learning (Bartosh et al., 2006). Moreover, focus on closing the achievement gap and retention has gained attention and has shifted school district priorities to support programs that have documented positive impacts on student success indicators (Bartosh et al., 2006). Despite many environmental science programs efforts to keep program costs low, they often are still cost prohibitive for many schools, making overnight environmental science programs an experience that is reserved for schools that can afford it (Dettmann-Easler \& Pease, 1999). Unfortunately, this phenomenon furthers the educational gap in experiences available to high and low socio-economic status children. In hopes of providing relevance to school curriculum and resolving this inequity, many environmental science programs have begun to structure their educational programming to support school district curriculum goals (Bartosh et al., 2006). In systems where students are limited by the funding available at schools, a district or state-wide commitment to out-of-class education programming could propel and re-engage disenfranchised students within the traditional classroom setting.

This study will contribute to the current research surrounding the achievement gap and provide a unique perspective through a quantitative lens of the impact of overnight environmental science programs on student success behaviors such as attendance. Understanding how overnight environmental science programs impact students will provide validation for the program implementation within the traditional school setting, inform school districts and other overnight environmental science 


\section{THE EFFECTS OF AN OVERNIGHT ENVIRONMENTAL PROGRAM}

programs of the benefits to student attendance that can lead to achievement, and provide valuable data to drive program improvement. 


\section{THE EFFECTS OF AN OVERNIGHT ENVIRONMENTAL PROGRAM}

\section{Literature Review}

School and policy leaders have drawn attention to a problem that has increasingly faced schools and our children: attendance. School administrators, teachers, and government agencies have called for the need to address student attendance in schools in order to confront the achievement gap and increased dropout rates. Common sense would argue that if students were not in school, they would be at a disadvantage. Studies corroborate this assumption and it has been documented that chronic absenteeism is related to lower achievement scores and can predict high school dropout (Hart Buehler et al., 2012; Gottfried, 2010).

Unfortunately, some groups of students are particularly vulnerable to poor attendance. Children from low-income families, minority students, and students in special education are disproportionally affected by high absenteeism rates (Fisher et al., 2011; Eaton et al., 2008). Fear, exposure to violent environments, and health issues influence whether students attend school on a regular basis (Ramirez et al., 2012; Bowen \& Bowen, 1999). While many factors contribute to poor attendance, finding interventions and strategies to incorporate within the school system will serve to both support students academically and narrow the achievement gap.

\section{Shifting School Priorities}

Impacts from, perhaps well-intentioned, educational policies have shifted the educational learning environment for students. Since the 2001 reauthorization of the Elementary and Secondary Act, renamed No Child Left Behind Act (NCLB) ("Elementary 


\section{THE EFFECTS OF AN OVERNIGHT ENVIRONMENTAL PROGRAM}

and Secondary Education Act | U.S. Department of Education,” n.d.), schools have been increasingly focused on teaching students core concepts of reading and math to increase student academic achievement, because they are being held accountable for these areas (Snyder, Flay, Vuchinich, Acock, Beets, \& Li, 2010). Moreover, some would say that as a consequence of the rigidity of NCLB, teachers and students have been left with a curriculum that is focused solely on topics addressed in the standardized tests leaving science and other subjects as peripheral (Marx \& Harris, 2006; Snyder et al., 2010). Further confounding the problem, this narrow focus has made it increasingly difficult for teachers to create the kind of engaging curriculum that excites students (Samuel \& Suh, 2012).

In addition to the pressures teachers face to meet NCLB requirements, the structure of middle school can present a challenge for students. Changes in school structure from elementary grades to middle school have been shown to present a decline in academic motivation indicators "such as attention in class, school attendance, and selfperception" (Eccles et al., 1993). When students move from small learning communities, classrooms, and individual attention given to students in elementary schools to larger middle schools with multiple classes and teachers, engagement and feelings of connection decrease (Meece, 2003). This decline in attendance and motivation in middle school years suggests interventions should be included within the middle school structure to support student growth, motivation, and learning. 


\section{THE EFFECTS OF AN OVERNIGHT ENVIRONMENTAL PROGRAM}

\section{Cultivating Rich Learning Environments}

Examining school environments which support student learning and foster motivation can guide schools to promote attendance and student engagement. SelfDetermination Theory has implications relating to students' engagement in school (Bandura, 1997). Furthermore, it provides a context from which to create the types of interventions to promote engagement and mitigate the influences leading to attendance issues. The premise of Self-Determination Theory suggests that people need to have feelings of competence, relatedness, and autonomy to promote the most favorable functioning, growth, and well being (Ryan \& Deci, 2000). Additionally, Ryan and Deci (2000) propose that humans have an inherent capacity to wonder and explore the world around them, leading to learning; however, environments where this learning takes place can either hinder or support this curiosity.

Motivation and engagement can be cultivated when elements in the learning environment are focused on developing student competence, a sense of relatedness to the teacher and peers, and autonomy over their learning (Skinner et al., 2009). Similarly, when feelings of connection and accomplishment are incorporated within the classroom content, students have been shown to increase self-efficacy and have improved classroom engagement (Lemberger, Selig, Bowers \& Rogers, 2015). Placing an intentional focus on out-of-class experiences to facilitate the three components of the self-determination theory (competence, relatedness, and autonomy) would further support student success and connectedness to the school setting, in turn influencing attendance rates. 


\section{THE EFFECTS OF AN OVERNIGHT ENVIRONMENTAL PROGRAM}

Alternative forms of education such as garden-based learning, field-based science education, and environmental education can serve as a context by which teachers promote students' engagement and motivation in the classroom. These authentic and placed-based contexts can provide students with the connection and relevance to their lives (Burns, 2009). Further, the relationships between garden-based education, science learning, motivation, and engagement was demonstrated in a longitudinal study by Skinner, Chi, \& The Learning-Gardens Educational Assessment Group (2011) which concluded that when students participated in garden-based science learning, their learning fostered "more intrinsic motivation and a greater sense of autonomy" (p. 32). These increases were potentially attributed to the ease at which students could feel competent in engaging fully in the activities. This research provides a compelling rationale for the notion that environmental education can cultivate a favorable educational experience for students by increasing student autonomy, relatedness, and competence leading to increased connections to school, self-efficacy and motivation.

Extending the notion of how exploratory educational contexts can lead to increases in student self-efficacy and achievement, we look to experiential education as a model for learning. Providing the vision and foundation for experiential education, Dewey (1938) posited that providing children with experiences that foster their creativity and inquiry initiates the development of students' engagement with learning experiences. Furthermore, he suggested these rich learning experiences could have a long lasting effect, resonating throughout a child's life (Dewey, 1938). As a result, many teachers 


\section{THE EFFECTS OF AN OVERNIGHT ENVIRONMENTAL PROGRAM}

seek learning experiences for students to have practical and meaningful application to students' lives (Samuel \& Suh, 2012). Environmental and field-based programs that engage students in hands-on learning provide a deeper understanding of science concepts (Mabie \& Baker, 1996; Simmons, 2000).

\section{Fostering Success Through Relationships}

Another influencing factor in creating an environment where students feel like they can be successful is by creating positive learning communities. Students who feel strong bonds to their school can have reduced threat of engaging in risky behaviors as a result of being absent from school (Eaton et al., 2008). Moreover, research has shown relatedness to school correlates with academic performance and motivation, while increasing a students' resilience from negative school environments and behaviors (Lemberger et al., 2015). Structuring learning environments where curriculum is learnercentered engages students in authentic learning opportunities that are culturally and socially relevant (Meece, 2003; Williams \& Taylor, 1999) which can lead to increases in engagement and motivation for middle school students promoting conceptual understanding and use of higher level thinking.

\section{Teacher beliefs and educational support.}

Teachers have an important role in defining and creating environments where students can take risks while feeling supported. Student-teacher relationships have been shown to have an effect on student's attitudes towards school and academic motivation (Eccles et al., 1993; Hardré et al., 2008). Tending to the emotional needs of students by 


\section{THE EFFECTS OF AN OVERNIGHT ENVIRONMENTAL PROGRAM}

creating a community of learners through building relationships, having high student expectations, and fostering a culture of care for themselves and their peers has been shown to be an effective strategy in successful classrooms, particularly for students of color (Love \& Kruger, 2005; Powell \& Seed, 2010; Palmer, 1998). Further, Evans (2000) argues that educators must "build relationships" with students to support their achievement and educational goals (p. 583). Fostering experiences where students can build relationships with teachers could have an important impact on student growth, motivation, and attitudes towards school.

In addition to fostering a school culture where students develop connections with their school (teachers and peers), develop motivation, and are engaged to learn critical thinking and citizenry skills, environmental science education meets another student need: differentiated instruction. Evans (2005) reasons that creating learning opportunities where students become the center of the educational experience through individualization should become the norm of any educational experience. Environmental science education can provide a varied learning environment for students who don't traditionally succeed within the four-walled classroom (Mabie \& Baker, 1996). Because many environmental science education programs provide small learning groups, they help students gain competence and offer individualized attention and autonomy that can allow students to ask for clarifying questions and learn through differentiation (Mabie \& Baker, 1996; Smith-Sebasto \& Obenchain, 2009; Webb \& Farivar, 1994). 


\section{THE EFFECTS OF AN OVERNIGHT ENVIRONMENTAL PROGRAM}

Addressing children's educational experience including their relationships, emotions, and academics, while fostering citizenry allows for students to engage with the learning in a powerful and deep way. Some believe that schools should encourage students to become active citizens, "who can gather and analyze information; who can develop and evaluate alternative courses of action," and communicate and solve social issues (Crockett, 1994). Hungerford \& Volk (1990) argued that environmental education is well poised to support schools in this endeavor because it fosters "behavior encompassing not only knowledge, attitudes, and skills, but also active participation in society" (p. 9). Furthermore, others suggest that environmental education programs cultivate motivated citizenry capable of addressing complex societal issues (Simmons, 2000; Stapp, 1969; Tbilisi Declaration, 1978). Similarly, engagement and motivation can increase when students begin to see the relevance of the curriculum within their daily lives (Dawes \& Larson, 2011). Transferring these experiences and skills to traditional learning environments can create a welcoming and inviting place for students to learn, extending the impact of the learning environment for students (Evans, 2005).

\section{Overnight Environmental Science Programs and Attendance}

Addressing attendance problems within the school setting is a complex issue requiring multiple approaches and interventions. While broad large-scale solutions will require a comprehensive system-wide reconstruction, educators can look existing practices that have been shown to promote motivation and engagement in the classroom. This study focuses its attention on an environmental science education program that 


\section{THE EFFECTS OF AN OVERNIGHT ENVIRONMENTAL PROGRAM}

supports student engagement and scientific learning through hands-on, inquiry, and fieldbased instruction. Ultimately, we want to show that overnight environmental science programs are not only focused on teaching students science concepts, but they are a method for engaging and motivating students to achieve in other subjects, and in school overall.

Several definitions of environmental education have surfaced since its inception in the 1960s and 1970s (McBeth \& Volk, 2010; Hungerford, 1998; Strapp et al., 1998). More recently, Simmons (2000) asserted that what sets environmental education apart from more traditional school curricula is the intentional focus that it places on teaching at the intersection of knowledge and skills. Another significant definition described by Stapp (1969) suggests that "environmental education is aimed at producing a citizenry that is knowledgeable concerning the biophysical environment and its associated problems, aware of how to help solve these problems, and motivated to work toward their solution" (p. 31). While the program in the research project has elements of environmental education, a broader definition that includes science education as a primary focus should be integrated. The Multnomah Education Service District (MESD) Outdoor School program is focused on educating and supporting science education, and its aim is to also promote an active and engaged citizenry through acquisition of natural science concepts at an overnight experience (“Outdoor School / Program Tour,” n.d.).

Drawing from the aforementioned definitions, we define the MESD Outdoor School program in this study as an Overnight Environmental Science Education Program 


\section{THE EFFECTS OF AN OVERNIGHT ENVIRONMENTAL PROGRAM}

that meets the following standards: (1) the focus of the program is on engaging students in hands-on, authentic studies of ecology and science that build knowledge and skills, while motivating students to become active citizens who have the capacity to solve current and future environmental problems, (2) students participate in the program for a minimum of two nights, (3) they attend the program with their class and teacher, and (4) as a central piece to the program structure, high school students participate as leaders, mentors, and teachers.

A number of researchers have investigated schools and their role in reducing attendance problems (Bowen \& Bowen, 1999; Hart Buehler et al., 2012; Eaton et al., 2008; Fisher et al., 2011; Gottfried, 2010). While others expound the benefits of environmental science education on achievement (Bartosh et al., 2006; Lieberman \& Hoody, 1998; Smith \& Motsenbocker, 2005), few if any have linked environmental science education as a moderating influencer on school attendance. Some research has questioned the connection between out-of-class school programs and school achievement acknowledging that if such programs can promote student engagement within the out-ofschool setting, they may be the "gateway to increased engagement in science class and in school” (Skinner et al., 2011, p. 20). Discovering a connection between environmental science education programs and attendance could support the anecdotal evidence discussed by teachers who say that their students' experience at the overnight environmental science education program propelled some of their most difficult students to reengage with the classroom community. 


\section{THE EFFECTS OF AN OVERNIGHT ENVIRONMENTAL PROGRAM}

While some would argue that the one-time programs would show little moderating influences on the indicators of success such as attendance, Transformational Learning Theory would suggest otherwise. Transformational learning occurs when students experience shifts in their thinking about their world view through critical reflection, relationship building, and meaning making (Baumgartner, 2001). Sterling (2011) emphasizes that for transformational learning to occur students "need to 'see' differently if [they] are to know and act differently" (p. 52). Providing alternative learning environments like overnight environmental science programs where students begin to recognize diverse perspectives and experience through living and learning with others from different schools can create a setting for this transformation to occur.

Students at the MESD Outdoor School program have enumerable opportunities to reflect and reshape their views, beliefs, and assumptions about the natural world and their community as they learn science in a place based setting. While at the program, students are immersed in the natural areas near their home, leading to a deep connection and "reeducation" of place where relationships with community and natural processes can

develop (Burns, 2009, p. 51). Through guided discussions about their actions that impact the environment, students begin to alter their relationship to the land and ethic of care (Williams \& Brown, 2012). During their experience, students live with students from other schools, which can enrich their understanding of diverse perspectives leading to building empathy and reflection of their values (Smith, 1999). Furthermore, the residential setting and hands-on nature of the program could lead to changes in students' 


\section{THE EFFECTS OF AN OVERNIGHT ENVIRONMENTAL PROGRAM}

perceptions of scientific learning and school in general. By changing educational setting students participate in to one where they can develop a deeper understanding and shift in their concept of what constitutes learning (Sterling, 2011). Although fostering opportunities for students to interact with science taught at overnight environmental science education programs could be a catalyst to increased scientific knowledge, the transformational impact of the program on the student's view of education might prove to have a more salient effect that reaches across curriculum objectives.

\section{Quantifying Impacts}

Although one might assume that programs with longer durations would provide a deeper impact on student learning, little empirical research has been conducted within the environmental education field to corroborate this assumption. Perhaps this gap in the research is due to the awareness that more contact days would provide a stronger influence on students, or it could be due to the vast differences between environmental education programs. The relatively new emphasis on quantifying impact creates an additional challenge for small-overextended environmental programs to meet the rigorous demands of an in-depth evaluation program or study (Ferguson, Angell, \& Tudor, 2001; Lieberman \& Hoody, 1998). Thus, this research will further the understanding of how length of educational programming impacts students attendance, ultimately demonstrating to educational leaders how duration plays an important role in the impact of the program. 


\section{THE EFFECTS OF AN OVERNIGHT ENVIRONMENTAL PROGRAM}

Demonstrating evidence for program impact on student's attendance will be an important step in discovering how overnight environmental science programs support the success of students within the traditional classroom setting; however, uniquely observed within this study will be the discovery of how overnight environmental science programs impact various demographic sub-groups of students differently. Considerable research over the past decade has been dedicated to understanding the achievement gap (Balfanz \& Byrnes, 2007; Desimone \& Long, 2010; Evans, 2005; Gardner, 2007; Lieberman \& Hoody, 1998), primarily looking to understand why and how underprivileged youth are not meeting the same educational benchmarks as their privileged peers. In this research study, our goal will be to discover if certain demographics of students demonstrate a stronger effect of positive attendance rate change than other students. We are also concerned with how overnight environmental science education programs might support in-class educational experiences relating specifically to attendance. Ultimately this research seeks to discover if overnight environmental science programs have a positive impact on students' attendance rate in school and if the impact of the MESD Outdoor School program differs depending on a student's economic, ethnic, and/or racial characteristics. 


\section{THE EFFECTS OF AN OVERNIGHT ENVIRONMENTAL PROGRAM}

\section{Methods}

For many environmental programs, qualitative data serves as a foundation to understand their impact. More recently, programs are including evaluative structures to document their educational and social impact for students. This evidence has often provided valuable feedback to the specific programs. Due to the variety of program structures, emphasis, and small study samples, challenges exist to speak broadly about how environmental education programs translate to success in schools. No study to date has had the opportunity to bring together such a large and rich data set to look quantifiably at an overnight environmental science education program. Consequently, we chose to document the impact of the MESD Outdoor School program through a quantitative lens to address this predicament and to validate the program impact through statistical means over multiple years.

We used multiple linear regression modeling to investigate the influence of the MESD Outdoor School sixth grade experience. We chose to focus our study on student attendance rate change for the school years before and after the experience. The intention was to understand if student's attendance rate varied significantly between fifth and seventh grade, and if they differed by the season they attended Outdoor School, and/or by demographics. In our study, we probed existing data including program attendance and school district records to understand if overnight environmental science programs have a positive impact on students' attendance rate in school. If so, where are the largest gains? 


\section{THE EFFECTS OF AN OVERNIGHT ENVIRONMENTAL PROGRAM}

Additionally, does the impact of these programs differ depending on a student's ethnic and/or racial characteristics? If so, how?

\section{Participants}

Using existing secondary data gathered by school districts and the MESD Outdoor School program, we compiled a large data set of 29,112 students from four school districts in a metropolitan area in the Pacific Northwest who participated in the overnight environmental science program for various durations during the 2006-2013 school years. Two different sources of secondary student data that were merged together from the participating districts were: MESD Outdoor School program attendance records, and school district data. The class lists provided by the overnight environmental science program documented school attended in sixth grade, sixth grade teacher, student name, program site attended, and dates attended. This data was coded to operationalize the data for use in the SPSS statistical software. The second source of existing data was garnered through public school district protocols. After sharing the research methodology and the intended use of the data with districts, we were granted permission to merge the program attendance lists with the district data pertaining to student test scores in math and science, attendance rates, incidents of referrals, suspensions, cumulative credits earned, and graduation data for the four districts within our study. The combination of both program and school district data served as a unique way to identify and understand programmatic impacts on students. 


\section{THE EFFECTS OF AN OVERNIGHT ENVIRONMENTAL PROGRAM}

\section{Participant recruitment.}

After drafting a Memorandum of Understanding between Portland State

University and the MESD Outdoor School program, the researchers began the selection of the districts included in our study through meetings with key stakeholders at the districts who participated in the overnight environmental science program. As a whole, the program serves seven districts and 7,000 students annually. Complying with the University protocols the research team drafted a Human Subjects Review application (Appendix A) which was approved through the Portland State University institutional review board (Appendix B). Upon successful review of the research methods and plan, we made formal inquiries with districts to seek their participation in our study (Appendix C). Four of the seven school districts agreed to participate and formal data requests were compiled and approved through district protocols (Appendices D-G).

Upon receiving informed consent from the four districts participating, we began compiling, tracking, and number coding the overnight environmental science program attendance records. Because our research exclusively utilized existing data gathered from the overnight environmental science program and school district records that would be unidentifiable to the researchers, we did not obtain individual informed consent. To further ensure the confidentiality of the participants, each student was given a proxy identification number and we aggregated student populations if disaggregated populations numbered ten or fewer. 


\section{THE EFFECTS OF AN OVERNIGHT ENVIRONMENTAL PROGRAM}

After compiling and coding the MESD Outdoor School records, researchers preformed a quality control check on a random selection of data points. For the fall of 2006, the researchers completed a quality check on $35 \%$ of the individuals because the data was input manually from handwritten forms, so the chance of human error was greatest. For the spring of 2007, a $15 \%$ check was performed because this data was input from typed documents, so the potential for errors was still high. For this school year, the margin of error was $<5 \%$ in the fall and $<1 \%$ in the spring. All following years included in the study had a quality control check at $10 \%$ and the margin of error was $<1 \%$.

Researchers then transferred the data to the data representative at the school district who assigned the proxy ID and matched students from the MESD Outdoor School attendance records with school district data. Through the process of merging the records, some students were excluded if they could not be confidently matched with the district identifiers of name, school, and grade. For example, student records were excluded if two students shared the same name (i.e.: Chris Jones), or if the name on the attendance records did not match the names within the school district reporting system. Overall, we retained $87 \%$ of the original 33,500 students, leaving the researchers with 29,000 unique records to analyze.

\section{Participant demographics.}

Our study analyzed data that spanned seven years, dating from the school years 2006-2007 to 2012-2013 and during this period, the federal government enacted a new system for delineating ethnicity and race. Prior to 2009, both ethnicity and race were 


\section{THE EFFECTS OF AN OVERNIGHT ENVIRONMENTAL PROGRAM}

categorized together in six categories: Asian, Black, Hispanic, Native American, Unspecified, and White. In 2009, the categorization changed to include a dichotomy for ethnicity, Hispanic or Non-Hispanic, with a sub-categorization of Race, which includes Asian, American Indian/Alaskan Native, Black/African American, Multi-Racial, Native Hawaiian/Pacific Islander, and White. This change in categorization scheme presented a challenge to delineate a consistent coding system across the span of our study. To ensure a uniform race and ethnicity across the span of our study we utilized guidelines set forth by the National Center for Education Statistics ("Standard 1-5 - NCES Statistical Standards," n.d.). Using these statistical standards, we aggregated the Native Hawaiian/Pacific Islander race within the Asian category and the Black/African American race within the Black category for the 2006-2008 ethnicity delineation. Students in the Hispanic category prior to 2009 were aggregated with the Hispanic/Latino category, with the exception of those who identified as a race of Black/African American. These individuals were combined within the Black/African American race category.

The effect of the dichotomy of ethnicity being Hispanic or Non-Hispanic and the addition of the Multi-racial category on our data set was particularly noteworthy. Prior to 2009, Native Americans had their own category within the ethnicity demographic; however, in 2009 the reporting standards changed to include individuals who have an origin in both North and South America with a tribal affiliation ("Standard 1-5 - NCES Statistical Standards," n.d.) This adaptation of the reporting scheme eliminated the specific category of the North American Native American population ("New Federal 


\section{THE EFFECTS OF AN OVERNIGHT ENVIRONMENTAL PROGRAM}

Race and Ethnicity Reporting: Assistance Manual,” 2010). Due to this re-categorization, the mean numbers of Native Americans fluctuated by approximately 36 individuals after 2009. The aggregated Native American/American Indian/Native Alaskan demographic was combined across the span of the study. White/Non-Hispanic category was incorporated within the White category. Students who identified as Multi-Racial after the re-categorization, could not be confidently analyzed within our demographics because prior to 2009 , the multi-racial category was not made available to students.

Unfortunately, these inconsistencies in the available ethnicity and race categorizations across the span of our study led the researchers to omit students who identified as Multiracial after 2009.

The sample size was reduced further based on the usable data for our study methods. While we had data for the 2006-2007, 2007-2008 and 2012-2013 school years, we were interested in the change rate in attendance for the students between the years prior to and after their sixth grade experience. This meant that we would need to pull data points from the year before and the year after their experience to get a reliable rate of change for the students. Researchers were unable to do this for students who attended the program in both the 2006-2007 and 2012-2013 school years. The researchers had to exclude the 2007-2008 school year as well due to inconsistencies in data reporting in some districts.

Table 1 documents our final compiling of secondary data for sixth grade students who attended the MESD Outdoor School from 2008-2012. Our final sample size 


\section{THE EFFECTS OF AN OVERNIGHT ENVIRONMENTAL PROGRAM}

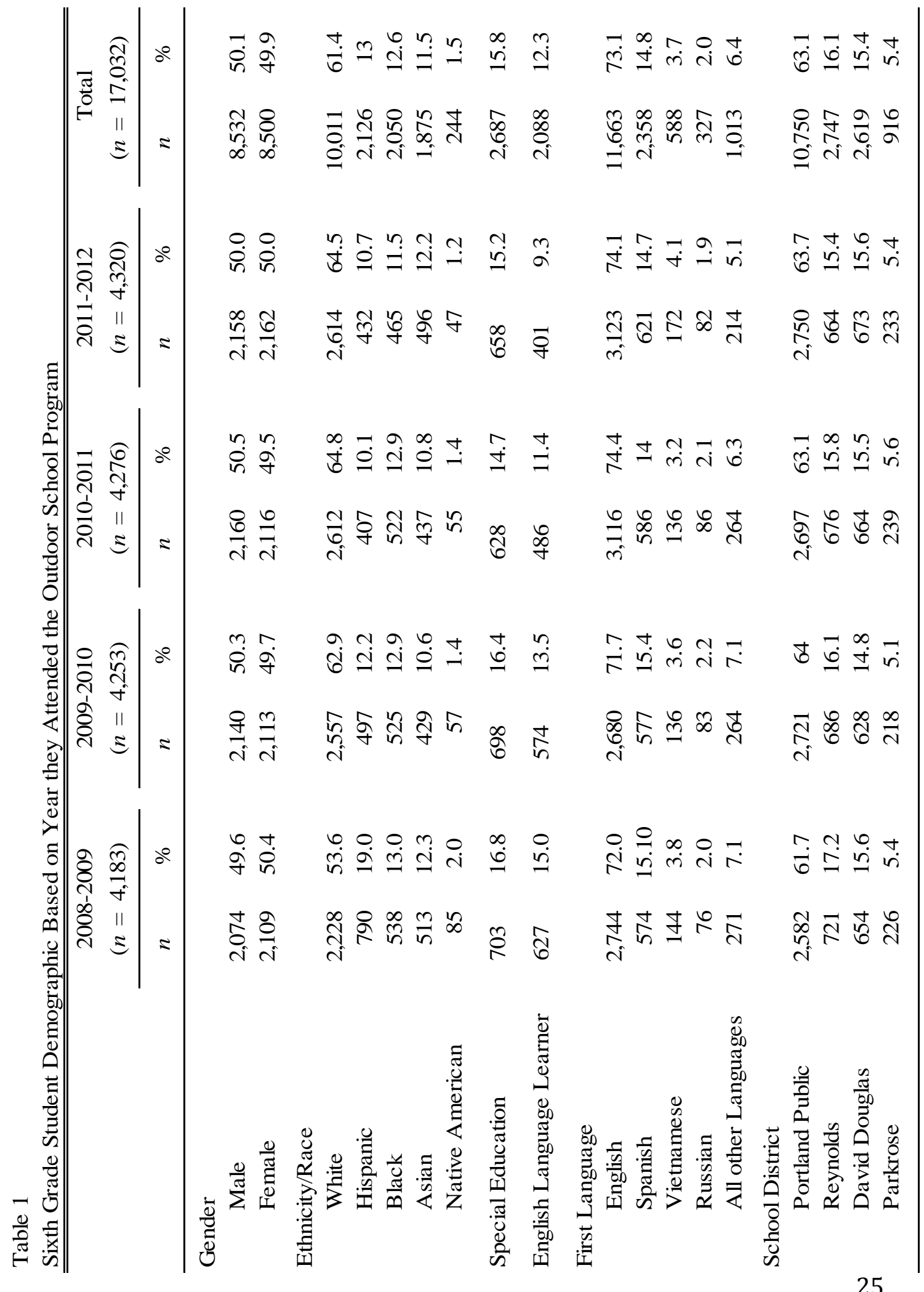




\section{THE EFFECTS OF AN OVERNIGHT ENVIRONMENTAL PROGRAM}

comprised of 17,032 sixth grade students from 4 districts and 58 schools, 8,532 identified themselves as male (50.1\%) and 8,500 identified themselves as female (49.9\%). The racial/ethnic demographics for the sixth grade sample were 1,875 Asian/Pacific Islander (11.5\%), 2,050 Black/African American (12.6\%), 2,126 Hispanic (13\%), 244 Native American/American Indian/Alaskan Native (1.5\%), and 10,011 White (61.4\%). The representation of students identified with special needs was 2,687 (15.8\%). The English Language Learner [ELL] population within our study included 2,088 sixth graders participating in the ELL support programs (12.3\%).

The sixth grade data analyzed for our research represents a large pool of students who participated in the Outdoor School program over the span of four years 2008-2012 from a predominately urban setting in the Pacific Northwest. The student population is one that draws from a diversity of socio-economic statuses from the surrounding metropolitan county with a population of 735,000 ("Multnomah County QuickFacts from the US Census Bureau," n.d.). Unique to the MESD Outdoor School program, the students who participated did not opt in by individual schools, but they attended the program as a whole school district. This means that if the student was enrolled as a sixth grader in a participating district, they attend the MESD Outdoor School program. Unlike other overnight environmental science programs, where a teacher or school may select to take their students to the field trip program, this program serves districts as a whole, engaging all sixth grade students in the district. This program design fosters the 


\section{THE EFFECTS OF AN OVERNIGHT ENVIRONMENTAL PROGRAM}

opportunity to impact a broad range of students in the region because barriers to access were removed.

Two factors that must be considered in replication and generalizability of the study are historical factors that influence the population. While the program reaches a large number of students in the region, due to the historical narrative of the county, the general population is less diverse than other urban cities of similar size (Hannah-Jones, 2011). While the ethnic make-up of the Pacific Northwest is slowly changing, it should be acknowledged that when compared to other urban cities it has far fewer numbers of minority populations. Another unique factor for the students in our study is that the Pacific Northwest has been recognized for its conservation ethic and ecological understanding shared between many individuals (Berkes \& Turner, 2006).

\section{School district program participation.}

The participating districts in our study provide a unique glimpse into our study due to the broad and diverse group of participants, socio-economic statuses, and students from varying urban and suburban neighborhoods. While these districts represent different groups of students participating in the MESD Outdoor School program, the inconsistency in program duration is another important difference. These variances in duration raise questions about potential impacts on student success indicators.

Portland Public School District, the largest district in our study, provided a vast degree of variation in its student population. This district represented $63.1 \%$ of the total population of students in the study and the district as a whole serves over 45,000 students 


\section{THE EFFECTS OF AN OVERNIGHT ENVIRONMENTAL PROGRAM}

(“DBI Reports," n.d.). During the study years, the overnight outdoor program served 10,750 middle and elementary schools from this particular district. The students in this district participated at a full week program for three of the four years and participated in a 3-day program during the last year of our study.

The David Douglas and Reynolds School Districts represented 15\% and 16\% respectively of the total population in our study. Both of these districts reside on the outskirts of the city limits and draw from low-socioeconomic neighborhoods. The students in these districts came from predominantly minority and/or migrant households. The David Douglas School District served students within the Portland city limits, while the Reynolds School District borders Portland and includes students from surrounding suburban cities. These two districts participated in the Outdoor School program for varying lengths of time. David Douglas School District participated for the full week program during 2008-2011 in our study then as a result of budget cuts, reduced their program to a 3-day program during the 2011-2012 school year. Although the Reynolds School District had consistent participation in the program over the past decade, they underwent budget cuts during the time frame of this study that impacted MESD Outdoor School funding. In 2008-2009, the Reynolds School District participated in a 6-day program. In 2009-2010, participation was reduced to a 2-day program, followed by and increase to a 3-day program in both 2010-2011 and 2011-2012.

Parkrose was the smallest district in our study with a total of approximately 230 students participating annually in the overnight outdoor school program. The sample size 


\section{THE EFFECTS OF AN OVERNIGHT ENVIRONMENTAL PROGRAM}

of the Parkrose School District should be noted as a factor in the overall scope and effect on the analysis. The total percentage representation of the Parkrose School District in our study was 5\% and 916 students over the four-year span of our study. Like other districts in our study, the Parkrose School District faced severe funding cuts during the span of our study and as a result participated at differing durations. In 2008-2009 they were involved in the 6-day program but reduced to a 2-day program in 2009-2010. Over the next two school years, they added an additional day each consecutive year: 3 -days in 2010-2011 and 4-days in 2011-2012.

The aforementioned sample sizes provided a solid foundation on which we may make inferences into the impact of the program on student success indicators such as attendance. Throughout the analysis, the population dynamic and duration attended by districts will provide additional meaning to the results when separated by year attended and district. Furthermore, the longitudinal nature of the analysis allows for drawing conclusions of the program over a four-year period of time.

\section{Procedure}

The specific research question was to investigate whether the attendance rate of students in fifth grade varied significantly from their seventh grade attendance rates, and whether there were any differences based on other demographic factors. We utilized multiple linear regression modeling to illustrate relationships between the independent and dependent variables across multiple years (2008-2012). For our first set of analyses completed, the dependent variable was: change in attendance rate between fifth and 


\section{THE EFFECTS OF AN OVERNIGHT ENVIRONMENTAL PROGRAM}

seventh grades. Previous anecdotal evidence from participating teachers indicate that attending Outdoor School in the fall builds classroom community, leading to stronger connections between students and school, which in-turn promotes positive behaviors such as increased school attendance. Our independent variables were whether students attended in the fall or the spring, gender, ethnicity/race, special education, English language learner, student's first language, and their RIT score on the Oregon statewide math test. RIT scores are calculated using the difficulty of each test item to estimate student achievement ("The RIT Scale | Northwest Evaluation Association (NWEA)," n.d.). Each of the variables was delineated in conjunction with students' attendance rate change from fifth to seventh grade. By citing different projections of attendance, we could make inferences as to the impact of students' sixth grade year as a factor influencing attendance.

\section{Attendance rate change variable.}

The variation in consistency of reporting by the four districts in our study limited the number of variables and data points we would be able to feasibly source for analysis. This consideration led us to focus on the use of the attendance rate variable. Guided by the assumption that most schools have an embedded system for tracking and documenting students, as well as the objective nature of attendance vs. non-attendance, we felt confident that we would find a fairly accurate account of the attendance rate consistently across schools. This was not the case when looking at variables such as incidents of behavior and suspension rates. 


\section{THE EFFECTS OF AN OVERNIGHT ENVIRONMENTAL PROGRAM}

To test our hypothesis if there was a difference for students attending the MESD Outdoor School program between their sixth grade attendance rate and other school years, we chose to utilize a paired sample t-test between the sixth grade attendance rate and the fifth grade attendance rate. This was an initial inquiry to determine whether further statistical tests should be administered. The next statistical test was an independent sample t-test between students sixth grade attendance and the season they attended: either fall or spring session. This test determined if our initial hypothesis that students attending the overnight environmental science program towards the start of the school year could provide evidence that attendance in the MESD Outdoor School program early in the year, might foster students feeling of connectedness to their teacher and peers contributing to positive attendance rate changes. While we did find significant changes in attendance rates, we found it difficult to attribute these results exclusively to the overnight environmental science program because we would expect there to be a variation in attendance regardless of program attendance. However, the results prompted further inquiry into the program attendance with regards to the whether student attended in the fall or spring, and how attendance rate change differed among the demographic characteristics.

For our multiple linear regression models, attendance rate was calculated using the number of days that a student is in attendance while school is in session. This number included late arrivals and if students attended for a partial day. In order to understand how the MESD Outdoor School experience influenced attendance we looked at data that 


\section{THE EFFECTS OF AN OVERNIGHT ENVIRONMENTAL PROGRAM}

was pre and post the student's sixth grade experience at MESD Outdoor School, so we took each student's fifth and seventh grade rate of attendance. We calculated the attendance rate difference by subtracting the fifth grade attendance rate from the seventh grade attendance rate giving us the variable $5^{\text {th }}$ to $7^{\text {th }}$ attendance rate change. The difference between these two data points represents the amount to which the student's attendance rate changed from fifth to seventh grades and spanned the middle school transition year. Students' fifth grade mathematics scores, and demographic/background characteristics, were taken into account, as part of the analysis. To enhance the interpretability of the corresponding regression coefficient, the mathematics RIT scores were re-centered (around grand mean scores) and rescaled (divided by ten).

We recoded each of the independent variables (Session, Gender, Ethnicity Race, Special Education, English Language Learner, and First Language into dichotomous variables and included them in the regression models. During the study the researchers ran multiple regression models to tease out variations between cohorts of students included in our study. Following the initial regression model, which included all of the students from 2008-2013, we then ran our regression model with the students separated by school year they attended, and then separated by district attended, and finally by both year and district attended. Each of the tests illuminated the variability among the years and districts within our study. 


\section{THE EFFECTS OF AN OVERNIGHT ENVIRONMENTAL PROGRAM}

\section{Results}

Multiple regression statistical models were used to inquire if demographic and program specific variables predicted students' attendance rate change between fifth and seventh grades. Researchers followed a series of steps to filter for, and delve deeper into, how the overnight environmental science education program impacted students' attendance rate change. The research questions guiding our inquiry were: (1) Do overnight environmental science programs have a positive impact on students' attendance rate in school? If so, where are the largest gains? (2) Does the impact of these programs differ depending on a student's economic, ethnic, and/or racial characteristics? If so, how?

We started our analysis with hypothesis testing to see if there would be enough evidence of variation in attendance rate change for the students attending the overnight environmental science program to solicit further investigation. We started with a paired sample t-test. Not surprisingly, the results from our paired sample t-test confirmed our hypothesis, that there is a difference between a student's fifth grade $(M=.946, S D=$ $.065)$ attendance rate and sixth grade $(M=.905, S D=.207)$ attendance rate; $t(29111)=$ $34.2, p=<.001$. Our second round of hypothesis testing was an independent sample ttest to analyze the affect of participating in the overnight environmental science program in the fall $(M=14,132, S D=.198)$ versus the spring $(M=14,980, S D=.215)$ on student attendance rate change between fifth and sixth grades; $t(29,094)=-2.66, p=.008$. Our final independent sample t-test was conducted to understand how duration affects 


\section{THE EFFECTS OF AN OVERNIGHT ENVIRONMENTAL PROGRAM}

attendance rate change. We split our study sample by whether students attended the overnight environmental program for 5-nights $(M=10,266, S D=.199)$ or partial weeks (less than 5 nights $)(M=18,843, S D=.211)$ to see the affect on attendance rate change between fifth and sixth grades. A significant difference was found between the full and partial durations $t(22,209)=-3.623, p=<.001$. Based on the findings that a significant difference was found between fifth and sixth grade attendance, fall and spring attendance in the overnight outdoor science program, and full vs. partial attendance; further analyses were conducted.

Following the initial hypothesis testing, we chose to create a dependent variable to account for a difference between a student's fifth grade attendance rate and a student's seventh grade attendance rate, to control for the sixth grade year as a moderator of the effect of the overnight environmental science program has. We chose the variable attendance rate change between $5^{\text {th }}$ and $7^{\text {th }}$ grades was chosen as our DV for the next set of analysis using multiple regression modeling. A series of multiple regressions were conducted for the attendance change variable paired with the season in which the students attended the program and demographic variables gender, ethnicity/race, special education, English language learner, first language, and fifth grade Math RIT score. The Math RIT score was used to quantify the expected change in attendance rate for every 10points scored on the fifth grade math test. The first regression incorporated all students across all of the years of the study $(n=17,032)$. Each subsequent series filtered students by district, year, or a combination of both. 


\section{THE EFFECTS OF AN OVERNIGHT ENVIRONMENTAL PROGRAM}

Table 2 outlines the regression coefficient (b) standard error, and $p$-value for each variable while holding all other variables constant, allowing us to view the individual effects of each variable on attendance rate change between fifth and seventh grades. When all students and districts were grouped together, many variables showed significant changes in attendance for students who attended the overnight outdoor science program. Specifically, fall participation predicted a significant positive attendance change for students compared to students who attended in the spring $(p<.001)$. When females were compared with males, males also had a positive attendance rate change from fifth to

Table 2

Multiple Regression for Attendance Change from 5th to 7th Grade for Students Attending Outdoor School Program in the 2008-2012 School Years

\begin{tabular}{lccc}
\hline \hline Independent Variable & $b$ & SE & $p$ \\
\hline Constant & -.004 & .002 & $.013^{*}$ \\
Session & -.004 & .001 & $<.001^{*}$ \\
Female & -.002 & .001 & $.029^{*}$ \\
Ethnicity/Race & & & \\
$\quad$ Asian & .007 & .002 & $.001^{*}$ \\
$\quad$ Black & .001 & .002 & .483 \\
$\quad$ Hispanic & -.008 & .002 & $<.001^{*}$ \\
$\quad$ Native American & -.014 & .004 & $.001^{*}$ \\
Special Education & .000 & .002 & .816 \\
English Language Learner & -.005 & .002 & $.017^{*}$ \\
First Language & & & \\
$\quad$ Spanish & .007 & .002 & $.003^{*}$ \\
$\quad$ Vietnamese & .005 & .003 & .146 \\
$\quad$ Russian & -.004 & .004 & .279 \\
$\quad$ All other Languages & .004 & .002 & .087 \\
5th Grade Math RIT & .003 & .001 & $<.001^{*}$ \\
\hline
\end{tabular}




\section{THE EFFECTS OF AN OVERNIGHT ENVIRONMENTAL PROGRAM}

seventh grades $(p=.029)$; however, this result did not present itself consistently across the other regression models. The ethnicity/race category demonstrated significant positive attendance rate change for Asians when compared with white students $(p=.001)$, and both Hispanic and Native American students showed a negative attendance rate change between fifth and seventh grades $(p<.001)$ and $(p=.001)$ respectively. Taken as a whole, English as a second language students exhibited a negative attendance rate change when compared with students not participating in English as a second language services $(p=.017)$; however, students whose first language is Spanish showed a positive attendance rate change which was also found in other series of analysis $(p=.003)$. In other words, when first language Spanish speakers are disaggregated from all other first language speakers, they have a more positive attendance rate change than students whose first language is English. The fifth grade Math RIT score showed significance and quantified the expected change for every 10-points above the mean $(p<.001)$.

\section{Attendance Rate Change by Year}

For our second set of regression analyses, we filtered the population by year they attended the program using the same independent variables in the overall regression model (Table 3). As we differentiated the students by year, which made the program duration relevant, we noticed some interesting trends in the statistically significant results. Figure 1 documents the duration that each of the school districts participated in the MESD Outdoor School program. In the 2008-2009 school year, all students in the study attended the program for a 6-day program. In 2009-2010, districts began making 


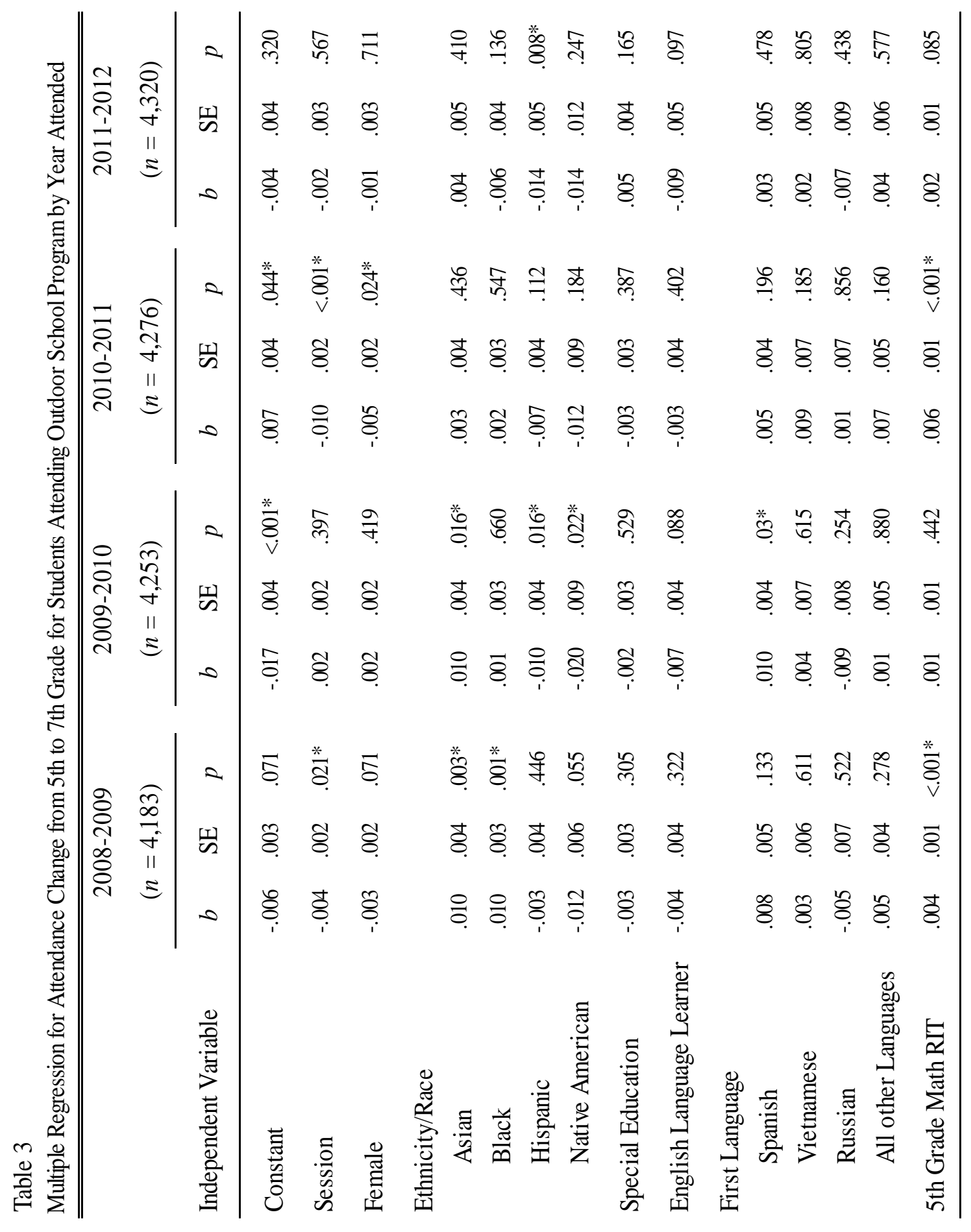




\section{THE EFFECTS OF AN OVERNIGHT ENVIRONMENTAL PROGRAM}

Figure 1

Number of Days Districts Participated in MESD Outdoor School by Year

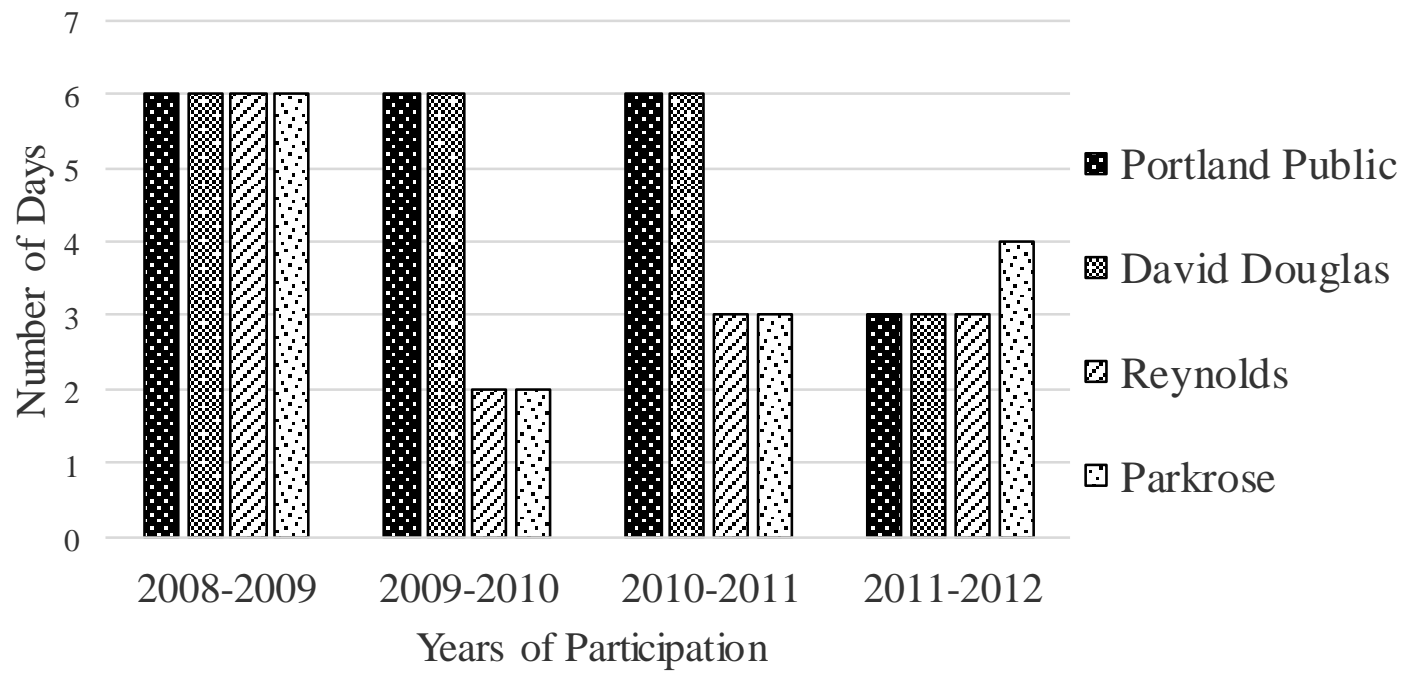

cuts, resulting in $21 \%$ of the students attending a 2-day program and the remaining $79 \%$ of students still participating in the 6-day program. During the 2010-2011 school year, students in our study participated in either a 6-day program (79\%) or a 3-day program (21\%). During the 2011-2012 school year, all of the students in our study attended for either a 3-day (95\%) or 4-day (5\%) program.

In the 2008-2009 school year, session attended was a significant predictor of positive attendance change between fifth and seventh grade years $(p=.021)$ and again in 2010-2011, $(p<.001)$. It should be noted, however, that the majority of students who attended the 6-day program in 2010-2011 primarily attended in the fall, thus potentially skewing the results in favor of the fall session. Gender differences in attendance rate change only appeared in the 2010-2011 school year where females had a negative attendance rate change when compared with males $(p=.024)$. In other words, males had a positive attendance rate change that year. Asian students demonstrated a positive 


\section{THE EFFECTS OF AN OVERNIGHT ENVIRONMENTAL PROGRAM}

attendance rate change in both 2008-2009 $(p=.003)$ and in 2009-2010 $(p=.016)$. In 2008-2009, the year where all students attended a 6-day program, African American students showed a positive attendance rate change $(p=.001)$, however, Hispanic students predicted a negative attendance rate change, which was significant in both 2009-2010 ( $p$ $=.016)$ and in 2011-2012 ( $p=.008)$. Native American students also showed a negative attendance rate change in 2009-2010 ( $p=.022)$. Interestingly, students whose first language is Spanish noted a positive attendance rate change when compared with their peers whose first language was English $(p=.030)$. The fifth grade Math RIT score was significant in both 2008-2009 $(p<.001)$ and in 2010-2011 $(p<.001)$.

\section{Attendance Rate Change by District}

Table 4 represents all of the students participating in the overnight outdoor program filtered by the district they attended, aggregated across all four years.

Consideration should be made for each district, because the make-up of these results includes students who attend for both partial weeks and 6-day weeks attributing to fluctuation in significant results. The largest district in our study, Portland Public School District, attended the program at a 6-day duration for three of the four years in our study and illustrates many significant findings across the independent variables. In particular, fall session attendance seems to predict positive increases in attendance change when compared with students in their district who attended in the spring $(p=.006)$. Drawing on the ethnicity/race variable, both Asian and African American students had positive increases in attendance rate change $(p=.006)$ and $(p=.016)$ respectively. Native 


\section{THE EFFECTS OF AN OVERNIGHT ENVIRONMENTAL PROGRAM}

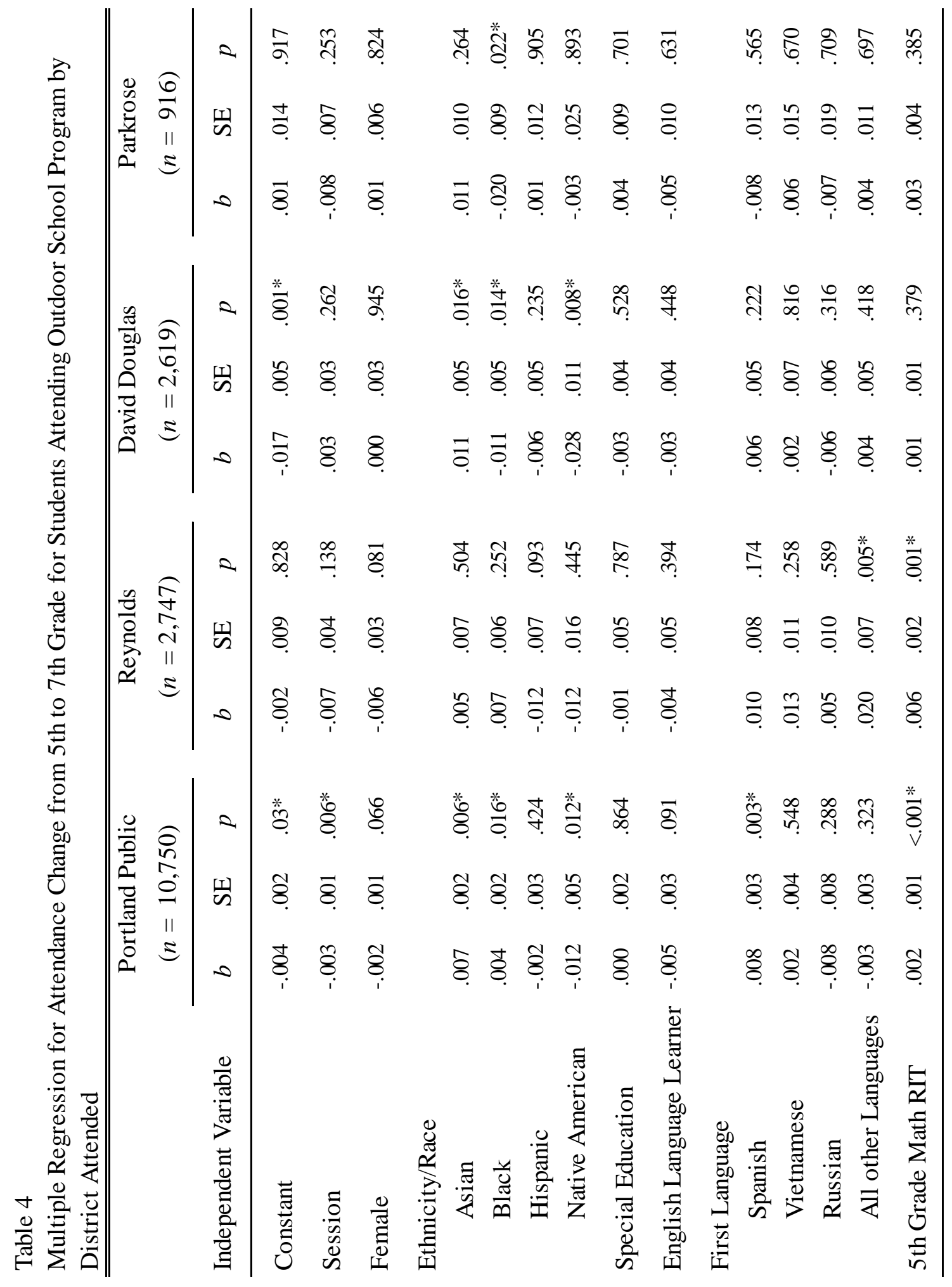




\section{THE EFFECTS OF AN OVERNIGHT ENVIRONMENTAL PROGRAM}

American students had a negative attendance rate change $(p=.012)$. Second language learners showed positive attendance rate changes for Spanish speaking students in Portland Public $(p=.003)$. Finally, fifth grade Math RIT scores were significant $(p<$ $.001)$.

Our second largest district, Reynolds, attended one year at a 6-day program, and the rest of the years in our study at a 1 or 3-day duration. In the Reynolds School District, the independent variable All other languages showed a positive attendance rate change when compared with students whose first language is English $(p=.005)$. The only other significant result was the fifth grade Math RIT score $(p<.001)$.

David Douglas district's ratio of students attending a 6-day program vs. a 3-day program over all four years is (3:1). Similar to other findings, Asian students show a positive attendance rate change $(p=.016)$, however both African American and Native American students show a negative attendance rate change when compared to white students $(p=.014)$ and $(p=.008)$. When all of the years of students, and consequently the years of shorter durations, are combined for the Parkrose district, African American students showed a negative attendance rate change compared with White students $(p=$ .022). Notable in these findings are the striking differences in significant results for the two districts: Parkrose and Reynolds that attended shortened duration programs for all but one of the years in the study. 


\section{THE EFFECTS OF AN OVERNIGHT ENVIRONMENTAL PROGRAM}

\section{Attendance Rate Change Separated by District and Year}

Exhibited in Table 5, the final regression filtered all students during the years of the study by both school district and year they attended detailing how the attendance rate changed by cohort and district.

\section{Fall vs. spring attendance.}

Variations between attendance in fall and spring participation demonstrated some interesting results throughout the years and districts in our study. Two districts had a positive attendance rate change that favored the spring when compared with the fall. In the 2009-2010 school year for David Douglas $(p=.007)$ and in 2010-2011 for the Reynolds School District $(p<.001)$; however Portland Public's students had a positive attendance rate change for the fall $(p=.001)$ in that same year.

\section{Ethnicity/race variable.}

The results of attendance rate change on variables of ethnicity and race highlight differences between years and districts in our study. Asian students had a positive attendance rate change in districts where they attended a 6-day program (David Douglas in 2009-2010 ( $p=.047)$ and Portland Public in 2008-2009 $(p=.035)$ and 2009-2010 $(p=$ .043)), however no significant results were found for Asian students in districts that participated in a reduced program. As documented previously, Native American and Hispanic students showed negative attendance rate changes throughout the study regardless of program duration or district. Negative attendance rate change for Native 


\section{THE EFFECTS OF AN OVERNIGHT ENVIRONMENTAL PROGRAM}

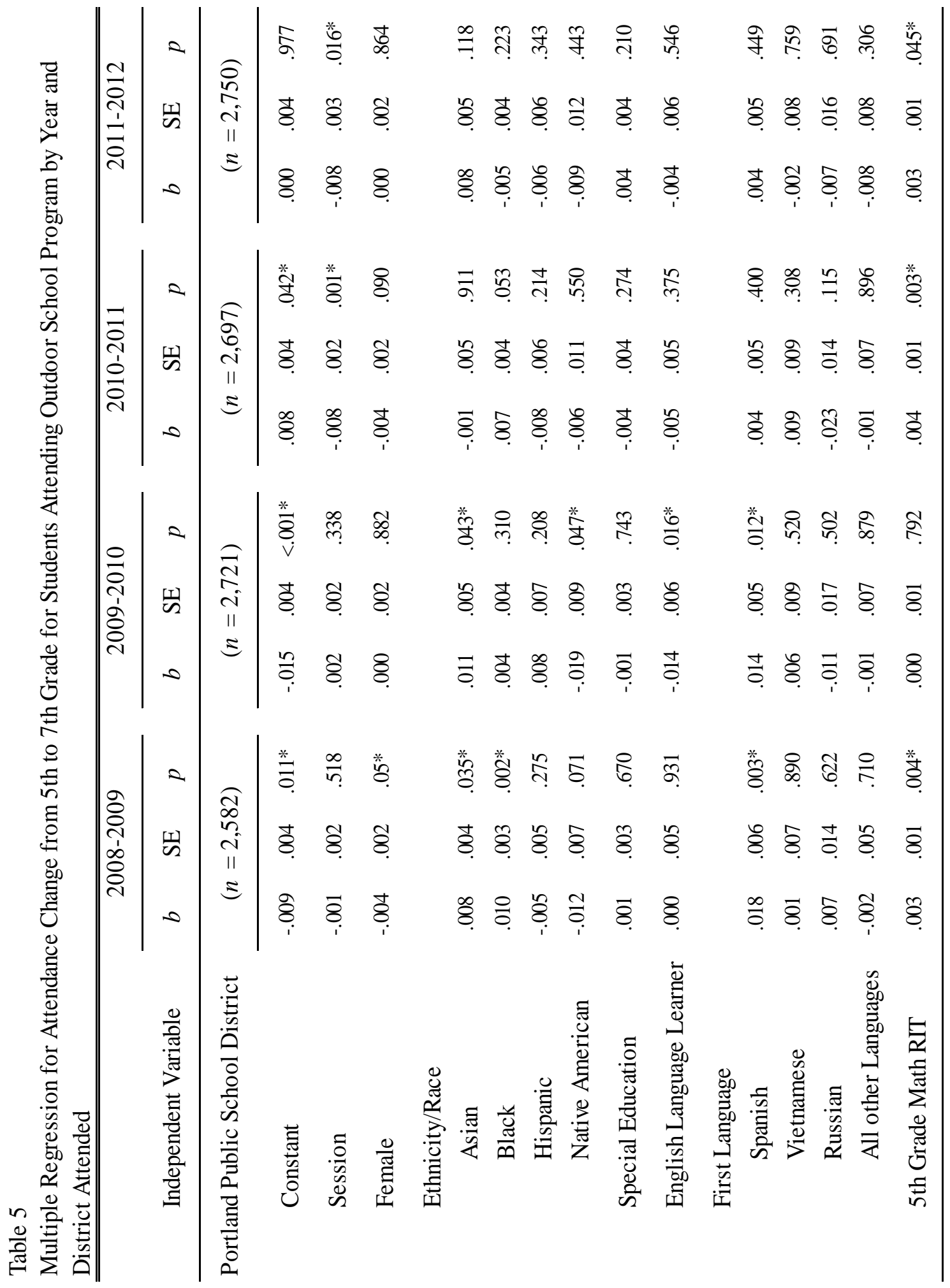




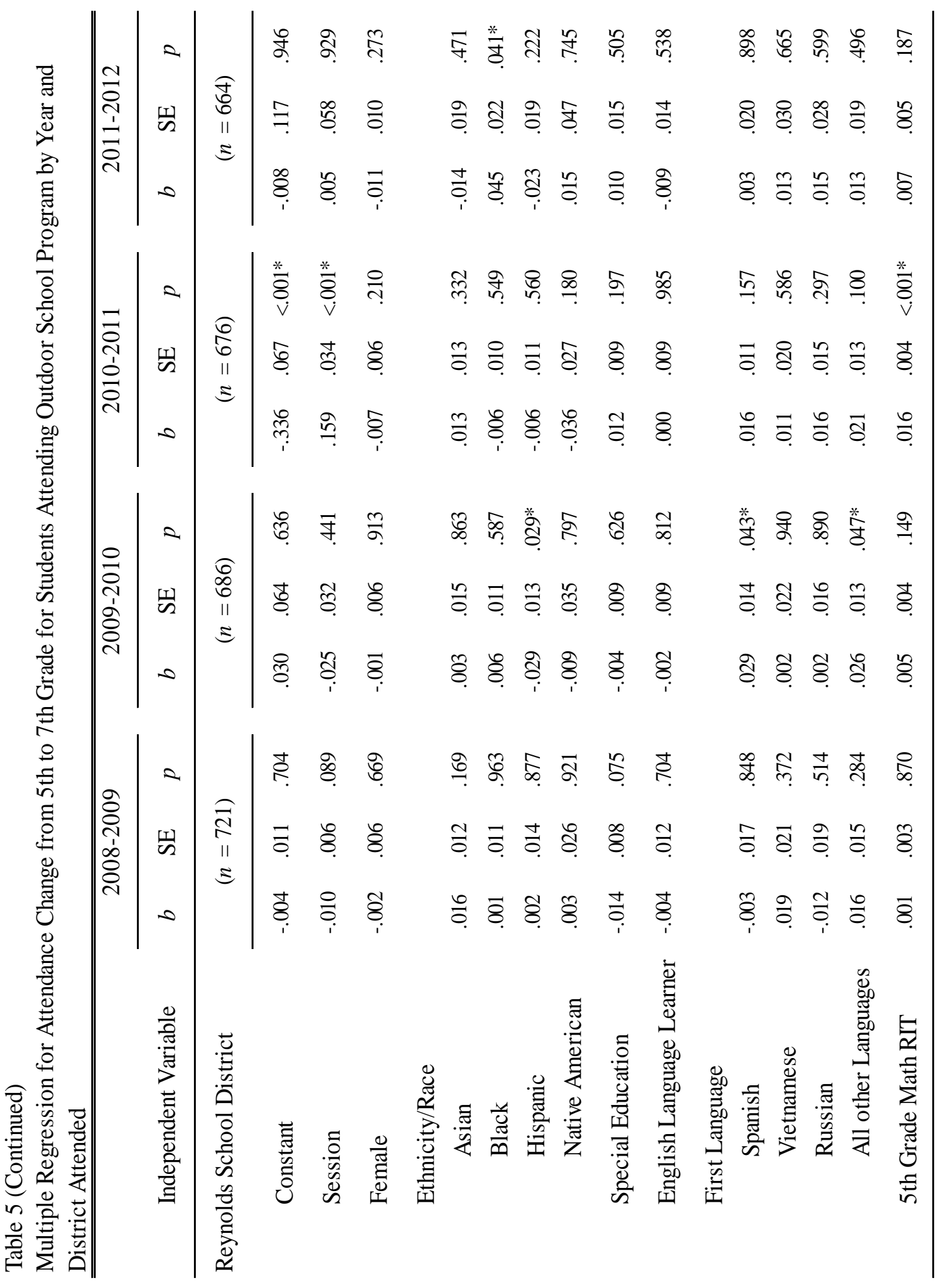




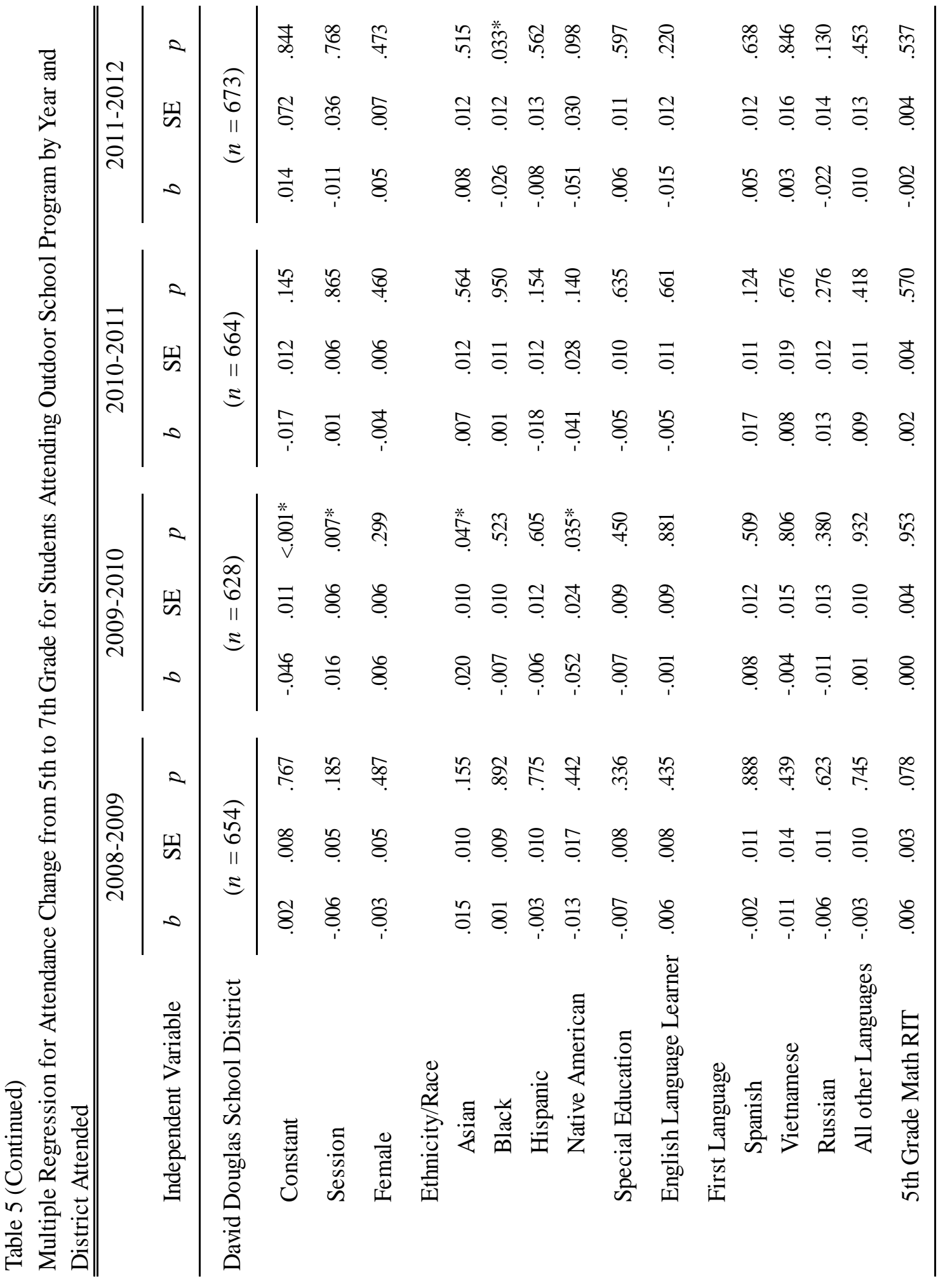




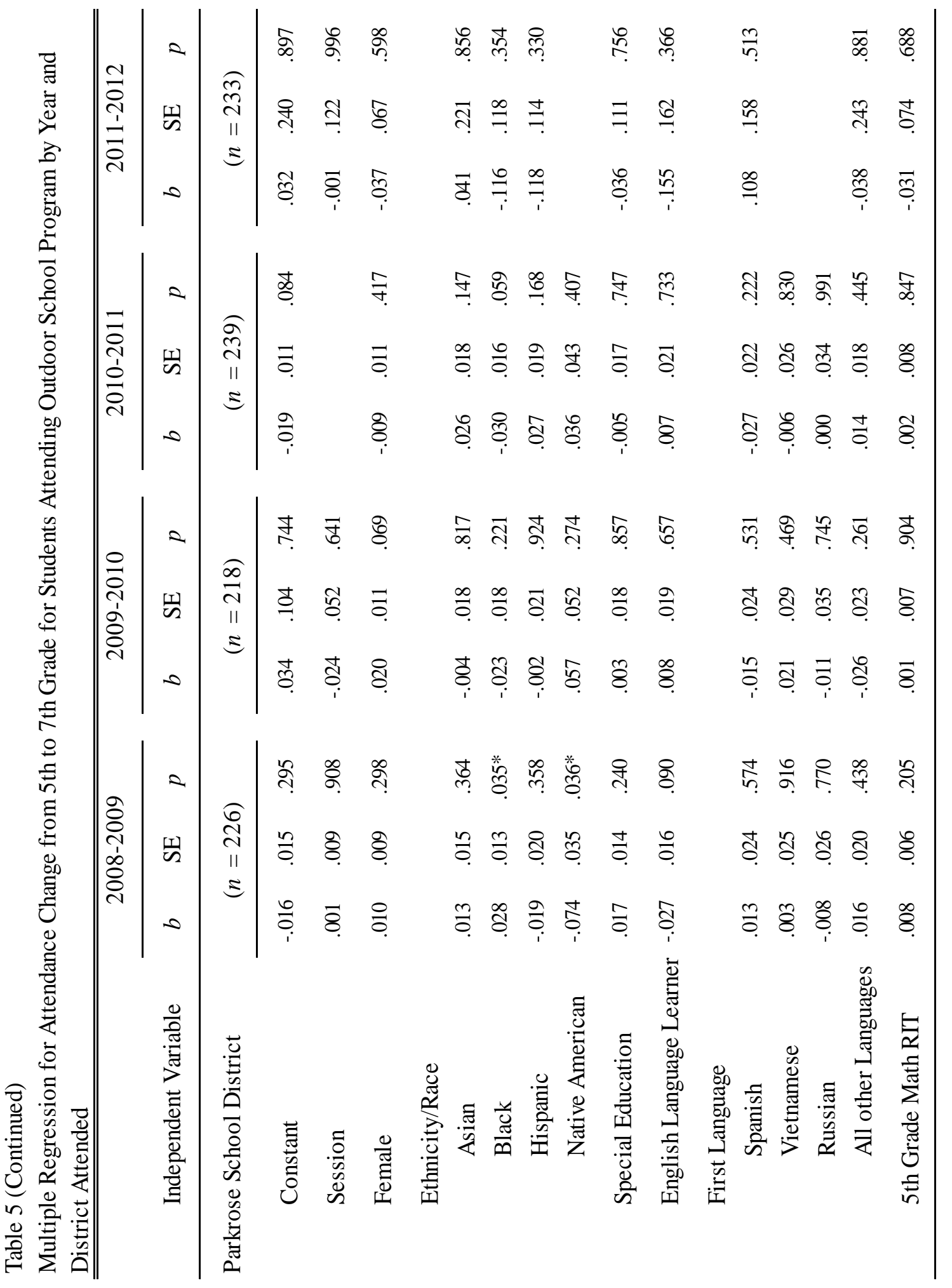




\section{THE EFFECTS OF AN OVERNIGHT ENVIRONMENTAL PROGRAM}

American students presented in 2008-2009 in Parkrose $(p=.036)$, and in 2009-2010 for David Douglas $(p=.035)$ and Portland Public $(p=.047)$.

During the 2008-2009 school year, when all students participated in a 6-day program we noticed some positive significant results for African American students in both the Parkrose School District $(p=.035)$ and Portland Public $(p=.002)$. The only other significant result for African American students was during 2011-2012 school year when all districts were participating in a 3-day program. Students from David Douglas showed a negative attendance rate change during this year $(p=.033)$, but in Reynolds, they documented a positive attendance rate change $(p=.041)$.

\section{English language learners/Spanish speakers.}

English Language Learners had a negative attendance rate change in the Portland Public School district in 2009-2010 ( $p=.016)$, however students whose first language is Spanish showed a positive attendance rate change during that same year $(p=.012)$. Positive attendance rate change held true for students in Reynolds in 2009-2010 ( $p=$ .043). The only exception to First Language Spanish speakers having positive results were from students who spoke All Other Languages in the Reynolds School district during 2009-2010 which revealed only marginal statistical significance $(p=.047)$.

\section{Math RIT scores.}

Throughout the results, the fifth grade math RIT score showed some significance in two of the districts, Portland Public and Reynolds. In the Portland Public School district students fifth grade Math RIT score was significant for students attending the 


\section{THE EFFECTS OF AN OVERNIGHT ENVIRONMENTAL PROGRAM}

program in 2008-2009 ( $p=.004), 2010-2011(p=.003)$, and only marginally significant in 2011-2012 ( $p=.045)$. Within the Reynolds School District, the only year the fifth grade Math RIT Score showed significance was in the 2010-2011 school year $(p<.001)$. 


\section{THE EFFECTS OF AN OVERNIGHT ENVIRONMENTAL PROGRAM}

\section{Discussion}

Consistent with our thesis, overnight environmental science education programs appear to support student attendance, which is a factor contributing to student success in school. Our study revealed and confirmed our assumption that students who attend the program towards the beginning of the school year have a stronger presence of positive attendance rate changes than those who attended only in the spring. The attendance rate change between students' fifth and seventh grade showed positive changes and more incidences of significant results during years where the majority of students attended longer programs. Asian, African American, and students whose first language is Spanish also demonstrated consistently positive attendance rate changes when compared with their white and English speaking peers. However, the impact of positive attendance rate change did not present itself among Hispanic, Native American, Special Education, or students currently English Language Learners. Although this phenomenon is unfavorable, the discrepancy in attendance rates for these populations is consistent with other research and can be associated with risk factors such as poverty (Rodríguez \& Conchas, 2009), school-level, and familial dynamics (Rumberger, 1995). Overall, positive attendance rate changes were found throughout the study and supported our hypothesis that attending an overnight environmental science program can positively impact many students' attendance rate leading to student success.

Congruent with current research surrounding school attendance, we found that attendance change varies by demographic factors. One might expect to see a drop in 


\section{THE EFFECTS OF AN OVERNIGHT ENVIRONMENTAL PROGRAM}

attendance rate changes from fifth to seventh grade as students often leave the selfcontained classes and small school setting in elementary school for the larger middle school setting with divergent classrooms and multiple teachers (Eccles et al., 1993; Meece, 2003). Although this phenomenon was demonstrated in some of the regression models we tested, we did find demographic groups of students who denoted a positive attendance rate change between these transition years. Students who identified as Asian, showed a positive attendance rate change between fifth and seventh grade for some of the years in our study and for districts that had attended the program for a longer duration. Similarly, African American students showed a positive attendance rate change in the largest district as well as during the years that all students attended for a 6-day program. Although, both Hispanic and Native American students showed a negative attendance rate change when the statistics demonstrated a significant result. While this trend does not support our inquiry hypothesis, it aligns with research regarding how attendance varies for Hispanic students (Hart Buehler et al., 2012; Garcia-Reid \& Peterson, 2005; Eaton et al., 2008). Studies have cited numerous factors including socio-economic status, family background, and school experiences as variables that contribute to disengagement in schools leading to poor attendance for Hispanic and minority youth (Rumberger, 1995). Similar effects might contribute to the negative attendance results for the Native American population in our study; however a more likely influence on the results could be the small number of Native American students in the study overall ( $\mathrm{n}=244)$.

Ultimately, these results highlight the need for both schools and overnight environmental 


\section{THE EFFECTS OF AN OVERNIGHT ENVIRONMENTAL PROGRAM}

science programs to continually create culturally responsive pedagogies that support students' educational capacity and build their social capital (Rodríguez \& Conchas, 2009).

The most salient finding in our study is the effect of participation in the MESD Outdoor School program in the fall when compared with the spring participation. While anecdotal evidence, and program teacher surveys has supported the assumption that attending the overnight outdoor science program supports classroom attendance, no research to date has demonstrated this. This research contributes to the knowledge surrounding classroom community and how engagement in the first few months of the school year can lead to greater success in academics and engagement in school (Bucholz \& Sheffler, 2009).

One possible rationale for these findings is that during an intensive overnight program, both students and teachers are able to build reciprocal relationships and connections while at Outdoor School that might not otherwise be fostered in a traditional classroom setting. Much literature has shown that when teachers make connections with students, they have a stronger view of their academic potential and in turn foster rigorous learning experiences for those students (Buxton, 2004; Love \& Kruger, 2005; Meece, 2003). Similarly, when students develop relationships with teachers, they can feel a bond with teachers leading to an increase in effort and performance (Buxton, 2004; Furrer \& Skinner, 2003; Garcia-Reid \& Peterson, 2007; Lemberger et al., 2015). In the case that 


\section{THE EFFECTS OF AN OVERNIGHT ENVIRONMENTAL PROGRAM}

students have an opportunity to foster these connections early in the school year, both students and teachers could reap the benefits throughout the school year.

While generally speaking teacher and student relationships are important to the success of the students, it should also be noted that this bond is particularly important to students struggling with attendance issues (Desimone \& Long, 2010; Love \& Kruger, 2005). Though many factors play into the effects of attendance, it has been shown that caring educational teachers can influence and alter a student's educational trajectory (Buxton, 2004; Eaton et al., 2008; Furrer \& Skinner, 2003; Garcia-Reid \& Peterson, 2007). Furthermore, giving opportunities for teachers to bond with students early in the year in an outdoor setting allows for them to acknowledge students' strengths outside of the classroom. The potential for overnight environmental science programs to cultivate these links allows for teachers to view students differently and to understand how to engage students who struggle academically.

Not only do the techniques used while teaching influence student motivation and engagement, content plays an integral role in teaching effectiveness. While this study doesn't specifically investigate the interconnection between science learning, teaching, and attendance, one could argue that since the focus of the overnight environmental program is strongly tied to science curriculum, there is at least a link connecting the impact of the program on students' attendance rate change. Many studies have shown that increases in attendance are linked to students engaging with content in authentic and applicable ways (Eccles et al., 1993; Fisher et al., 2011; Garcia-Reid \& Peterson, 2007; 


\section{THE EFFECTS OF AN OVERNIGHT ENVIRONMENTAL PROGRAM}

Meece, 2003). Transferring this knowledge to the program in this study, confirms the assumptions that content, technique, and relationships all work together to support student attendance and success in school.

Another factor at play when investigating potential influences of overnight environmental science programs on student attendance are the way lessons are taught. Throughout the experience students are exposed to science concepts through a hands-on, participatory inquiry method that is modeled for teachers and students. (Simmons, 2000) These strategies have been shown to increase student engagement and in turn influence participation within the classroom (Furguson, Angell \& Tudor, 2001; Skinner et al., 2011; Smith-Sebasto \& Obenchain, 2009). During these types of programs, teachers are exposed to a whole new way of teaching with the potential to influence their own teaching methodology. Though exposure alone cannot account for a shift in teaching style, one must go through the stages of implementation. Familiarity with alternative forms of teaching and how they engage various students in their classrooms might prompt teachers to develop specific techniques for engaging students struggling with attendance (Hall, 1974).

Conventional wisdom would lead us to believe that the more students are exposed to a particular experience, the more impactful it would be on their overall learning gains. Our research seems to support this claim. Environmental science programs that provide students with multiple experiences in authentic scientific settings would have a stronger impact on them (Bradley, Waliczek, \& Zajicek, 2010; Hungerford \& Volk, 1990). 


\section{THE EFFECTS OF AN OVERNIGHT ENVIRONMENTAL PROGRAM}

Relating to the overnight environmental program included in this study, it could also be said that committing to the longer week experience would be valuable and allow for students to wholly invest in the experience leading further to larger gains. For example, when African Americans from Parkrose were analyzed across the four years of students, they had a negative attendance rate change. However, during the only year students attended a 6-day program, African American students had a positive attendance rate change. Similarly, over the four years in our study, we notice a decline in the amount of significant attendance rate change results, which correspond to the years of the reduced program duration. Although causal relationships cannot be claimed, it highlights a discrepancy between attendance rate changes between fifth and seventh grades in districts that participated in shorter lengths of programs. Further, it accentuates the need for equity of access for students with fewer resources to have access to programs that support their academic success.

Throughout the study we found noteworthy results when students were disaggregated by ethnicity and race. This is significant because many studies acknowledge some environmental programs may be geared towards white students (Blanchet-Cohen \& Reilly, 2013; Buxton, 2004; Lewis \& James, 1995), potentially providing a more significant impact for them; however consistent with other research surrounding environmental programs, our research shows that for some years, the program supports a greater positive attendance rate change for African American and Asian students when compared with their white counterparts (Sheppard, 1995; Stern, 


\section{THE EFFECTS OF AN OVERNIGHT ENVIRONMENTAL PROGRAM}

Powell, Ardoin, 2010). This occurrence was demonstrated more strongly during years where participation was at 6-day participation. In line with current research surrounding attendance during the middle school years for Hispanic and Native American populations, we noted a negative increase in attendance change scattered throughout our results for these populations (Hart Buehler et al., 2012; Eaton et al., 2008). While we cannot make claims that the MESD Outdoor School program is the only factor influencing this phenomenon, it is tangible evidence that programs need to ensure culturally responsive pedagogies to engage and re-engage students outside of the classroom (Blanchet-Cohen \& Reilly, 2013; Sheppard, 1995; Stern et al., 2010; Rodríguez \& Conchas, 2009). Intentional focus by districts to participate in the overnight environmental science programs could prove to be beneficial in engaging some vulnerable populations.

Despite the results of negative increases in attendance change between fifth and seventh grades for Hispanic and Native American populations, in some years Spanish as a first language population showed a higher increase in attendance rate change than their white counterparts. This supports the theory that hands-on active engagement contributes to curriculum learning (Mabie \& Baker, 1996; Smith \& Motsenbocker, 2005; Snyder et al., 2010) and particularly for students learning English as a second language. When all first languages are combined within the English Language Learner variable in our study, this finding does not pan out for all students who are learning English as a second language. This finding could be explained in part because of the number of Spanish 


\section{THE EFFECTS OF AN OVERNIGHT ENVIRONMENTAL PROGRAM}

speaking first language students in our study was much higher when compared with the other languages included.

\section{Limitations}

Considering the large scope of the data collected, one should be cautious in attributing the overall results to specific groups of students. Additionally, causation of the effect of the overnight environmental science program on attendance cannot be assumed given the nature of the regression analysis and the secondary source data collection. A more in depth investigation of attendance rate change that can account for inconsistencies in the data and variables might be better facilitated with case studies of students. This research also demonstrates a need to implement integrated systems for data collection, tracking, and analyses to better facilitate ongoing inquiries into overnight environmental science program impacts.

This research has illuminated the need to explore the relationship between overnight environmental science programs and student success factors further, particularly for disadvantaged youth. This study focused on one of many outdoor environmental science programs across the country, each with variations in structure and focus, which limits our ability to generalize the results across programs. Likewise, the scope of the data includes four districts within the region, however it excludes three of the seven districts that participated in the program. If included, those districts would provide a more comprehensive view of the program and might also further support or deny the findings in this research. 


\section{THE EFFECTS OF AN OVERNIGHT ENVIRONMENTAL PROGRAM}

Another significant limitation of the study was the process for collecting data. The data collection was sourced using existing data, which proved to be in some cases inconsistently reported or missing. Although steps were taken to ensure the most accurate reflection of the student population, we found that some years of students had missing data points due to statewide reporting problems, and were therefore excluded during merging of the program and district datasets, or could not be confidently aggregated within a demographic (e.g. multi-racial students prior to 2009). Similarly, variable methods for reporting and documenting data between districts and schools limited the avenues for further study of student success indicators such as behavior and incidents of referrals, an area of interest for the researchers.

The goal of this research was to probe existing data to investigate whether overnight environmental science programs have an effect on student success indicators. While we have found evidence of positive impacts on students who attend, one must use caution generalizing these results broadly across all overnight environmental programs. The specific program investigated has a long history in the Pacific Northwest dating over 45 years and serving over 318,000 students since its inception (Prince, 2015). Besides the community support for the MESD Outdoor School program across generations, school endorsement should not be taken lightly as an influence in the overall longevity and impact of the program on students (Etheridge, 2001). Environmental education programs that align with school district goals and closely link to curriculum objectives can bolster 


\section{THE EFFECTS OF AN OVERNIGHT ENVIRONMENTAL PROGRAM}

student achievement and attendance (Bartosh et al., 2006; Fazio \& Karrow, 2013;

Furguson et al., 2001; Lieberman \& Hoody, 1998). 


\section{THE EFFECTS OF AN OVERNIGHT ENVIRONMENTAL PROGRAM}

\section{Conclusion}

Overall, our research supports the assumption that students who attend the MESD Outdoor School program have a positive increase in attendance, particularly for certain groups of students. This research also documents a unique phenomenon where students who attended the overnight environmental science program in the fall had a more positive impact on their attendance rates than those students who attended in the spring. We believe this is in part because the teachers can solidify their classroom community and build relationships with their students while at MESD Outdoor School and they are able to draw from this shared learning experience throughout the year. Additionally, this research draws attention to the variations in significant results based on program duration. Taken together, the overall findings and gradually decreasing occurrence of statistically significant results as more schools attended for shorter durations supports the claim that overnight environmental science programs promote increases in school attendance rates, particularly when programs are longer than three days in duration.

While this research illuminates some interesting phenomenon regarding the change in attendance rate for students who have attended the overnight environmental science program, the research has generated many more questions that we seek to investigate further. Time and coordination with larger efforts across the state would garner a more thorough understanding of how overnight environmental science education programs impacts students. Suggestions for further research might include examining how overnight environmental science programs impact student achievement and how 


\section{THE EFFECTS OF AN OVERNIGHT ENVIRONMENTAL PROGRAM}

they vary among groups who have attended the program for different durations. Our research demonstrated positive outcomes for attendance rate changes for various demographics of students, and for students who attended in the fall. Looking more deeply into the factors behind these results would provide more thorough glimpse into program outcomes. Additionally, this study, while it had a large number of participants, did not compare groups of students across the state to investigate potential differences between programs and the impacts on student outcomes between those who have attended an overnight environmental science program compared with those who have not. Each of these analyses could amass a more comprehensive view of program impact. Finally, investigating how overnight environmental programs that also serve high school students impact high school graduation and achievement could serve as a way to understand the full effect of program participants.

This initial research has only begun to scratch the surface of the demonstrated impacts of the MESD Outdoor School program and, broadly, overnight environmental science programs; the possibilities for further research have enormous potential. Although further investigation over time will provide a richer story, we feel the findings to date need to be shared and are quite significant for educational policy and funding decisions. Additionally, it speaks to the need for research, practice, and assessment to be embedded within the overnight environmental science programs to establish a consistent procedure for gathering and assessing data to communicate program goals. The state and local districts have identified school attendance as a key indicator of academic success 


\section{THE EFFECTS OF AN OVERNIGHT ENVIRONMENTAL PROGRAM}

(Hart Buehler et al., 2012; Fisher et al., 2011); therefore, programs that show potential to increase attendance rates, particularly at this critical period of adolescent development and for our most vulnerable populations, should be fully supported, expanded in reach, and continually evaluated and improved. 


\section{THE EFFECTS OF AN OVERNIGHT ENVIRONMENTAL PROGRAM}

\section{References}

Balfanz, R., \& Byrnes, V. (2006). Closing the mathematics achievement gap in highpoverty middle schools: Enablers and constraints. Journal of Education for Students Placed at Risk, 11(2), 143-159.

Bandura, A. (1997). Self-Efficacy: The Exercise of Control. Macmillan.

Bartosh, O., Tudor, M., Ferguson, L., \& Taylor, C. (2006). Improving test scores through environmental education: Is it possible? Applied Environmental Education \& Communication, 5(3), 161-169. http://doi.org/10.1080/15330150600912937

Basch, C. E. (2011). Inattention and hyperactivity and the achievement gap among urban minority youth. Journal of School Health, 81(10).

Baumgartner, L. M. (2001). An update on transformational learning. New Directions for Adult and Continuing Education, (89), 15-24.

Baum, S., Ma, J., \& Payea, K. (2013). Education pays 2013: The benefits of higher education for individuals and society. College Board.

Berkes, F., \& Turner, N. J. (2006). Knowledge, learning and the evolution of conservation practice for social-ecological system resilience. Human Ecology: An Interdisciplinary Journal, 34(4), 479-494.

http://doi.org/10.1007/s10745-006-9008-2 


\section{THE EFFECTS OF AN OVERNIGHT ENVIRONMENTAL PROGRAM}

Blanchet-Cohen, N., \& Reilly, R. C. (2013). Teachers' perspectives on environmental education in multicultural contexts: Towards culturally-responsive environmental education. Teaching \& Teacher Education, 36, 12-22.

http://doi.org/10.1016/j.tate.2013.07.001

Bowen, N. K., \& Bowen, G. L. (1999). Effects of crime and violence in neighborhoods and schools on the school behavior and performance of adolescents. Journal of Adolescent Research, 14(3), 319-342. http://doi.org/10.1177/0743558499143003

Bradley, J. C., Waliczek, T. M., \& Zajicek, J. M. (1999). Relationship between environmental knowledge and environmental attitude of high school students. The Journal of Environmental Education, 30(3), 17-21. http://doi.org/10.1080/00958969909601873

Bucholz, J., \& Sheffler, J. (2009). Creating a warm and inclusive classroom environment: Planning for all children to feel welcome. Electronic Journal for Inclusive Education, 2(4). Retrieved from http://corescholar.libraries.wright.edu/ejie/vol2/iss $4 / 4$

Burns, H. (2009). Education as sustainability: an action research study of the burns model of sustainability pedagogy. (Dissertations and Theses). Retrieved from http://pdxscholar.library.pdx.edu/open_access_etds/942

Buxton, C. A. (2006). Creating contextually authentic science in a "low-performing" urban elementary school. Journal of Research in Science Teaching, 43(7), 695-721. http://doi.org/10.1002/tea.20105 


\section{THE EFFECTS OF AN OVERNIGHT ENVIRONMENTAL PROGRAM}

Camargo, C., \& Shavelson, R. (2009). Direct measures in environmental education evaluation: Behavioral intentions versus observable actions. Applied Environmental Education \& Communication, 8(3-4), 165-173.

http://doi.org/10.1080/15330150903269266

Crockett, M. J. (1994). The social sciences and the social studies: An essay on the development of and need for citizenship education. Retrieved from http://eric.ed.gov/?id=ED375051

Dawes, N. P., \& Larson, R. (2011). How youth get engaged: Grounded-theory research on motivational development in organized youth programs. Developmental Psychology, 47(1), 259-269. http://doi.org/10.1037/a0020729

DBI Reports. (n.d.). Retrieved October 19, 2015, from http://www.ode.state.or.us/sfda/reports/r0073Select2.asp

Desimone, L., \& Long, D. A. (2010). Teacher effects and the achievement gap: Do teacher and teaching quality influence the achievement gap between black and white and high- and low-SES students in the early grades? Teachers College Record, 112(12), 3024-3073.

Dettmann-Easler, D., \& Pease, J. L. (1999). Evaluating the effectiveness of residential environmental education programs in fostering positive attitudes toward wildlife.

The Journal of Environmental Education, 31(1), 33-39.

http://doi.org/10.1080/00958969909598630

Dewey, J. (1938). Experience And Education. Simon and Schuster. 


\section{THE EFFECTS OF AN OVERNIGHT ENVIRONMENTAL PROGRAM}

Eaton, D. K., Brener, N., \& Kann, L. K. (2008). Associations of health risk behaviors with school absenteeism. Does having permission for the absence make a difference? Journal of School Health, 78(4), 223-229. http://doi.org/10.1111/j.17461561.2008.00290.x

Eccles, J. S., Midgley, C., Wigfield, A., Buchanan, C. M., Reuman, D., Flanagan, C., \& Mac Iver, D. (1993). Development during adolescence: The impact of stageenvironment fit on young adolescents' experiences in schools and in families. American Psychologist, 48(2), 90-101.

http://doi.org/http://dx.doi.org.proxy.lib.pdx.edu/10.1037/0003-066X.48.2.90

Elementary and Secondary Education Act | U.S. Department of Education. (n.d.). Retrieved from http://www.ed.gov/esea

Etheridge, S. D. (2001). Title I schoolwide programs: District support for achieving success. Journal of Education for Students Placed at Risk (JESPAR), 6(4), 335-356. http://doi.org/10.1207/S15327671ESPR0604_3

Evans, R. (2005). Reframing the achievement gap. The Phi Delta Kappan, 86(8), 582589.

Fazio, X., \& Karrow, D. D. (2013). Negotiating the constraints of schools: environmental education practices within a school district. Environmental Education Research, 19(5), 639-655. http://doi.org/10.1080/13504622.2012.729812

Ferguson, L., Angell, T., \& Tudor, M. (2001). Better test scores through environmental education? Clearing, 110, 1 . 


\section{THE EFFECTS OF AN OVERNIGHT ENVIRONMENTAL PROGRAM}

Fisher, D., Frey, N., \& Lapp, D. (2011). Focusing on the participation and engagement gap: A case study on closing the achievement gap. Journal of Education for Students Placed at Risk, 56-64. http://doi.org/10.1080/10824669.2011.545976

Furrer, C., \& Skinner, E. (2003). Sense of relatedness as a factor in children's academic engagement and performance. Journal of Educational Psychology, 95(1), 148-162. http://doi.org/http://dx.doi.org.proxy.lib.pdx.edu/10.1037/0022-0663.95.1.148

Garcia-Reid, P., Reid, R. J., \& Peterson, N. A. (2005). School engagement among Latino youth in an urban middle school context valuing the role of social support.

Education and Urban Society, 37(3), 257-275.

http://doi.org/10.1177/0013124505275534

Gardner, D. (2007). Confronting the achievement gap. Phi Delta Kappan, 88(7), 542546. http://doi.org/10.1177/003172170708800715

Gottfried, M. A. (2010). Evaluating the relationship between student attendance and achievement in urban elementary and middle schools an instrumental variables approach. American Educational Research Journal, 47(2), 434-465.

http://doi.org/10.3102/0002831209350494

Hall, G. E. (1974). The concerns-based adoption model: A developmental conceptualization of the adoption process within educational institutions. Retrieved from http://eric.ed.gov/?id=ED111791 


\section{THE EFFECTS OF AN OVERNIGHT ENVIRONMENTAL PROGRAM}

Hamilton, L. S., Stecher, B. M., Marsh, J. A., McCombs, J. S., \& Robyn, A. (2007). Standards-based accountability under No Child Left Behind: Experiences of teachers and administrators in three states. Rand Corporation. Retrieved from https://books.google.com/books?hl=en\&lr=\&id=ZrKE6DCq3QMC\&oi=fnd\&pg=PP 2\&dq=Standardsbased+accountability+under+no+child+left+behind:\&ots=YzyRH6 J6aZ\&sig=sGunYCk_mUfa3dSs0BmlDo8gtps

Hannah-Jones, N. (2011, April 30). In Portland's heart, 2010 Census shows diversity dwindling. The Oregonian. Retrieved from http://impact.oregonlive.com/pacificnorthwest-news/print.html?entry=/2011/04/in_ portlands_heart_diversity_dwindles.html

Hardre, P. L., Davis, K. A., \& Sullivan, D. W. (2008). Measuring teacher perceptions of the "how" and "why" of student motivation. Educational Research and Evaluation, 14(2), 155-179.

Hart Buehler, M., Tapogna, J., \& Chang, H. N. (2012). Why Being in School Matters: Chronic Absenteeism in Oregon Public Schools (A Research Brief). Attendance Works.

Hungerford, H. R., Bluhm, W. J., Volk, T. L., \& Ramsey, J. M. (1998). Essential Readings in Environmental Education. Retrieved from http://eric.ed.gov/?id=ED440821 


\section{THE EFFECTS OF AN OVERNIGHT ENVIRONMENTAL PROGRAM}

Hungerford, H. R., \& Volk, T. L. (1990). Changing learner behavior through environmental education. The Journal of Environmental Education, 21(3), 8-21. http://doi.org/10.1080/00958964.1990.10753743

Lemberger, M. E., Selig, J. P., Bowers, H., \& Rogers, J. E. (2015). Effects of the student success skills program on executive functioning skills, feelings of connectedness, and academic achievement in a predominantly Hispanic, low-income middle school district. Journal of Counseling \& Development, 93(1), 25-37. http://doi.org/10.1002/j.1556-6676.2015.00178.x

Lewis, S., \& James, K. (2010). Whose voice sets the agenda for environmental education? Misconceptions inhibiting racial and cultural diversity. The Journal of Environmental Education. Retrieved from http://www-tandfonlinecom.proxy.lib.pdx.edu/doi/abs/10.1080/00958964.1995.9941440

Lieberman, G. A. (2013). Education and the Environment: Creating Standards-Based Programs in Schools and Districts. Cambridge, MA: Harvard Education Press.

Lieberman, G. A., Hoody, L. L., \& State Education and Environment Roundtable. (1998). Closing the achievement gap: using the environment as an integrating context for learning. Poway, Calif.: Science Wizards.

Louv, R. (2007). Leave No Child Inside Testimony before the Interior and Environmental Subcommittee. 


\section{THE EFFECTS OF AN OVERNIGHT ENVIRONMENTAL PROGRAM}

Love, A., \& Kruger, A. C. (2005). Teacher beliefs and student achievement in urban schools serving African American students. The Journal of Educational Research, 99(2), 87-98. http://doi.org/10.3200/JOER.99.2.87-98

Mabie, R., \& Baker, M. (1996). A comparison of experiential instructional strategies upon the science process skills of urban elementary students. Journal of Agricultural Education, 37(2). http://doi.org/10.5032/jae.1996.02001

Marx, R. W., \& Harris, C. J. (2006). No child left behind and science education: Opportunities, challenges, and risks. The Elementary School Journal, 106(5), 467478. http://doi.org/10.1086/505441

McBeth, W., \& Volk, T. L. (2009). The national environmental literacy project: A baseline study of middle grade students in the United States. The Journal of Environmental Education, 41(1), 55-67. http://doi.org/10.1080/00958960903210031

McDermott, P. A., \& Mordell, M. Stoltzfus, J. C. (2001). The organization of student performance in American Schools: Discipline, motivation, verbal learning, and nonverbal learning. Journal of Educational Psychology, 93(1), 65-76.

Meece, J. L. (2003). Applying learner-centered principles to middle school education. Theory Into Practice, 42(2), 109.

Multnomah County QuickFacts from the US Census Bureau. (n.d.). Retrieved from http://quickfacts.census.gov/qfd/states/41/41051.html

New Federal Race and Ethnicity Reporting: Assistance Manual. (2010, February). Education Enterprise Steering Committee. 


\section{THE EFFECTS OF AN OVERNIGHT ENVIRONMENTAL PROGRAM}

Orr, D. W. (2010). Hope Is an Imperative: The Essential David Orr (Reprint edition). Washington, DC: Island Press.

Outdoor School / Program Tour. (n.d.). Retrieved November 12, 2015, from http://www.mesd.k12.or.us/Page/249

Palmer, P. (1997). Courage to Teach: Exploring the Inner Landscape of a Teacher's Life. Jossey-Bass, Inc.

Powell, A., \& Seed, A. (2010). Developing a caring ethic for middle school mathematics classrooms: EBSCOhost. Retrieved from http://web.a.ebscohost.com.proxy.lib.pdx.edu/ehost/detail/detail?sid=f1ca2c39-a1a74e39-b92f36d0adf4b445\%40sessionmgr4005\&crlhashurl=login.aspx $\% 253$ fdirect $\% 253 \mathrm{dtrue} \%$ 2526scope $\% 253 \mathrm{~d}$ site $\% 2526 \mathrm{db} \% 253 \mathrm{dehh} \% 2526 \mathrm{AN} \% 253 \mathrm{~d} 48553470 \% 2526 \mathrm{msid} \% 2$ 53d201345497\&hid=4214\&vid=0\&bdata=JnNpdGU9ZWhvc3QtbG12ZQ\%3d\%3d\# $\mathrm{AN}=48553470 \& \mathrm{db}=\mathrm{ehh}$

Prince, D. (2015). Microsoft Excel 2008 for Mac (Version 12.2.6). [MESD attendance 1966-2015]. MESD Outdoor School Program.

Ramirez, M., Wu, Y., Kataoka, S., Wong, M., Yang, J., Peek-Asa, C., \& Stein, B. (2012). Youth violence across multiple dimensions: A study of violence, absenteeism, and suspensions among middle school children. The Journal of Pediatrics, 161(3), 542546.e2. http://doi.org/10.1016/j.jpeds.2012.03.014 


\section{THE EFFECTS OF AN OVERNIGHT ENVIRONMENTAL PROGRAM}

Rodríguez, L. F., \& Conchas, G. Q. (2009). Preventing truancy and dropout among urban middle school youth understanding community-based action from the student's perspective. Education and Urban Society, 41(2), 216-247.

http://doi.org/10.1177/0013124508325681

Rumberger, R. W. (1995). Dropping out of middle school: A multilevel analysis of students and schools. American Educational Research Journal, 32(3), 583-625. http://doi.org/10.3102/00028312032003583

Ryan, R. M., \& Deci, E. L. (2000). Self-determination theory and the facilitation of intrinsic motivation, social development, and well-being. American Psychologist, 55(1), 68-78. http://doi.org/http://dx.doi.org.proxy.lib.pdx.edu/10.1037/0003066X.55.1.68

Samuel, F. A., \& Suh, B. (2012). Teacher candidates reconcile the child and the curriculum with no child left behind. The Educational Forum, 76(3), 372-382. http://doi.org/10.1080/00131725.2012.682201

Sheppard, J. A. C. (1995). The black-white environmental concern gap: An examination of environmental paradigms. The Journal of Environmental Education, 26(2), 2435. http://doi.org/10.1080/00958964.1995.9941437

Simmons, B. (2000). Towards excellence in environmental education a view from the United States. Water, Air \& Soil Pollution, 123(1/4), 517-524. 


\section{THE EFFECTS OF AN OVERNIGHT ENVIRONMENTAL PROGRAM}

Skinner, E. A., Chi, U., \& The Learning-Gardens Educational Assessment Group. (2011). Intrinsic motivation and engagement as "active ingredients" in garden-based education: Examining models and measures derived from self-determination theory. The Journal of Environmental Education, 43(1), 16-36. http://doi.org/10.1080/00958964.2011.596856

Skinner, E. A., Kindermann, T. A., \& Furrer, C. J. (2009). A motivational perspective on engagement and disaffection conceptualization and assessment of children's behavioral and emotional participation in academic activities in the classroom. Educational and Psychological Measurement, 69(3), 493-525. http://doi.org/10.1177/0013164408323233

Smith, G. A., (1999), Creating a public of environmentalists: The role of nonformal education. In G. A. Smith \& D. R. Williams (Eds.), Ecological education in action: On weaving education, culture, and the environment (pp. 79-102). Albany, NY: SUNY Press.

Smith, L. L., \& Motsenbocker, C. E. (2005). Impact of hands-on science through school gardening in Louisiana public elementary schools. HortTechnology, 15(3), 439-443.

Smith-Sebasto, N. J., \& Obenchain, V. L. (2009). Students' perceptions of the residential environmental education program at the New Jersey school of conservation. The Journal of Environmental Education, 40(2), 50-62. http://doi.org/10.3200/JOEE.40.2.50-62 


\section{THE EFFECTS OF AN OVERNIGHT ENVIRONMENTAL PROGRAM}

Snyder, F., Flay, B., Vuchinich, S., Acock, A., Washburn, I., Beets, M., \& Li, K.-K. (2010). Impact of the positive action program on school-level indicators of academic achievement, absenteeism, and disciplinary outcomes: A matched-pair, cluster randomized, controlled trial. Journal of Research on Educational Effectiveness, 3(1), 26-55. http://doi.org/10.1080/19345740903353436

Standard 1-5 - NCES Statistical Standards. (n.d.). Retrieved October 19, 2015, from http://nces.ed.gov/statprog/2002/std1_5.asp

Stapp, W. B. (1969). The concept of environmental education. Environmental Education, 1(1), 30-31. http://doi.org/10.1080/00139254.1969.10801479

Stern, M. J., Powell, R. B., \& Ardoin, N. M. (2010). Evaluating a constructivist and culturally responsive approach to environmental education for diverse audiences. The Journal of Environmental Education, 42(2), 109-122. http://doi.org/10.1080/00958961003796849

Sterling, S. R. (2011). Sustainable Education: Re-visioning Learning and Change. Green Books for the Schumacher Society.

Tbilisi Declaration. (1978). Connect 3(1), 1-8.

The RIT Scale | Northwest Evaluation Association (NWEA). (n.d.). Retrieved October 19, 2015, from https://legacysupport.nwea.org/node/4344

Webb, N. M., \& Farivar, S. (1994). Promoting helping behavior in cooperative small groups in middle school mathematics. American Educational Research Journal, 31(2), 369-395. http://doi.org/10.2307/1163314 


\section{THE EFFECTS OF AN OVERNIGHT ENVIRONMENTAL PROGRAM}

Williams, D., \& Brown, J. (2012). Learning gardens and sustainability education: Bringing life to schools and schools to life (1 edition). New York: Routledge.

Williams, D., \& Taylor, S., (1999). From margin to center: Initiation and development of an environmental school from the ground up. In G. A. Smith \& D. R. Williams (Eds.), Ecological education in action: On weaving education, culture, and the environment (pp. 79-102). Albany, NY: SUNY Press. 
THE EFFECTS OF AN OVERNIGHT ENVIRONMENTAL PROGRAM

Appendix A - Human Subjects Review Application 


\section{THE EFFECTS OF AN OVERNIGHT ENVIRONMENTAL PROGRAM}

\section{Appendix A - Human Subjects Review Application}

\section{Human Subject Research Review Committee Research and Strategic Partnerships Portland State University}

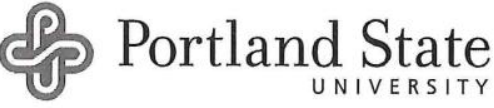

\section{Section 1: Investigator's Assurance}

Principal Investigator (or faculty advisor)__ Dr. Sybil Kelley
Co-Principal Investigator __ Moti Hara
Other Personnel (GA, Project Mgr., etc.) _ Jennifer Basham
Other Personnel (GA, Project Mgr., etc.) __ Dan Prince

Dept. _Educational Leadership and Policy__ Campus Mail Code__ED

E-Mail ___ sybilkel@pdx.edu
E-Mail___ mhara@pdx.edu
E-Mail__ jbasham@pdx.edu__
E-Mail___ dprince@mesd.k12.or.us___

Preferred Phone \# _503-725-5976

Title of Proposal: The effects of the MESD Outdoor School program on student's academic achievement, behavior, and attendance

Mailing Address __PO Box 751 (ED 504F), Portland, OR 97207

Proposed Duration of Project (months/years)_12 months/1 year Anticipated Start Date_Jan 6, 2014

Type of Funding (Federal/Federal pass-through/State/Foundation/Other/None) _Foundation

Funding Agency: _ Gray Family Foundation and Goodman Foundation ___ PIAF \#

If funded: Have the PI/co-PI completed the annual financial conflict of interest in research disclosure?

$$
X \text { yes no }
$$

Does this project create any changes to the current disclosure?

$$
\text { yes } X \text { no }
$$

\section{PLEASE NOTE THAT DATA COLLECTION CANNOT BEGIN UNTIL APPROVAL IS GRANTED BY HSRRC.}

\section{Investigator's Assurance}

A. I will promptly report changes in the proposed study and any unanticipated problems involving risk to subjects, including adverse reactions, to the Human Subjects Review Committee. In case of DHHS supported activities, I will also report these problems to the Department of Health and Human Services (through the respective granting office).

B. I assure that documentary evidence of informed consent will be retained for at least three years after the proposed study has been completed or discontinued.

C. Since the Committee is obligated to review this activity at least on an annual basis, I will furnish it with a progress report approximately six weeks prior to the expiration of my project's approval.

D. I, the undersigned, will be responsible for the ethical standards of this project, and for protecting the rights and welfare of

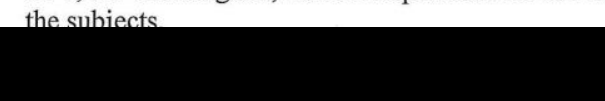

Signăture of Principal Investigator or Faculty Advisor

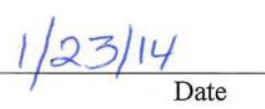

STUDENTS ONLY:

PSU ID \#_964592922___ X Master's Thesis $\square$ PhD/EdD Dissertation (Approval Date: __ $\square$ Other *

*Projects and studies that do not meet the definition of human subjects research may not require HSRRC oversight.

Under advisement from the above faculty member, I verify that I will conduct this research in accordance with PSU's Human Subjects Research Review Policy.

Student (print and sign) Jewnifer Basham Email_jbasham@pdx.edu

Please submit completed applications to RSP (hsrre@pdx.edu). 


\section{THE EFFECTS OF AN OVERNIGHT ENVIRONMENTAL PROGRAM}

Appendix A - Human Subjects Review Application

\section{Investigator's Assurance Form}

See Attached

\section{Project Title \& Prospectus}

Title: The effects of the MESD Outdoor School program on student's academic achievement, behavior, and attendance.

School programs that focus on engaging students in hands-on, field based scientific inquiry create positive opportunities that enhance the learning experience for students and allow students to participate in authentic, meaningful, and real-world applications of science, technology, engineering, and math concepts. Unfortunately, in many elementary schools, an extreme focus placed on literacy and math due to standardized tests has pushed science education to the back burner (Hamilton, et al., 2007). New emphasis placed on Science, Technology, Engineering and Mathematical (STEM) learning within the classroom is one step toward fixing this curriculum deficiency, however multiple barriers still exist in order to truly implement a robust scientific curriculum that includes both in-class and outdoor field activities (DettemannEasler and Pease, 1999).

This study seeks to understand the impact of one program that focuses on providing hands-on scientific inquiry for students: Multnomah Education Service District's Outdoor School. This investigation seeks to address the following questions:

- Does the Outdoor School program have an impact on students' academic achievement? If so, where are the largest gains?

- Does the impact of Outdoor School differ depending on a student's background characteristics? If so, how?

Understanding how the program impacts students will provide validation for the program implementation within the traditional school setting, inform school districts and other programs like the MESD Outdoor School program of the benefits to student achievement and success indicators; and provide valuable data to drive program improvement.

Although residential environmental programs vary from program to program, most, if not all, provide students with the chance to "experience first-hand the richness and excitement of learning about the natural world" (Jackson, Dukerich, \& Hestenes, 2008, p. 10). Furthermore, Melber and Brown (2008) indicate that "when science is taught in a hands-on, inquiry-based manner, it is the preferred subject area" (p. 36) for many students. In addition to increases in scientific knowledge, residential environmental programs allow students to spend valuable time outdoors, which Ewert, Place, and Sibthorp (2005) suggest as "the most influential factor in developing concern for the environment" (p. 228). Melber and Brown (2008) suggest, "informal sciencelearning experiences, or learning experiences that occur outside a traditional classroom, are one way these authentic, inquiry-based experiences can be shared with students" (pg. 36). 


\title{
THE EFFECTS OF AN OVERNIGHT ENVIRONMENTAL PROGRAM
}

\author{
Appendix A - Human Subjects Review Application
}

While residential programs often foster a student's ecological concern in addition to scientific application and knowledge gain, schools can find it difficult to justify these experiences outside of the classroom due to the cost and, more importantly, the lack of quantifiable evidence of the impact on student learning. Moreover, focus on closing the achievement gap has gained attention and has shifted school district priorities to support programs that have documented positive impacts on student success indicators. This research hopes to build on the current research surrounding the achievement gap and provide a unique perspective of the impact of the Outdoor School program on academic outcomes through quantitative methods, a process that few researchers have ventured beyond observations made based on anecdotal evidence. Ultimately, this research can serve as a starting point for why Outdoor School programs, in particular, deserve our attention.

\section{Type of Review}

Our understanding is that this research project would qualify for Exempt human subjects review because data collected for the purpose of this study will meet the requirements under U.S. Department of Health and Human Services guidelines for exemption under 45 CFR 46.101(b). This research intends to analyze existing data and records of student academic, behavior, and attendance records gathered in established or commonly accepted educational settings involving normal education practices. Specifically, we will be utilizing existing data from existing enrollment records collected at Outdoor School and merging them with existing secondary data including academic, behavior, and attendance records held by each of the component districts; Centennial, Corbett, David Douglas, Gresham-Barlow, Parkrose, Portland Public, Reynolds, and Riverdale School Districts. This data will be gathered in such a way that students cannot be identified, directly or through identifiers linked to the subjects.

\section{IV.Subject Recruitment}

The proposed study seeks to understand the impact of the MESD Outdoor School program on student's academic achievement, attendance, and referral rates (disciplinary data) among various demographic populations of students who have attended the program through an analysis of secondary data. We will not be recruiting subjects for the purpose of this study; instead, information will be gathered through attendance records of the MESD Outdoor School program for the years dating 2006-2013. This enrollment information has dates of attendance, program length, site attended, school, teacher, student attendance records, and high school volunteering enrollment.

We will be working with the Multnomah Education Service District and the component districts that participate in the Outdoor School program to compile and merge student data with attendance records from the program. We will be requesting specific information such as high school completion, attendance records, referral rates, science test scores, and demographic information. All personally identifiable information will 


\title{
THE EFFECTS OF AN OVERNIGHT ENVIRONMENTAL PROGRAM
}

\author{
Appendix A - Human Subjects Review Application
}

be expunged from the data set after Outdoor School attendance records have been merged with the student-specific data, prior to the researchers receiving the data sources.

\section{Informed Consent}

Our informed consent for this research project will be gathered through each district. Because our research will not include direct contact with students, we will be obtaining informed consent through each school district within Multnomah Education Service District including; Centennial, Corbett, David Douglas, Gresham-Barlow, Parkrose, Portland Public, Reynolds, and Riverdale School Districts. (See Appendix 1 for Consent to Participate in Outdoor School Research)

\section{First-Person Scenario}

Today I received a request in the mail from Sybil Kelley, assistant professor at Portland State University for access to de-identified student data from my district for the years ranging from 2006-2013. The purpose of this research study is to understand the impact of the Multnomah Education Service District Outdoor School program on students with regards to student achievement and behavioral indicators such as attendance and incidence of referrals. The research team requests the release of student data such as student ID numbers, state test scores, attendance, and behavior records. I was happy to see that the researchers have strict protocols for maintaining confidentiality and secure file storage through password-protected servers. Sybil communicated through the proposal that she and her team are working in conjunction with the MESD technology staff members who are responsible for maintaining student records throughout the Portland area and with approval from our district will compile the information requested. I was also reassured to know that any personally identifiable data will be deleted prior to the research team gaining access to it. Before I can approve their request, our district research and evaluation committee will discuss the proposal in one of our monthly research meetings. After our committee meeting, I was happy to grant the request for data to both Sybil and the MESD technology technician.

\section{Potential Risks and Safeguards}

The potential risks to students are minimal and would not exceed what a student within a traditional education setting would endure. Additionally, the data collected for the purpose of this study will be garnered through existing data sources and all personally identifiable information will be removed prior to the data being made available to researchers. In some cases, the researchers will aggregate data within a larger demographic population if disaggregated sub-groups of race or ethnicity result in a group of 10 students or less. The greatest risk to participants would be the accidental loss of confidentiality. Safeguards for this risk will be implemented by ensuring that all documents and raw data will be stored in password-protected files and servers. 


\title{
THE EFFECTS OF AN OVERNIGHT ENVIRONMENTAL PROGRAM
}

\author{
Appendix A - Human Subjects Review Application
}

Furthermore, the transfer of data will be minimized by utilizing secure servers as the main storage system for electronic files, and locked cabinets for paper copies. Data accumulated and compiled for this research project will be protected with access given only to the principle investigators, Sybil Kelley, Moti Hara, Jennifer Basham, and Dan Prince.

\section{Potential Benefits}

The benefits of this research will be to understand the impact of the Outdoor School program on student's academics, attendance, and behavior. (See Appendix 2 for specific variables being requested) This knowledge will further our understanding of how the Multnomah Education Service District Outdoor School program supports students within the traditional educational settings. Understanding how the program impacts students will provide validation for the program implementation within the traditional school setting while additionally informing school districts and other programs like the MESD Outdoor School program of the benefits to student achievement. Furthermore, this research may provide documentation of the variable effects related to the length of program participation in conjunction with informing opportunities for program improvement.

Researchers participating in the development of the study are interested in the dissemination of our findings to a broad audience of education professionals, nonprofits, foundations, academia, and state and local policy makers. We plan to share our findings through three avenues: Practitioner (e.g. presentations and reports for the general public); Academic (e.g. refereed publications and conference presentations); and to inform policy makers through local and statewide initiatives (No Oregon Child Left Inside coalition and Oregon Environmental Literacy Plan implementation and advocacy). The collaborative effort of the four researchers involved in the study will be recognized in all artifacts of the study, thus benefiting the professional growth of all involved.

\section{Confidentiality, Records \& Distribution}

Researchers will ensure the confidentiality of all participants by adhering to various protocols for maintaining confidentiality. Digital student attendance records will be stored in secure password protected servers, to which Jennifer Basham will hold access. Paper confidential records will be stored in locked cabinets within the Multnomah Education Service District building. Coding scripts will be stored in a password protected excel file within the secure server. All student names will be expunged from the data source prior to researchers having access to ensure the maximum level of confidentiality possible. Data collected and utilized in this study will be purged 3 years after the completion of the research project. 


\section{THE EFFECTS OF AN OVERNIGHT ENVIRONMENTAL PROGRAM}

Appendix A - Human Subjects Review Application

\section{Training and Experience}

Principal Investigator, Sybil Kelley, Assistant Professor in the Educational Leadership \& Policy Department at Portland State University has been engaged in educational research since 2000, and completed the NIH training module for research with human participants in 2004. Her research has included an in-depth study of engagement, critical thinking, and learning of $6^{\text {th }}$ grade participants, as well as research with adult participants. Additionally, PI Kelley is mid-way through the CITI training modules for researchers and IRB members, and anticipates completion by January 1, 2014.

Jennifer Basham is a graduate student within the Educational Leadership and Policy program working towards her master's thesis project. She will be working under the guidance and supervision of Drs. Sybil Kelley and Moti Hara. Jennifer has worked with the Multnomah Education Service District Outdoor School in a variety of roles from high school volunteer to Site Supervisor helping improve curriculum, support teachers, and continue building support of the program through targeted outreach.

Moti Hara, Assistant Professor within the Educational Leadership and Policy Department at Portland State University. Dr. Hara, Co-Principal Investigator, has conducted research with large-scale longitudinal data-files in educational research and public health, and was a recipient of the NIH/NIDA Pre-doctoral Research Fellowship while at the Semel Institute for Neuroscience and Human Behavior, UCLA David Geffen School of Medicine.

Daniel Prince, MS, is the Coordinator of Outdoor School Programs at Multnomah Education Service District in Portland, Oregon. His Masters degree is in Education Administration is from Portland State University, and his B.A. in Philosophy is from Whitman College. His twenty-five years in experiential, environmental education has generated a strong interest in understanding how non-formal, co-curricular learning experiences support student learning in STEM and other disciplines.

\section{References}

Dettmann-Easler, D., \& Pease, J. L. (1999). Evaluating the Effectiveness of Residential Environmnetal Education Programs in Fostering Positive Attitudes Toward Wildlife. Journal of Environmental Education , 31 (1), 33-39.

Ewert, A., Place, G., \& Sibthorp, J. (2005). Early-Live Outdoor Experiences and an Individual's Environmental Attitudes. Leisure Sciences , 27, 225-239.

Hamilton, L. S., Stecher, B. M., Marsh, J. A., Sloan McCombs, J., Robyn, A., Russell, J., et al. (2007). Standards-based accountability under no child left behind: Experiences of teachers and administrators in three states. Santa Monica, CA: RAND Corporation. 


\section{THE EFFECTS OF AN OVERNIGHT ENVIRONMENTAL PROGRAM}

Appendix A - Human Subjects Review Application

Jackson, J., Dukerich, L., \& Hestenes, D. (2008). Modeling Instruction: An Effective Model for Science Education. Science Educator , 17 (1), 10-17.

Melber, L. M., \& Brown, K. D. (2008). "Not like a Regular Science Class": Informal Science Education for Students with Disabilities. The Clearing House: Informal Sciece Education , 82 (1), 35-39.

\section{Appendices}

Appendix 1 - Consent to Participate in Outdoor School Research (See attached)

Appendix 2 - Student Data Request for MESD Component Districts (See attached)

Appendix 3 - Portland State and Multnomah Education Service District MOU (See attached)

Appendix 4 - MESD Request for Release of Attendance Records, Approval Letter, and Example Class List Form (See attached) 
THE EFFECTS OF AN OVERNIGHT ENVIRONMENTAL PROGRAM

Appendix A - Human Subjects Review Application

Consent to Participate in Outdoor School Research

Graduate School of Education

Educational Leadership \& Policy

Leadership for Sustainability Education

Post Office Box 751

Portland, Oregon 97207-0751
503-725-5976 tel

503-725-8475 fax

sybilkel@pdx.edu

\title{
Portland State UNIVERSITY
}

\author{
The Portland State University \\ Consent to Participate in Research
}

Understanding the effects of the MESD Outdoor School program on
student's academic achievement, behavior, and attendance.

$2 / 11 / 14$

\section{Introduction}

A collaborative research team from MESD Outdoor School and Portland State University are conducting a research study impact of the Outdoor School program on student's academic achievement, behavior, and attendance. As a representative of School District, you are being asked to participate in the research study

that is being done by Sybil Kelley who is the Principal Investigator, Moti Hara, Jennifer Basham, from the Department of Educational Leadership \& Policy, at Portland State University in Portland, Oregon and Dan Prince from the Multnomah Education Service District Outdoor School program. You are being asked to participate in this study because sixth graders in your school district have attended a partial or full week experience at Outdoor School with the Multnomah Education Service District.

This form will explain the research study, and will also explain the possible risks as well as the possible benefits to you. We encourage you to talk with your district representatives before you decide to take part in this research study. If you have any questions, please ask one of the study investigators.

\section{What will happen if ___ district agrees to participate?}

If your district approves this research, the following things will happen: 


\section{THE EFFECTS OF AN OVERNIGHT ENVIRONMENTAL PROGRAM}

Appendix A - Human Subjects Review Application

1. Your district will grant access to archival data such as Student ID numbers, state test scores, attendance, and behavior records through the Cascade Technology Alliance staff members for the years ranging 2006-2013. (See Appendix 2 for specific data request form)

2. Cascade Technology Alliance staff members will merge school district records with Multnomah Education School District Outdoor School attendance records.

3. Cascade Technology Alliance staff members will expunge student ID numbers and personal identifiers.

4. Researchers will receive the data sources.

5. Researchers will then analyze the unidentified data. No analysis will be conducted when student subgroups result in 10 or fewer participants to further protect the confidentiality of the participants.

6. Researchers will report the findings, and then all data will be deleted 3 years after the completion of the study. Because this research study is a secondary data analysis, there will be no direct contact with participants.

\section{Study Duration and Time Commitments}

Beyond review of the application, there will be no time commitment from your school district employees.

\section{What are the potential risks of this study? What safeguards are in place?}

The potential risks to students are minimal and would not exceed what a student within a traditional education setting would endure. The data collected for the purpose of this study will be garnered through existing data sources and all personally identifiable information will be removed prior to the data being made available to researchers. In some cases, the researchers will aggregate data within a larger demographic population if sub-groups of race or ethnicity result in a group of 10 students or less. The greatest risk to participants would be the accidental loss of confidentiality. Safeguards for this risk will be implemented by ensuring that all documents and raw data will be stored in password-protected files and servers. Furthermore, the transfer of data will be minimized by utilizing secure servers as the main storage system for electronic files, and locked cabinets for paper copies. Data accumulated and compiled for this research project will be protected with access given only to the principle investigators, Sybil Kelley, Moti Hara, Jennifer Basham, and Dan Prince.

For more information about risks and discomforts, ask the investigator. 
Appendix A - Human Subjects Review Application

\section{What are the potential benefits of this study?}

The benefits of this research will be to understand the impact of the Outdoor School program on student's academics, attendance, and behavior. This knowledge will further our understanding of how the Multnomah Education Service District Outdoor School program supports students within the traditional education settings. Understanding how the program impacts students will provide validation for program implementation and provide valuable data to drive program improvement. There will be no direct benefit to the school districts participating in this study.

\section{How will student information be kept confidential?}

Researchers will ensure the confidentiality of all participants by adhering to various protocols for maintaining confidentiality. Digital student attendance records will be stored in secure password protected servers, to which only the researchers will hold access. Paper confidential records will be stored in locked cabinets within the Multnomah Education Service District building. Coding scripts will be stored in a password protected excel file within the secure server. All student names will be expunged from the data source prior to researchers having access to maintain the highest level of confidentiality possible. Data collected and utilized in this study will be purged 3 years after the completion of the research project.

\section{Will I be paid for taking part in this study?}

No. Your school district will not be financially compensated for participating in this study.

\section{Can I stop being in the study once I begin?}

Your school district participation in this study is completely voluntary. You have the right to choose not to participate or to withdraw your participation at any point in this study without penalty or loss of benefits to which you are otherwise entitled.

\section{Whom can I call with questions or complaints about this study?}

If you have any questions, concerns or complaints at any time about the research study, Sybil Kelley, or her associates will be glad to answer them.

Sybil Kelley, Principle Investigator, Email: sybilkel@pdx.edu, Phone: 503-725-5976

Moti Hara, Assistant Professor, Email: mhara@ pdx.edu, Phone: 503-725-9903 


\section{THE EFFECTS OF AN OVERNIGHT ENVIRONMENTAL PROGRAM}

Appendix A - Human Subjects Review Application

Jennifer Basham, Graduate Assistant, Email: jbasham @pdx.edu, Phone: 971-275-6269

Dan Prince, ODS Coordinator, Email: dprince@mesd.k12.or.us, Phone: 503-257-1600

\section{Whom can I call with questions about my rights as a research participant?}

If you have questions regarding your rights as a research participant, you may call the PSU Office for Research Integrity at (503) 725-2227 or 1(877) 480-4400. The ORI is the office that supports the PSU Institutional Review Board (IRB). The IRB is a group of people from PSU and the community who provide independent oversight of safety and ethical issues related to research involving human participants. For more information, you may also access the IRB website at https://sites.google.com/a/pdx.edu/research/integrity. 
THE EFFECTS OF AN OVERNIGHT ENVIRONMENTAL PROGRAM

Appendix A - Human Subjects Review Application

Student Data Request for MESD Component Districts 


\section{THE EFFECTS OF AN OVERNIGHT ENVIRONMENTAL PROGRAM}

\section{Appendix A - Human Subjects Review Application}

\section{Student Data Request for MESD Component Districts}

Requested By Sybil Kelley and Jennifer Basham

Organization PSU Graduate School of Ed - ELP Dept.

Note: Data may not be re-released to any other organization without consent of the parent/guardian.
Date Submitted Upon Approval of IRB

Date Due ASAP

Street Address PO Box 751

City Portland

Phone 503-725-4619

\section{State}

Email Address

\section{sybilkel@pdx.edu}

ibasham@mesd.k12.or.us

Purpose of To understand how Outdoor School impacts students related to student success. Specific areas request of interest are: high school completion, career and college readiness, and goals outlined OEIB.

Districts Place a check mark (click on the box) next to the districts you want included in this request. If student-level (identifiable) records are needed, provide a contact for each district in the box below the corresponding district name (see "Type of Data" and "Release Type" below).
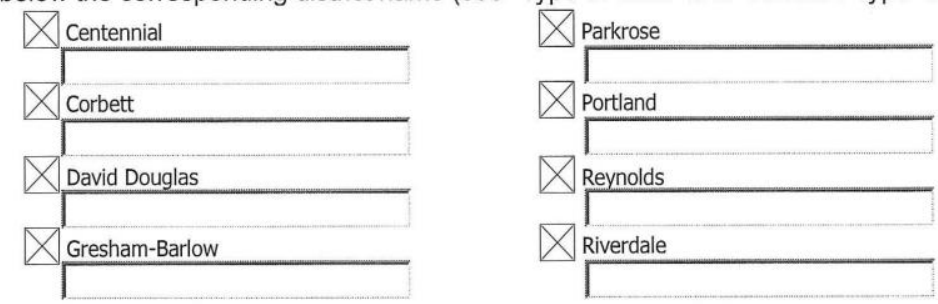

Schools If you need data for specific schools within the district(s) listed above, please list those below.

\section{Grade Levels to}

include All students included in Outdoor School attendance data

\footnotetext{
Type of Data $\square$ Summary (non-identifiable data)

Needed De-identified data (e.g., proxy IDs \& no identifiable fields) -- check agreement below

$\triangle$ I agree that I will NOT attempt to make records identifiable (e.g., link to data from a separate request)

Student-level (identifiable) records* -- check certification below

$\square$ I certify that I have read, understand and agree to abide by all FERPA laws.
}

Release Type* $\square$ signed parent release forms $\quad$ Contract or Memorandum of Understanding (MOU) with district(s) NOTE: Provide a district contact for releases/contracts/MOUs below each district selected above.

Data Elements Complete the "Data Elements, Advanced Evaluation Export Fields" form (third tab) to identify data elements that are required for completion of this data request. Add additional comments below.

*NOTES 1. If student-level (identifiable) records are required you MUST select a release type (see FERPA notice attached) and provide a district contact for each district. This is not required for summary or deidentified data.

2. Final release of any/all data is at the discretion of district staff. 


\title{
THE EFFECTS OF AN OVERNIGHT ENVIRONMENTAL PROGRAM
}

\author{
Appendix A - Human Subjects Review Application
}

\section{Data Elements}

\section{Advanced Evaluation Export Fields}

Please place an " $X$ " in the "Include Field?" column for each data element that is required for this data request. Behavior Data

NOTE: You must be able to justify each data element requested in terms of the purpose of the data request. Attendace Data

\begin{tabular}{|c|c|c|c|}
\hline Item & Field & More Info & Include Field? \\
\hline 1 & Pupil Number & Student's eSIS ID number & \\
\hline 2 & SSID & Student's state ID number & $\mathrm{x}$ \\
\hline 3 & Last Name & Preferred & $\mathrm{X}$ \\
\hline 4 & First Name & Preferred & $\mathrm{X}$ \\
\hline 5 & Ethnicity & Hispanic or Not Hispanic & $\mathrm{x}$ \\
\hline 6 & Race & Any of the six individual items, or "Multi" & $\mathrm{X}$ \\
\hline 7 & ODE E_R Code & $\begin{array}{l}\text { Ethnicity/Race code as defined by ODE. If a student's ethnicity is } \\
\text { "Hispanic", this code will read "H" regardless of race. If the student's } \\
\text { ethnicity is "Not Hispanic", this code will reflect the student's race. } \\
\text { Following is a list of codes: } \\
\text { A=Asian } \\
B=B l a c k \text { / African American } \\
\text { H=Hispanic } \\
\text { I=American Indian / Alaskan Native } \\
\text { M=Multi-Racial / Ethnic } \\
P=\text { Pacific Islander / Native Hawaiian } \\
\text { W=White }\end{array}$ & $x$ \\
\hline 8 & Gender & $\mathrm{M} / \mathrm{F}$ & $\mathrm{X}$ \\
\hline 9 & Birth Date & & \\
\hline 10 & Current Grade & & $\mathrm{x}$ \\
\hline 11 & Current Registration Date & Date of most recent registration & \\
\hline 12 & Grade 9 Entry Date & If applicable & \\
\hline 13 & LEP Entry Date & & \\
\hline 14 & LEP Exit Date & & \\
\hline 15 & FARMs Base Year & $\begin{array}{l}\text { Only if user security allows, otherwise null. This field will read "Y" } \\
\text { during the carry-over period if a student was eligible the following year. }\end{array}$ & \\
\hline 16 & Counselor & & \\
\hline 17 & Homeroom & Hrm1 Teacher Name & \\
\hline 18 & School ID & Currently Enrolled School ID & $\mathrm{X}$ \\
\hline 19 & School Name & Currently Enrolled School & $\mathrm{X}$ \\
\hline 20 & First Admit Date & First Admission date found on eSIS for the current district. & \\
\hline 21 & Num Schls & Count of school transitions recorded in the SIS (regardless of district). & $\mathrm{X}$ \\
\hline 22 & Zip Code & & $\mathrm{X}$ \\
\hline 23 & County & & $\mathrm{X}$ \\
\hline 24 & Catchment & & \\
\hline 25 & GPA & Current Cumulative GPA & $\mathrm{x}$ \\
\hline 26 & First Language & & $\mathrm{X}$ \\
\hline 27 & Language at Home & & $\mathrm{x}$ \\
\hline 28 & Diploma Earned & Type of diploma earned if any & $\mathrm{X}$ \\
\hline 29 & Diploma Name & Name of the diploma currently assigned to the student & \\
\hline
\end{tabular}


THE EFFECTS OF AN OVERNIGHT ENVIRONMENTAL PROGRAM

Appendix A - Human Subjects Review Application

\section{Data Elements}

\section{Advanced Evaluation Export Fields}

SS Demographics

School Info

Please place an " $X$ " in the "Include Field?" column for each data element that is required for this data request. Behavior Data NOTE: You must be able to justify each data element requested in terms of the purpose of the data request. Attendace Data

\begin{tabular}{|c|c|c|c|}
\hline & & & Achievement Data \\
\hline Item & Field & More Info & Include Field? \\
\hline 30 & SpEd & $Y / N / X$ (X=exited during the year) & \\
\hline 31 & ELL & Y/N/M/R (M=Monitored; R=Refused) & \\
\hline 32 & TAG & $\mathrm{Y} / \mathrm{N}$ ( $\mathrm{Y}$ if any active programs from TAG group) & \\
\hline 33 & Academic Priority & Y/N ( $\mathrm{Y}$ if active program "Academic Priority") & \\
\hline 34 & Section 504 & $\mathrm{Y} / \mathrm{N}$ (Y if active program "Section 504") & \\
\hline 35 & Expulsions Pform Year & Count of Expulsions & $\mathrm{x}$ \\
\hline 36 & Suspensions Pform Year & Count of Suspensions - Out of School & $\mathrm{X}$ \\
\hline 37 & Incidents ALL Pform Year & Count of any incident recorded in eSIS for this student & $\mathrm{X}$ \\
\hline 38 & Expulsions Pform Year - 1 & Count of Expulsions & $\mathrm{X}$ \\
\hline 39 & Suspensions Pform Year - 1 & Count of Suspensions - Out of School & $\mathrm{X}$ \\
\hline 40 & Incidents ALL Pform Year - 1 & Count of any incident recorded in eSIS for this student & $\mathrm{X}$ \\
\hline 41 & Total Late & Pform Year Only & $x$ \\
\hline 42 & Days Present Pform Year & Pform Year Total Days Present & $\mathrm{x}$ \\
\hline 43 & Days Absent Pform Year & Pform Year Total Days Absent & $x$ \\
\hline 44 & Attendance Rate Pform Year & Pform Year; Days Present / (Days Present + Days Absent) & $\mathrm{X}$ \\
\hline 45 & Days Present Pform Year - 1 & Pform Year - 1 Total Days Present & $\mathrm{X}$ \\
\hline 46 & Days Absent Pform Year - 1 & Pform Year - 1 Total Days Absent & $\mathrm{X}$ \\
\hline 47 & $\begin{array}{l}\text { Attendance Rate Pform Year - } \\
1\end{array}$ & Pform Year - 1: Days Present / (Days Present + Days Absent) & $x$ \\
\hline 48 & $\begin{array}{l}\text { OAKS - Math Pform Year (if } \\
\text { any) }\end{array}$ & Multiple fields; similar to "Assessment Export" & \\
\hline & (Note: Individual assessment & Assessment Date & \\
\hline & fields marked to the right & Test Level & \\
\hline & will be included for all & Performance Level & \\
\hline & assessments/years selected & RIT Score & \\
\hline & below) & Quintile & \\
\hline & & Percentile & \\
\hline & & Lexile (Reading Only) & \\
\hline 49 & OAKS - Math Pform Year - 1 & Same data elements as above & $\mathrm{X}$ \\
\hline 50 & OAKS - Math Pform Year - 2 & Same data elements as above & $\mathrm{X}$ \\
\hline 51 & OAKS -- Reading Pform Year & Same data elements as above & \\
\hline 52 & $\begin{array}{l}\text { OAKS - Reading Pform Year } \\
1\end{array}$ & Same data elements as above & . \\
\hline 53 & $\begin{array}{l}\text { OAKS - Reading Pform Year } \\
2\end{array}$ & Same data elements as above & \\
\hline 54 & OAKS - Science Pform Year & Same data elements as above & $\mathrm{X}$ \\
\hline 55 & $\begin{array}{l}\text { OAKS - Science Pform Year - } \\
1\end{array}$ & Same data elements as above & $\mathrm{x}$ \\
\hline 56 & $\begin{array}{l}\text { OAKS - Science Pform Year - } \\
2\end{array}$ & Same data elements as above & $\mathrm{x}$ \\
\hline
\end{tabular}




\title{
THE EFFECTS OF AN OVERNIGHT ENVIRONMENTAL PROGRAM
}

\author{
Appendix A - Human Subjects Review Application
}

\section{Data Elements}

\section{Advanced Evaluation Export Fields}

SS Demographics

School Info

Please place an "X" in the "Include Field?" column for each data element that is required for this data request. Behavior Data NOTE: You must be able to justify each data element requested in terms of the purpose of the data request. Attendace Data

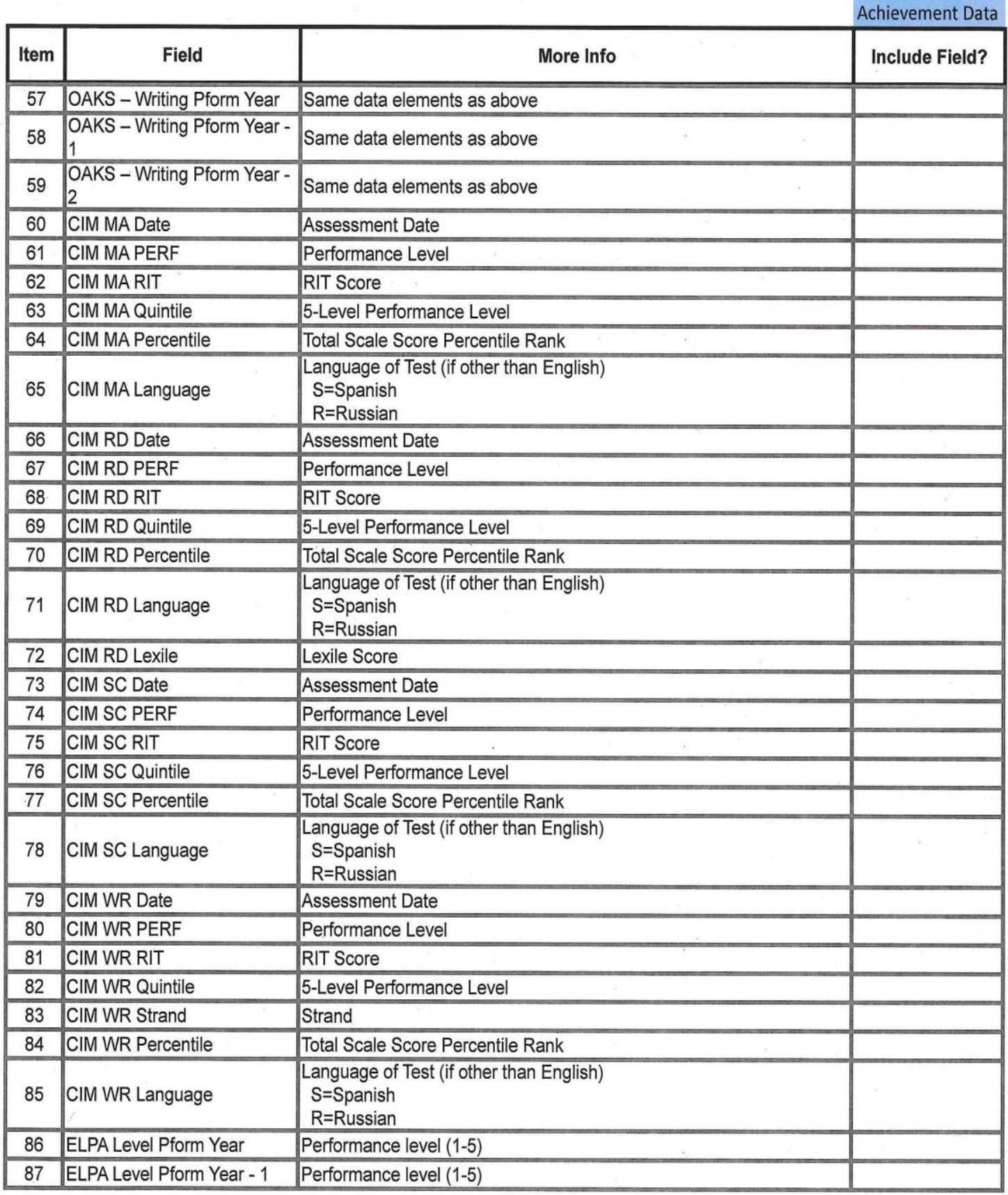




\title{
THE EFFECTS OF AN OVERNIGHT ENVIRONMENTAL PROGRAM
}

\author{
Appendix A - Human Subjects Review Application
}

\section{Data Elements}

\section{Advanced Evaluation Export Fields}

Please place an " $X$ " in the "Include Field?" column for each data element that is required for this data request. Behavior Data NOTE: You must be able to justify each data element requested in terms of the purpose of the data request. Attendace Data

\begin{tabular}{|c|c|c|c|}
\hline & & & Achievement Data \\
\hline Item & Field & More Info & Include Field? \\
\hline 88 & ELPA Level Pform Year - 2 & Performance level (1-5) & \\
\hline 89 & $\begin{array}{l}\text { Cum HS Diploma Credits } \\
\text { Earned }\end{array}$ & $\begin{array}{l}\text { Total HS credits student has earned to date that fulfill diploma } \\
\text { requirements. }\end{array}$ & . \\
\hline 90 & Cum HS Credits Attempted & Total HS credits student has attempted to date & $\mathrm{x}$ \\
\hline 91 & HS Credits Earned Base Yr & HS credits earned base year & $\mathrm{x}$ \\
\hline 92 & $\begin{array}{l}\text { HS Credits Attempted Base } \\
Y_{r}\end{array}$ & HS credits attempted base year & $\mathrm{x}$ \\
\hline 93 & $\begin{array}{l}\text { Cumulative Math Credits } \\
\text { Earned }\end{array}$ & $\begin{array}{l}\text { Sum of credits earned for Math courses (Note: All credits summarized } \\
\text { below are based on course subject. This may or may not correspond to } \\
\text { the diploma subject area for HS classes.) }\end{array}$ & $x$ \\
\hline 94 & $\begin{array}{l}\text { Cumulative Math Credits } \\
\text { Attempted }\end{array}$ & Sum of credits attempted for Math courses & $\mathrm{x}$ \\
\hline 95 & $\begin{array}{l}\text { Math Credits Earned Pform } \\
\text { Year }\end{array}$ & Sum of credits earned for Math courses & $\mathrm{x}$ \\
\hline 96 & $\begin{array}{l}\text { Math Credits Attempted } \\
\text { Pform Year }\end{array}$ & Sum of credits attempted for Math courses & $\mathrm{x}$ \\
\hline 97 & $\begin{array}{l}\text { Math Credits Earned Pform } \\
\text { Year - } 1\end{array}$ & Sum of credits earned for Math courses & $x$ \\
\hline 98 & $\begin{array}{l}\text { Math Credits Attempted } \\
\text { Pform Year - } 1\end{array}$ & Sum of credits attempted for Math courses & $\mathrm{x}$ \\
\hline 99 & $\begin{array}{l}\text { Cumulative Language Arts } \\
\text { Credits Earned }\end{array}$ & Sum of credits earned for Language Arts courses & \\
\hline 100 & $\begin{array}{l}\text { Cumulative Language Arts } \\
\text { Credits Attempted }\end{array}$ & Sum of credits attempted for Language Arts courses & \\
\hline 101 & \begin{tabular}{|l} 
Language Arts Credits \\
Earned Pform Year
\end{tabular} & Sum of credits earned for Language Arts courses & \\
\hline 102 & \begin{tabular}{|l} 
Language Arts Credits \\
Attempted Pform Year
\end{tabular} & Sum of credits attempted for Language Arts courses & \\
\hline 103 & \begin{tabular}{|l|} 
Language Arts Credits \\
Earned Pform Year - 1 \\
\end{tabular} & Sum of credits earned for Language Arts courses & \\
\hline 104 & \begin{tabular}{|l} 
Language Arts Credits \\
Attempted Pform Year - 1
\end{tabular} & Sum of credits attempted for Language Arts courses & \\
\hline 105 & $\begin{array}{l}\text { Cumulative Science Credits } \\
\text { Earned }\end{array}$ & Sum of credits earned for Science courses & $\mathrm{x}$ \\
\hline 106 & $\begin{array}{l}\text { Cumulative Science Credits } \\
\text { Attempted }\end{array}$ & Sum of credits attempted for Science courses & $\mathrm{x}$ \\
\hline 107 & $\begin{array}{l}\text { Science Credits Earned } \\
\text { Pform Year }\end{array}$ & Sum of credits earned for Science courses & $\mathrm{x}$ \\
\hline 108 & $\begin{array}{l}\text { Science Credits Attempted } \\
\text { Pform Year }\end{array}$ & Sum of credits attempted for Science courses & $\mathrm{x}$ \\
\hline 109 & $\begin{array}{l}\text { Science Credits Earned } \\
\text { Pform Year - } 1\end{array}$ & Sum of credits earned for Science courses & $\mathrm{x}$ \\
\hline 110 & $\begin{array}{l}\text { Science Credits Attempted } \\
\text { Pform Year - } 1\end{array}$ & Sum of credits attempted for Science courses & $\mathrm{x}$ \\
\hline 111 & $\begin{array}{l}\text { Cumulative Social Studies } \\
\text { Credits Earned }\end{array}$ & Sum of credits earned for Social Studies courses & \\
\hline
\end{tabular}




\title{
THE EFFECTS OF AN OVERNIGHT ENVIRONMENTAL PROGRAM
}

\author{
Appendix A - Human Subjects Review Application
}

\section{Data Elements}

\section{Advanced Evaluation Export Fields} NOTE: You must be able to justify each data element requested in terms of the purpose of the data request. Attendace Data

\begin{tabular}{|c|c|c|c|}
\hline Item & Field & More Info & Include Field? \\
\hline 112 & $\begin{array}{l}\text { Cumulative Social Studies } \\
\text { Credits Attempted }\end{array}$ & Sum of credits attempted for Social Studies courses & \\
\hline 113 & $\begin{array}{l}\text { Social Studies Credits Earned } \\
\text { Pform Year }\end{array}$ & Sum of credits earned for Social Studies courses & \\
\hline 114 & $\begin{array}{l}\text { Social Studies Credits } \\
\text { Attempted Pform Year }\end{array}$ & Sum of credits attempted for Social Studies courses & \\
\hline 115 & $\begin{array}{l}\text { Social Studies Credits Earned } \\
\text { Pform Year - } 1\end{array}$ & Sum of credits earned for Social Studies courses & \\
\hline 116 & $\begin{array}{l}\text { Social Studies Credits } \\
\text { Attempted Pform Year - } 1\end{array}$ & Sum of credits attempted for Social Studies courses & \\
\hline 117 & PL Met & Has the Personalized Learning requirement been met? Y / N & \\
\hline 118 & Ess Skills Rdg Met & Has the Essential Skills Reading requirement been met? Y / N / N/A & \\
\hline 119 & Ess Skills Rdg How Met & $\begin{array}{l}\text { How the Essential Skills Reading requirement was met. Possible } \\
\text { values are: } \\
\text { OSA = State Assessment } \\
\text { WS=Work Sample } \\
\text { NAT=National test } \\
\text { blank=Not yet met }\end{array}$ & 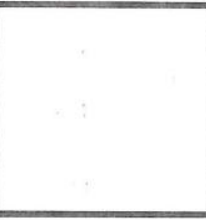 \\
\hline 120 & OSAT Rdg RIT & Best reading assessment score & \\
\hline 121 & OSAT Rdg Date & Date of best reading assessment & \\
\hline 122 & R-IN WS Status & Status of the reading informative work sample. & \\
\hline 123 & R-IN WS Date & $\begin{array}{l}\text { Date of reading informative work sample. If status is met, this will be } \\
\text { the earliest date. If unmet, this will be the most recent attempt. }\end{array}$ & \\
\hline 124 & R-Othr WS Status & $\begin{array}{l}\text { Status of the second reading work sample (M=Meets; } D=\text { Does not } \\
\text { meet). Can be either an additional informative or a literary work } \\
\text { sample. }\end{array}$ & \\
\hline 125 & R-Othr WS Date & $\begin{array}{l}\text { Date of the second reading work sample. If status is met, this will be } \\
\text { the earliest date. If unmet, this will be the most recent attempt. }\end{array}$ & \\
\hline 126 & Ess Skills Wr Met & Has the Essential Skills Writing requirement been met? Y / N / N/A & \\
\hline 127 & Ess Skills Wr How Met & $\begin{array}{l}\text { How the Essential Skills Writing requirement was met. Possible values } \\
\text { are: } \\
\text { OSA = State Assessment } \\
\text { WS=Work Sample } \\
\text { NAT=National test } \\
\text { blank=Not yet met }\end{array}$ & \\
\hline 128 & OSAT Wr RIT & Best writing assessment score & \\
\hline 129 & OSAT Wr Date & Date of best writing assessment & \\
\hline 130 & W-WS1 Type & $\begin{array}{l}\text { Type of the first writing work sample. Will always be either EX for } \\
\text { expository or PV for persuasive. One of either type is required. }\end{array}$ & \\
\hline 131 & W-WS1 Status & $\begin{array}{l}\text { Status of the expository or persuasive work sample (M=Meets; } \\
D=\text { Does not meet) }\end{array}$ & . \\
\hline 132 & W-WS1 Date & $\begin{array}{l}\text { Date of the writing expository or persuasive work sample. If status is } \\
\text { met, this will be the earliest date. If unmet, this will be the most recent } \\
\text { attempt. }\end{array}$ & $=$ \\
\hline
\end{tabular}




\title{
THE EFFECTS OF AN OVERNIGHT ENVIRONMENTAL PROGRAM
}

\author{
Appendix A - Human Subjects Review Application
}

\section{Data Elements}

\section{Advanced Evaluation Export Fields}

Please place an "X" in the "Include Field?" column for each data element that is required for this data request. Behavior Data NOTE: You must be able to justify each data element requested in terms of the purpose of the data request. Attendace Data

\begin{tabular}{|c|c|c|c|}
\hline Item & Field & More Info & Include Field? \\
\hline 133 & W-WS2 Type & $\begin{array}{l}\text { Type of the second writing work sample. This can be any of the } 3 \\
\text { types (expository, persuasive or narrative, which is NA) }\end{array}$ & \\
\hline 134 & W-WS2 Status & $\begin{array}{l}\text { Status of the second writing work sample (M=Meets; } \mathrm{D}=\text { Does not } \\
\text { meet) }\end{array}$ & \\
\hline 135 & W-WS2 Date & $\begin{array}{l}\text { Date of the second writing work sample. If status is met, this will be } \\
\text { the earliest date. If unmet, this will be the most recent attempt. }\end{array}$ & \\
\hline 136 & Ess Skills Ma Met & Has the Essential Skills Math requirement been met? Y / N / N/A & \\
\hline 137 & Ess Skills Ma How Met & $\begin{array}{l}\text { How the Essential Skills Math requirement was met. Possible values } \\
\text { are: } \\
\text { OSA = State Assessment } \\
\text { WS=Work Sample } \\
\text { NAT=National test } \\
\text { blank=Not yet met }\end{array}$ & \\
\hline 138 & OSAT Ma RIT & Best math assessment score & \\
\hline 139 & OSAT MA Date & Date of best math assessment & \\
\hline 140 & M-Alg WS Status & $\begin{array}{l}\text { Status of the algebra work sample (M=Meets; } D=\text { Does not meet). } \\
\text { Note that } 2 \text { math work samples are required, one each from any two } \\
\text { areas (algebra, geometry or statistics) }\end{array}$ & \\
\hline 141 & M-Alg WS Date & $\begin{array}{l}\text { Date of the algebra work sample. If status is met, this will be the } \\
\text { earliest date. If unmet, this will be the most recent attempt. }\end{array}$ & \\
\hline 142 & M-Geom WS Status & 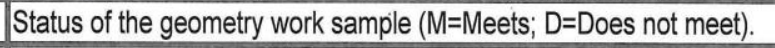 & \\
\hline 143 & M-Geom WS Date & $\begin{array}{l}\text { Date of the geometry work sample. If status is met, this will be the } \\
\text { earliest date. If unmet, this will be the most recent attempt. }\end{array}$ & \\
\hline 144 & M-Stat WS Status & Status of the statistics work sample (M=Meets; $D=$ Does not meet). & \\
\hline 145 & M-Stat WS Date & $\begin{array}{l}\text { Date of the statistics work sample. If status is met, this will be the } \\
\text { earliest date. If unmet, this will be the most recent attempt. }\end{array}$ & \\
\hline 146 & ACT - Eng Score & Highest ACT English Score & \\
\hline 147 & ACT - Math Score & Highest ACT Math Score & \\
\hline 148 & ACT - Reading Score & Highest ACT Reading Score & \\
\hline 149 & ACT - Science Score & Highest ACT Science Score & \\
\hline 150 & ACT - Composite Score & Highest ACT Composite Score & \\
\hline 151 & \begin{tabular}{|l} 
ACT - Combined \\
English/Writing Score
\end{tabular} & Highest ACT Combined English/Writing Score & \\
\hline 152 & PSAT - Math Score & Highest PSAT Math Score & \\
\hline 153 & PSAT - Reading Score & Highest PSAT Reading Score & \\
\hline 154 & PSAT - Writing Score & Highest PSAT Writing Score & \\
\hline 155 & SAT - Math Score & Highest SAT Math Score & \\
\hline 156 & SAT - Verbal Score & Highest SAT Verbal Score & \\
\hline 157 & SAT - Writing Score & Highest SAT Writing Score & \\
\hline
\end{tabular}




\title{
THE EFFECTS OF AN OVERNIGHT ENVIRONMENTAL PROGRAM
}

\author{
Appendix A - Human Subjects Review Application
}

MESD Contract \# - C01676

HSR Application

\author{
MEMORANDUM OF UNDERSTANDING \\ Portland State University \\ and \\ Multnomah Education Service District
}

\section{Partnership}

Portland State University (PSU) and the Multnomah Education Service District (MESD)

Outdoor School program are conducting a collaborative research study on the effects of the

MESD Outdoor School program. This investigation seeks to address the following questions:

- Does the Outdoor School program have an impact on students' academic achievement? If so, where are the largest gains?

- Does the impact of Outdoor School differ depending on a student's background characteristics? If so, how?

As a partner in the Outdoor School research project, Portland State University (PSU) and

Multnomah Education Service District (MESD) will contribute the following resources:

\section{Multnomah Education Service District}

- Multnomah Education Service District Outdoor School will provide technology (i.e. computer, access to a secure server, Internet access, and printing capabilities), office space, and supplies.

- Multnomah Education Service District will provide access to technology service staff members who will assist in compiling, merging, and de-identifying data sets, authorized through component school district protocols.

- Provide support, guidance, and help research team gain access to school district representatives, advisory committee members, and Multnomah Education Service District employees as needed.

\section{Portland State University}

- Portland State University research team members will provide support, guidance, and access to school district representatives and Portland State University resources as needed.

- Portland State University will provide access to relevant computer programs and secure technology services to assist with data analysis.

- Portland State University research team members will provide knowledge and expertise with advanced quantitative research methods and practices to analyze data and findings.

Kelley, Hara, Basham, Prince - 1/24/14 


\title{
THE EFFECTS OF AN OVERNIGHT ENVIRONMENTAL PROGRAM
}

\author{
Appendix A - Human Subjects Review Application
}

MESD Contract \# - C01676

HSR Application

- Portland State University will supervise the research process to ensure that it is conducted in a professional and ethical manor in-line with the highest research standards.

- Portland State University will make data requests to school districts, store data, and share results with Multnomah Education Service District and Friends of Outdoor School Foundation.

\section{Benefits}

Through their participation in this partnership, Portland State University (PSU) and Multnomah Education Service District (MESD) will receive the following benefits and recognition:

- This knowledge will further our understanding of how the Multnomah Education Service District Outdoor School program supports students within traditional educational settings.

- This research may provide documentation of the variable effects related to the length of program participation.

- Research findings will provide opportunities to inform Outdoor School program improvement.

- Research team will disseminate findings to a broad audience of education professionals, non-profits, foundations, academia, and state and local policy makers to support the case for implementation of the Outdoor School program.

- The collaborative effort of the four researchers involved in the study will be recognized in all artifacts of the study, thus benefiting the professional growth of all involved.

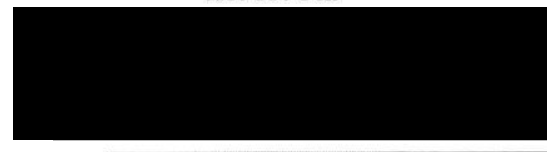

Barbara Jorgensen, Superintendent, Multnomah Education Service District

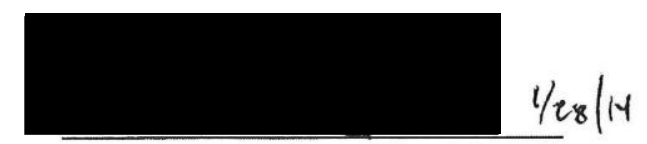

Dan Prince, Outdoor School Coordinator, Multnomah Education Service District

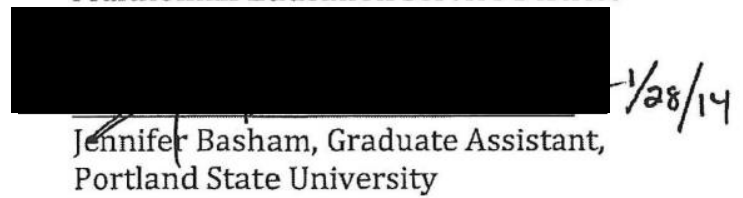

Kelley, Hara, Basham, Prince - 1/28/14
$02 / 05 / 14$
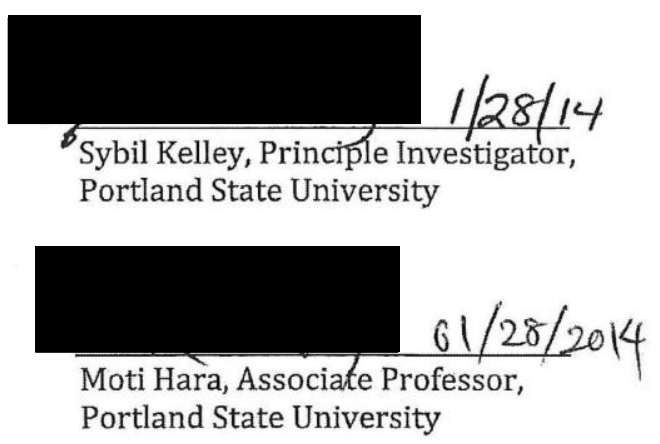


\section{THE EFFECTS OF AN OVERNIGHT ENVIRONMENTAL PROGRAM}

Appendix A - Human Subjects Review Application

MESD Request for Release of Attendance Records, Approval Letter, and Example Class Form 


\title{
Appendix A - Human Subjects Review Application
}

\author{
Graduate School of Education \\ Educational Leadership \& Policy \\ Leadership for Sustainability Education \\ Post Office Box 751 \\ 503-725-5976 tel \\ Portland, Oregon 97207-0751 503-725-8475 fax
}

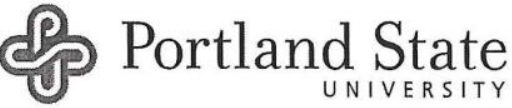

October 22, 2013

Dear Dan Prince,

This letter is to formally request the attendance records for students attending the Multnomah Education Service District Outdoor School program. The purpose of this request is to conduct a research study to understand how Outdoor School impacts students, related to the goals outlined by OEIB with a specific focus on student success, high school completion, career and college readiness, and the Essential Skills defined by the Oregon Department of Education.

We request that this data be supplied in the form of Outdoor School schedules and class lists denoting students in attendance, school, teacher, site and dates attended. Every effort will be made to ensure confidentiality and abide by the highest standard of research integrity. Additionally, research methods in this study will be subject to successful acceptance by the PSU Human Subjects Review Committee, the governing body that ensures research conducted at PSU is ethical, neutral, and as low-risk as possible.

The requested data will be used to conduct a research study using quantitative research methods and seek to understand the impact of Outdoor School on various populations with regards to program length, how the program supports student success, and high school completion.

Thank you in advance for your anticipated cooperation in this matter. I look forward to receiving your response to this request at your earliest convenience.

Sincerelv

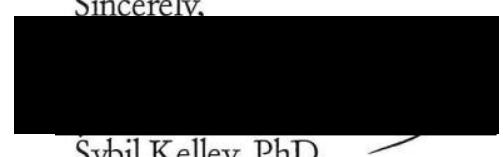

Sybil Kelley, $\mathrm{PhD}$.

Associate Professor

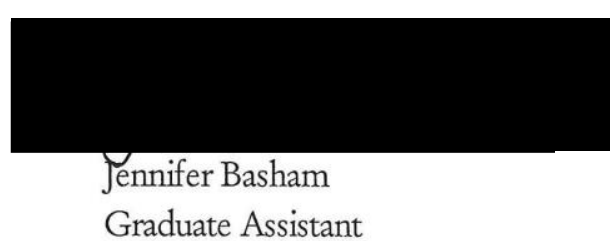




\section{THE EFFECTS OF AN OVERNIGHT ENVIRONMENTAL PROGRAM}

Appendix A - Human Subjects Review Application

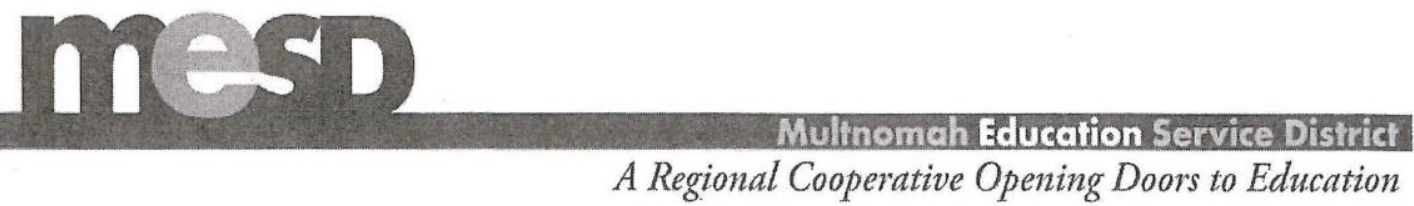

October 31,2013

Dear Sybil Kelley, PhD. and Jennifer Basham,

MESD Outdoor School is happy to partner with Portland State University in researching how Outdoor School impacts students. Please consider this letter approval for your request of attendance records for students attending MESD Outdoor School.

Yours truly,

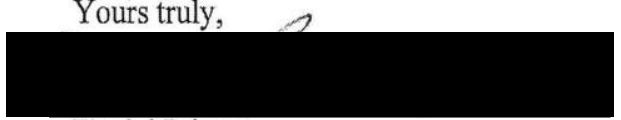

Daniel Prince

Coordinator, Outdoor School

Multnomah Education Service District 


\section{THE EFFECTS OF AN OVERNIGHT ENVIRONMENTAL PROGRAM}

\section{Appendix A - Human Subjects Review Application}

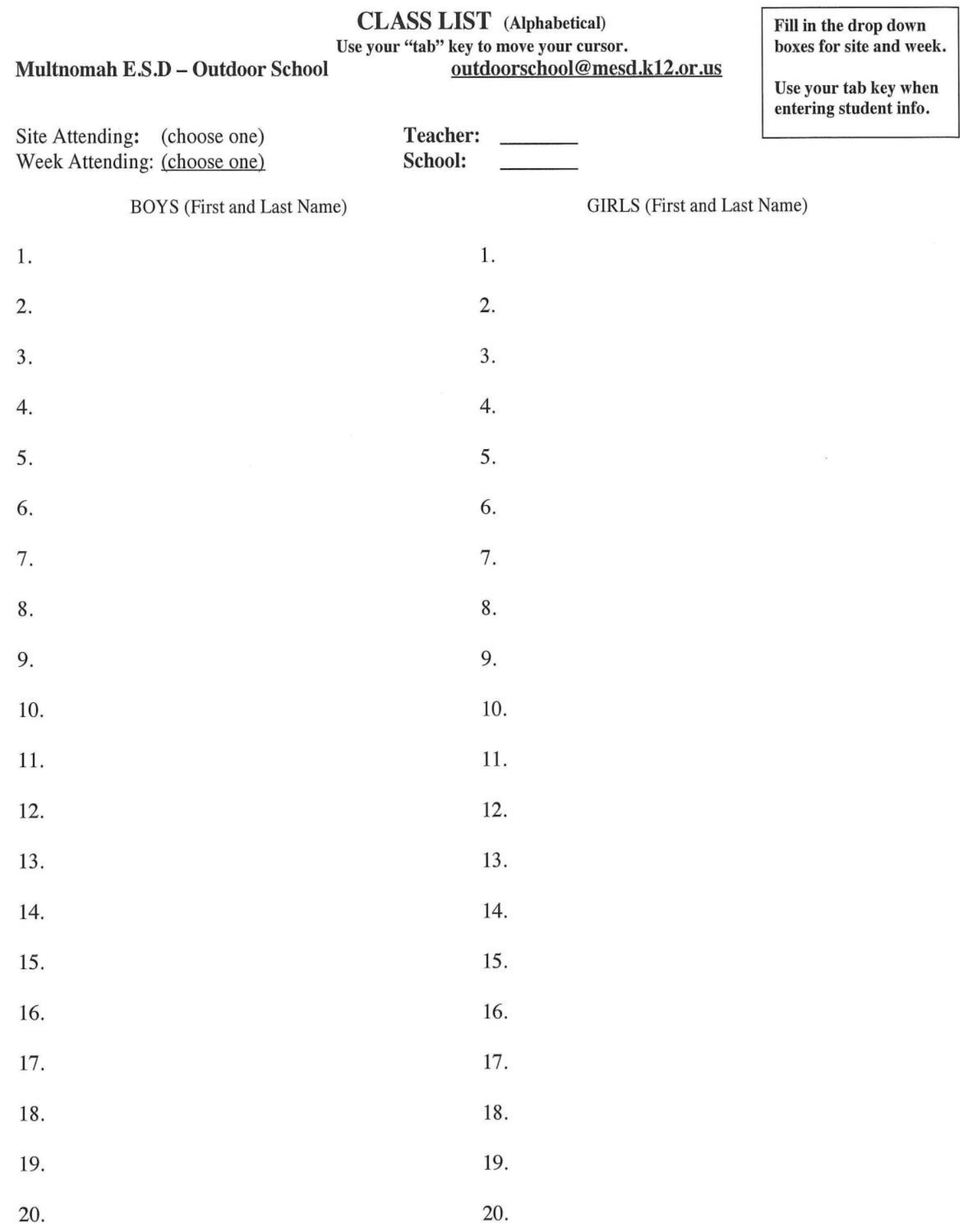


THE EFFECTS OF AN OVERNIGHT ENVIRONMENTAL PROGRAM

Appendix B - Human Subjects Review Approval 


\title{
THE EFFECTS OF AN OVERNIGHT ENVIRONMENTAL PROGRAM
}

\author{
Appendix B - Human Subjects Review Approval
}

$\begin{array}{lr}\text { Post Office Box } 751 & 503-725-2227 \text { tel } \\ \text { Portland, Oregon 97207-0751 } & 503-725-8170 \text { fax } \\ \text { Human Subjects Research Review Committee } \\ \end{array}$

Date: February 27, 2014

To: Sybil Kelley

From: Karen Cellarius, HSRRC Chair

Re: $\quad$ HSRRC approval for your project titled, "The Effects of the MESD Outdoor School Program on Students' Academic Achievement, Behavior, and Attendance" HSRRC Proposal \# 142973

Review Type: Exempt, Categories 1, 4

In accordance with your request, the Human Subjects Research Review Committee has reviewed your proposal referenced above for compliance with PSU and DHHS policies and regulations covering the protection of human subjects. The Committee is satisfied that your provisions for protecting the rights and welfare of all subjects participating in the research are adequate, and your project is approved. Please note the following requirements:

Approval: You are approved to conduct this research study after receipt of this approval letter; and the research must be conducted according to the plans and protocol submitted (approved copy enclosed).

Consent: Signed consent is required from all participating school districts in this study. Consent is waived for students.

Changes to Protocol: Any changes in the proposed study, whether to procedures, survey instruments, consent forms or cover letters, must be outlined and submitted to the Committee immediately. The proposed changes cannot be implemented before they have been reviewed and approved by the Committee.

Adverse Reactions and/or Unanticipated Problems: If any adverse reactions or unanticipated problems occur as a result of this study, you are required to notify the Committee immediately. If the issue is serious, approval may be withdrawn pending an investigation by the Committee.

Completion of Study: Please notify the Committee as soon as your research has been completed. Study records, including protocols and signed consent forms for each participant, must be kept by the investigator in a secure location for three years following completion of the study (or per any requirements specified by the project's funding agency).

If you have questions or concerns, please contact the Office of Research Integrity in the PSU RSP at 503-725-2227, 1600 SW 4th Ave., Market Center Building, Suite 620. 
THE EFFECTS OF AN OVERNIGHT ENVIRONMENTAL PROGRAM

Appendix C - Example District Request for Study Participation (PPS) 


\title{
THE EFFECTS OF AN OVERNIGHT ENVIRONMENTAL PROGRAM
}

Appendix C - Example District Request for Study Participation (PPS)

\section{Portland Public School District Research Proposal}

\begin{abstract}
Title:
The effects of the MESD Outdoor School program on student's academic achievement, behavior, and attendance
\end{abstract}

\author{
Submitted by: \\ Sybil Kelley \\ Principal Investigator, Assistant Professor \\ Portland State University \\ PO Box 751 (ED 504F), Portland, OR 97207 \\ Phone: 503-725-5976 Email: sybilkel@pdx.edu
}

Date:

March 4, 2014 
THE EFFECTS OF AN OVERNIGHT ENVIRONMENTAL PROGRAM

Appendix C - Example District Request for Study Participation (PPS)

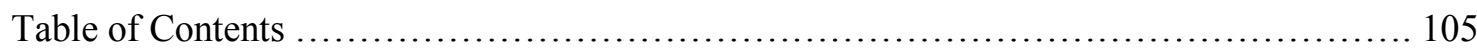

Research Proposal ............................................................ 106

Appendix 1 - Consent to Participate in Outdoor School Research ......................... 114

Appendix 2 - Student Data Request for MESD Component Districts .................... 119

Appendix 3 - Portland State and Multnomah Education Service District MOU ............. 127

Appendix 4 - Researcher Training and Experience ................................. 130

Appendix 5 - MESD Request for Release of Attendance Records, Approval Letter, and Example Class List Form ................................................ 131

Appendix 6 - Portland State University Human Subjects Review Approval Letter ......... 135 
Appendix C - Example District Request for Study Participation (PPS)

\title{
PORTLAND PUBLIC SCHOOLS Research Proposal
}

\author{
Sybil Kelley \\ Principal Investigator \\ Portland State University, Assistant Professor \\ PO Box 751 (ED 504F), Portland, OR 97207 \\ Phone: 503-725-5976 Email: sybilkel@ pdx.edu
}

Title: The effects of the MESD Outdoor School program on student's academic achievement, behavior, and attendance.

\section{The Scope and Significance of the Study:}

This year the MESD Outdoor School program has an opportunity to conduct a research project in partnership with Portland State University to understand the impacts of Outdoor School on student achievement, attendance, and behavior as it relates to the OEIB Strategic Investments. While our initial goal is to understand the impacts of Outdoor School, this research precedes a larger initiative set forth by PSU, School Districts, and the Oregon Department of Education to research educational impacts across many educational initiatives.

The proposed study seeks to understand the impact of the MESD Outdoor School program on attendance, and referral rates (disciplinary data) among various demographic populations of students who have attended the program through an analysis of secondary data. This investigation seeks to address the following questions:

- Does the Outdoor School program have an impact on students' academic achievement? If so, where are the largest gains?

- Does the impact of Outdoor School differ depending on a student's background characteristics? If so, how? 


\title{
THE EFFECTS OF AN OVERNIGHT ENVIRONMENTAL PROGRAM
}

\author{
Appendix C - Example District Request for Study Participation (PPS)
}

Understanding how the program impacts students will provide validation for the program implementation within the traditional school setting, inform school districts and other programs like the MESD Outdoor School program of the benefits to student achievement and success indicators; and provide valuable data to drive program improvement.

Although residential environmental programs vary from program to program, most, if not all, provide students with the chance to "experience first-hand the richness and excitement of learning about the natural world" (Jackson, Dukerich, \& Hestenes, 2008, p. 10). Furthermore, Melber and Brown (2008) indicate that "when science is taught in a hands-on, inquiry-based manner, it is the preferred subject area" (p. 36) for many students. In addition to increases in scientific knowledge, residential environmental programs allow students to spend valuable time outdoors, which Ewert, Place, and Sibthorp (2005) suggest as "the most influential factor in developing concern for the environment" (p. 228). Melber and Brown suggest, "informal science-learning experiences, or learning experiences that occur outside a traditional classroom, are one way these authentic, inquiry-based experiences can be shared with students" (2008).

While residential programs often foster a student's ecological concern in addition to scientific application and knowledge gain, schools can find it difficult to justify these experiences outside of the classroom due to the cost and, more importantly, the lack of quantifiable evidence of the impact on student learning. Moreover, focus on closing the achievement gap has gained attention and has shifted school district priorities to support programs that have documented positive impacts on student success indicators (Evans, 2005, pg. 582; Early Learning Council SB 909 Report, pg. 3). This research hopes to build on the current research surrounding the achievement gap and provide a unique perspective of the impact of the Outdoor School program on academic outcomes through quantitative methods, a process that few researchers have ventured beyond observations made based on anecdotal evidence. Ultimately, this research can serve as a starting point for why Outdoor School programs, in particular, deserve our attention.

\section{The Research Design:}

We will not be recruiting subjects for the purpose of this study; instead, information will be gathered through attendance records of the MESD Outdoor School program for the years dating 2006-2013 and merged with student data from participating school districts. All personally identifiable information will be removed prior to the data being made available to researchers. In some cases, the researchers will aggregate data within a larger demographic population if disaggregated sub-groups of race or ethnicity result 


\title{
THE EFFECTS OF AN OVERNIGHT ENVIRONMENTAL PROGRAM
}

\author{
Appendix C - Example District Request for Study Participation (PPS)
}

in a group of 10 students or less. The researchers will analyze the unidentified, merged data set using quantitative statistical analysis and then report findings.

Our understanding is that this research project would qualify for Exempt human subjects review because data collected for the purpose of this study will meet the requirements under U.S. Department of Health and Human Services guidelines for exemption under 45 CFR 46.101(b). This research intends to analyze existing data and records of student academic, behavior, and attendance gathered in established or commonly accepted educational settings involving normal education practices.

Inclusion criteria:

We will be working with the Multnomah Education Service District and the component districts (Centennial, Corbett, David Douglas, Gresham-Barlow, Parkrose, Portland Public, Reynolds, and Riverdale School Districts) that participate in the Outdoor School program to compile and merge student data with attendance records from the program. We will be requesting specific information such as high school completion, attendance records, referral rates, science test scores, and demographic information. All personally identifiable information will be expunged from the data set after Outdoor School attendance records have been merged with the student-specific data, prior to the researchers receiving the data sources. This data will be gathered in such a way that students cannot be identified, directly or through identifiers linked to the subjects.

The proposed study seeks to understand the impact of the MESD Outdoor School program on student's academic achievement, attendance, and referral rates (disciplinary data) among various demographic populations of students who have attended the program through an analysis of secondary data. We will not be recruiting subjects for the purpose of this study; instead, information will be gathered through attendance records of the MESD Outdoor School program for the years dating 2006-2013. This enrollment information has dates of attendance, program length, site attended, school, teacher, student attendance records, and high school volunteering enrollment.

\section{Logistics of the Study:}

1. Your district will grant access to archival data such as Student ID numbers, state test scores, attendance, and behavior records through the MESD technology staff members for the years ranging 2006-2013. (See Appendix 2 for specific data request form) 


\section{THE EFFECTS OF AN OVERNIGHT ENVIRONMENTAL PROGRAM}

Appendix C - Example District Request for Study Participation (PPS)

2. MESD technology staff members will merge school district records with Multnomah Education School District Outdoor School attendance records.

3. MESD technology staff members will expunge student ID numbers and personal identifiers.

4. Researchers will receive the data sources.

5. Researchers will then analyze the unidentified data. No analysis will be conducted when student subgroups result in 10 or fewer participants to further protect the confidentiality of the participants.

6. Researchers will report the findings, and all data will be deleted 3 years after the completion of the study. Because this research study is a secondary data analysis, there will be no direct contact with participants.

\section{A. Selection and Definitions of the Study Population}

The populations from whom data will be collected for the purpose of this study are students who attended the Multnomah Education Service District Outdoor School program in sixth grade from the years ranging $2006-2013$.

\section{B. Data to be Collected and Management}

Information will be collected through school district protocols and contracts with MESD technology staff as well as a Memorandum of Understanding. We will be requesting specific information such as high school completion, attendance records, referral rates, science test scores, and demographic information. Once granted permission from districts to utilize student data, it will be merged and deidentified by MESD technology staff. Quantitative expert, Moti Hara, will then conduct data analysis.

Researchers will ensure the confidentiality of all participants by adhering to various protocols for maintaining confidentiality. Digital student attendance records will be stored in secure password protected servers, to which Jennifer Basham will hold access. Paper confidential records will be stored in locked cabinets within the Multnomah Education Service District building. Coding scripts will be stored in a password protected excel file within the secure server. All student names will be expunged from the data source prior to researchers having access to ensure the maximum level of confidentiality possible. Data collected and utilized in this study will be purged 3 years after the completion of the research project. 


\section{THE EFFECTS OF AN OVERNIGHT ENVIRONMENTAL PROGRAM}

Appendix C - Example District Request for Study Participation (PPS)

\section{Potential Risks and Safeguards-Potential Benefits}

The potential risks to students are minimal and would not exceed what a student within a traditional education setting would endure. Additionally, the data collected for the purpose of this study will be garnered through existing data sources and all personally identifiable information will be removed prior to the data being made available to researchers. In some cases, the researchers will aggregate data within a larger demographic population if disaggregated sub-groups of race or ethnicity result in a group of 10 students or less. The greatest risk to participants would be the accidental loss of confidentiality. Safeguards for this risk will be implemented by ensuring that all documents and raw data will be stored in password-protected files and servers. Furthermore, the transfer of data will be minimized by utilizing secure servers as the main storage system for electronic files, and locked cabinets for paper copies. Data accumulated and compiled for this research project will be protected with access given only to the principle investigators, Sybil Kelley, Moti Hara, Jennifer Basham, and Dan Prince.

The benefits of this research will be to understand the impact of the Outdoor School program on student's academics, attendance, and behavior. (See Appendix 2 for specific variables being requested) This knowledge will further our understanding of how the Multnomah Education Service District Outdoor School program supports students within the traditional education setting in addition to providing essential metrics to drive program improvement.

Researchers participating in the development of the study are interested in the dissemination of our findings to a broad audience of education professionals, nonprofits, foundations, academia, and state and local policy makers. We plan to share our findings through three avenues: Practitioner (e.g. presentations and reports for the general public); Academic (e.g. refereed publications and conference presentations); and to inform policy makers through local and statewide initiatives (No Oregon Child Left Inside coalition and Oregon Environmental Literacy Plan implementation and advocacy). The collaborative effort of the four researchers involved in the study will be recognized in all artifacts of the study, thus benefiting the professional growth of all involved.

\section{F. Proposed Start and End Date}

This study will approximately start upon acceptance of the Research Proposal from 


\section{THE EFFECTS OF AN OVERNIGHT ENVIRONMENTAL PROGRAM}

Appendix C - Example District Request for Study Participation (PPS)

Portland Public School District. Below is a tentative timeline.

\section{Time Schedule for Research}

\begin{tabular}{|c|c|}
\hline Task & Time Period \\
\hline $\begin{array}{l}\text { Obtain all needed information and forms from PSU Human Subjects Research } \\
\text { Review Committee, and School District Research and Evaluation Departments }\end{array}$ & $\begin{array}{l}\text { September } \\
2013\end{array}$ \\
\hline Recruit and finalize Research Team members & October 2013 \\
\hline Draft Human Subjects Review & October 2013 \\
\hline $\begin{array}{l}\text { Complete Memorandum of Understanding between Multnomah Education } \\
\text { Service District and Portland State University }\end{array}$ & January 2014 \\
\hline Complete Human Subjects Review Committee research proposal & January 2014 \\
\hline $\begin{array}{l}\text { Submit Human Subjects Review Committee \& research proposal to PSU } \\
\text { Institutional Review Board }\end{array}$ & January 2014 \\
\hline $\begin{array}{l}\text { Once Humans Subjects Review Committee approves the proposal, submit a } \\
\text { research proposal to PPS Research, Evaluation, and Assessment Department }\end{array}$ & $\begin{array}{l}\text { February } \\
2014\end{array}$ \\
\hline Data Collection of MESD Attendance Reports & March 2014 \\
\hline $\begin{array}{l}\text { After R\&E approves the study, coordinate data merging with Portland Public } \\
\text { School District and MESD technology staff members }\end{array}$ & March 2014 \\
\hline Researchers receive unidentified merged data set & March 2014 \\
\hline $\begin{array}{l}\text { Analyze data and write draft report. Submit results to PPS Research \& } \\
\text { Evaluation Department }\end{array}$ & $\begin{array}{l}\text { Summer } \\
2014\end{array}$ \\
\hline Disseminate results to appropriate agencies & $\begin{array}{l}\text { Fall-Winter } \\
\quad 2014\end{array}$ \\
\hline
\end{tabular}

\section{Informed Consent:}

Due to the nature of this secondary data analysis study, consent to participate is being requested at the school district institutional level. Please see attached Portland Public School District informed consent (appendix 1). The research partnership between 


\section{THE EFFECTS OF AN OVERNIGHT ENVIRONMENTAL PROGRAM}

Appendix C - Example District Request for Study Participation (PPS)

Portland State University and Multnomah Education Service District has been recognized by both institutions through a Memorandum of Understanding between Portland State University and Multnomah Education Service District (appendix 3). Moreover, this research proposal has met rigorous ethical standards for research with human subjects through Portland State University Institutional Review Board. Please see the approval letter attached (appendix 6).

If you have any questions, concerns or complaints at any time about the research study, Sybil Kelley, or her associates will be glad to answer them.

Sybil Kelley, Principle Investigator, Email: sybilkel@pdx.edu, Phone: 503-725-5976

Moti Hara, Assistant Professor, Email: mhara@pdx.edu, Phone: 503-725-9903

Jennifer Basham, Graduate Assistant, Email: jbasham@pdx.edu, Phone: 971-275-6269

Dan Prince, ODS Coordinator, Email: dprince@mesd.k12.or.us, Phone: 503-257-1600

\section{References}

Early Learning Council. (2011). Early learning council SB 909 report. Retrieved from http://library.state.or.us/blogs/ReportsToLegislature/wordpress/?s=Early+Learning+SB $+909$

Ewert, A., Place, G., \& Sibthorp, J. (2005). Early-Live Outdoor Experiences and an Individual's Environmental Attitudes. Leisure Sciences , 27, 225-239.

Jackson, J., Dukerich, L., \& Hestenes, D. (2008). Modeling Instruction: An Effective Model for Science Education. Science Educator, 17 (1), 10-17.

Melber, L. M., \& Brown, K. D. (2008). "Not like a Regular Science Class": Informal Science Education for Students with Disabilities. The Clearing House: Informal Science Education , 82 (1), 35-39.

\section{Appendices:}

Appendix 1 - Consent to Participate in Outdoor School Research 


\section{THE EFFECTS OF AN OVERNIGHT ENVIRONMENTAL PROGRAM}

Appendix C - Example District Request for Study Participation (PPS)

Appendix 2 - Student Data Request for MESD Component Districts

Appendix 3 - Portland State and Multnomah Education Service District MOU

Appendix 4 - Researcher Training and Experience

Appendix 5 - MESD Request for Release of Attendance Records, Approval Letter, and Example Class List Form

Appendix 6 - Portland State University Human Subjects Review Approval Letter 
Appendix C - Example District Request for Study Participation (PPS)

Graduate School of Education

Educational Leadership \& Policy

Leadership for Sustainability Education

Post Office Box $751 \quad 503-725-5976$ tel

Portland, Oregon 97207-0751 503-725-8475 fax

\section{The Portland State University Consent to Participate in Research}

Understanding the effects of the MESD Outdoor School program on student's academic achievement, behavior, and attendance.

$1 / 23 / 14$

\section{Introduction}

A collaborative research team from MESD Outdoor School and Portland State University are conducting a research study impact of the Outdoor School program on student's academic achievement, behavior, and attendance. As a representative of Portland Public School District, you are being asked to participate in the research study that is being done by Sybil Kelley who is the Principal Investigator, Moti Hara, Jennifer Basham, from the Department of Educational Leadership \& Policy, at Portland State University in Portland, Oregon and Dan Prince from the Multnomah Education Service District Outdoor School program. You are being asked to participate in this study because sixth graders in your school district have attended a partial or full week experience at Outdoor School with the Multnomah Education Service District.

This form will explain the research study, and will also explain the possible risks as well as the possible benefits to you. We encourage you to talk with your district representatives before you decide to take part in this research study. If you have any questions, please ask one of the study investigators. 
Appendix C - Example District Request for Study Participation (PPS)

\section{What will happen if Portland Public School District agrees to participate?}

If your district approves this research, the following things will happen:

1. Your district will grant access to archival data such as Student ID numbers, state test scores, attendance, and behavior records through the MESD technology staff members for the years ranging 2006-2013. (See Appendix 2 for specific data request form)

2. MESD technology staff members will merge school district records with Multnomah Education School District Outdoor School attendance records.

3. MESD technology staff members will expunge student ID numbers and personal identifiers.

4. Researchers will receive the data sources.

5. Researchers will then analyze the unidentified data. No analysis will be conducted when student subgroups result in 10 or fewer participants to further protect the confidentiality of the participants.

6. Researchers will report the findings, and then all data will be deleted 3 years after the completion of the study. Because this research study is a secondary data analysis, there will be no direct contact with participants.

\section{Study Duration and Time Commitments}

Beyond review of the application, there will be no time commitment from your school district employees.

\section{What are the potential risks of this study? What safeguards are in place?}

The potential risks to students are minimal and would not exceed what a student within a traditional education setting would endure. The data collected for the purpose of this study will be garnered through existing data sources and all personally identifiable information will be removed prior to the data being made available to researchers. In some cases, the researchers will aggregate data within a larger demographic population if sub-groups of race or ethnicity result in a group of 10 students or less. The greatest risk to participants would be the accidental loss of confidentiality. Safeguards for this risk will be implemented by ensuring that all documents and raw data will be stored in password-protected files and servers. Furthermore, the transfer of data will be 


\section{THE EFFECTS OF AN OVERNIGHT ENVIRONMENTAL PROGRAM}

Appendix C - Example District Request for Study Participation (PPS)

minimized by utilizing secure servers as the main storage system for electronic files, and locked cabinets for paper copies. Data accumulated and compiled for this research project will be protected with access given only to the principle investigators, Sybil Kelley, Moti Hara, Jennifer Basham, and Dan Prince.

For more information about risks and discomforts, ask the investigator.

\section{What are the potential benefits of this study?}

The benefits of this research will be to understand the impact of the Outdoor School program on student's academics, attendance, and behavior. This knowledge will further our understanding of how the Multnomah Education Service District Outdoor School program supports students within the traditional education settings. Understanding how the program impacts students will provide validation for program implementation and provide valuable data to drive program improvement. There will be no direct benefit to the school districts participating in this study.

\section{How will student information be kept confidential?}

Researchers will ensure the confidentiality of all participants by adhering to various protocols for maintaining confidentiality. Digital student attendance records will be stored in secure password protected servers, to which only the researchers will hold access. Paper confidential records will be stored in locked cabinets within the Multnomah Education Service District building. Coding scripts will be stored in a password protected excel file within the secure server. All student names will be expunged from the data source prior to researchers having access to maintain the highest level of confidentiality possible. Data collected and utilized in this study will be purged 3 years after the completion of the research project. 
THE EFFECTS OF AN OVERNIGHT ENVIRONMENTAL PROGRAM

Appendix C - Example District Request for Study Participation (PPS)

\section{Will I be paid for taking part in this study?}

No. Your school district will not be financially compensated for participating in this study.

\section{Can I stop being in the study once I begin?}

Your school district participation in this study is completely voluntary. You have the right to choose not to participate or to withdraw your participation at any point in this study without penalty or loss of benefits to which you are otherwise entitled.

\section{Whom can I call with questions or complaints about this study?}

If you have any questions, concerns or complaints at any time about the research study, Sybil Kelley, or her associates will be glad to answer them.

Sybil Kelley, Principle Investigator, Email: sybilkel@pdx.edu, Phone: 503-725-5976

Moti Hara, Assistant Professor, Email: mhara@pdx.edu, Phone: 503-725-9903

Jennifer Basham, Graduate Assistant, Email: jbasham@pdx.edu, Phone: 971-275-6269

Dan Prince, ODS Coordinator, Email: dprince@mesd.k12.or.us, Phone: 503-257-1600

\section{Whom can I call with questions about my rights as a research participant?}

If you have questions regarding your rights as a research participant, you may call the PSU Office for Research Integrity at (503) 725-2227 or 1(877) 480-4400. The ORI is the office that supports the PSU Institutional Review Board (IRB). The IRB is a group of people from PSU and the community who provide independent oversight of safety and ethical issues related to research involving human participants. For more information, you may also access the IRB website at https://sites.google.com/a/pdx.edu/research/integrity. 
THE EFFECTS OF AN OVERNIGHT ENVIRONMENTAL PROGRAM

Appendix C - Example District Request for Study Participation (PPS)

\section{CONSENT}

You are making a decision whether to participate in this study. Your signature below indicates that you have read the information provided (or the information was read to you). By signing this consent form, you are not waiving any of your legal rights as a research participant.

You have had an opportunity to ask questions and all questions have been answered to your satisfaction. By signing this consent form, you agree to participate in this study. A copy of this consent form will be provided to you.

Name of District Representative (print)
Signature of District Representative
Date

School District

\section{INVESTIGATOR SIGNATURE}

This research study has been explained to the participating district representative and all of his/her questions have been answered. The district representative understands the information described in this consent form and freely consents to participate.

Name of Investigator/ Research Team Member (type or print)

(Signature of Investigator/ Research Team Member) Date 
THE EFFECTS OF AN OVERNIGHT ENVIRONMENTAL PROGRAM

Appendix C - Example District Request for Study Participation (PPS)

Student Data Request for MESD Component Districts 


\title{
THE EFFECTS OF AN OVERNIGHT ENVIRONMENTAL PROGRAM
}

\section{Appendix C - Example District Request for Study Participation (PPS)}

\section{Student Data Request for MESD Component Districts}

\author{
Requested By Sybil Kelley and Jennifer Basham \\ Organization PSU Graduate School of Ed - ELP Dept. \\ Note: Data may not be re-released to any other organization \\ without consent of the parent/guardian.
}

Date Submitted Upon Approval of IRB

Date Due ASAP

Street Address PO Box 751

City Portland

Phone 503-725-4619

\section{State OR Zip 97207 \\ sybilkel@pdx.edu,}

Email Address ibasham@mesd.k12.or.us

Purpose of To understand how Outdoor School impacts students related to student success. Specific areas request of interest are: high school completion, career and college readiness, and goals outlined OEIB.

Districts Place a check mark (click on the box) next to the districts you want included in this request. If student-level (identifiable) records are needed, provide a contact for each district in the box below the corresponding district name (see "Type of Data" and "Release Type" below).
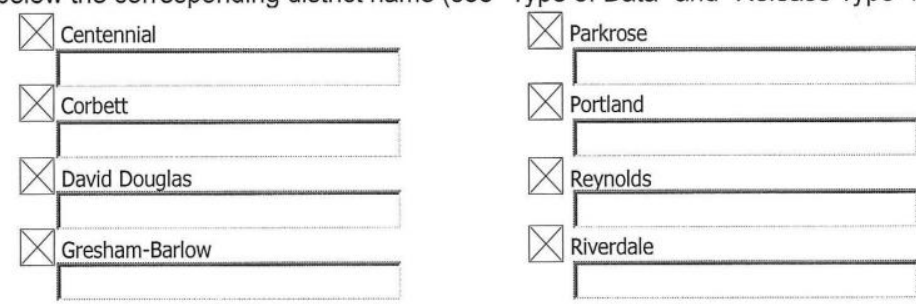

Schools If you need data for specific schools within the district(s) listed above, please list those below.

Grade Levels to

include All students included in Outdoor School attendance data
Type of Data $\square$ Summary (non-identifiable data)
Needed De-identified data (e.g., proxy IDs \& no identifiable fields) -- check agreement below
I agree that I will NOT attempt to make records identifiable (e.g., link to data from a separate request)
Student-level (identifiable) records* -- check certification below
$\square$ I certify that I have read, understand and agree to abide by all FERPA laws.

Release Type* $\square$ Signed parent release forms $\quad$ Contract or Memorandum of Understanding (MOU) with district(s) NOTE: Provide a district contact for releases/contracts/MOUs below each district selected above.

Data Elements Complete the "Data Elements, Advanced Evaluation Export Fields" form (third tab) to identify data elements that are required for completion of this data request. Add additional comments below.

*NOTES 1. If student-level (identifiable) records are required you MUST select a release type (see FERPA notice attached) and provide a district contact for each district. This is not required for summary or deidentified data.

2. Final release of any/all data is at the discretion of district staff. 


\section{THE EFFECTS OF AN OVERNIGHT ENVIRONMENTAL PROGRAM}

Appendix C - Example District Request for Study Participation (PPS)

\section{Data Elements}

\section{Advanced Evaluation Export Fields}

Please place an ' $\mathrm{X}$ ' in the "Include Field?" column for each data element that is required for this data request. Behavior Data NOTE: You must be able to justify each data element requested in terms of the purpose of the data request. Attendace Data

\begin{tabular}{|c|c|c|c|}
\hline & & & Achievement Data \\
\hline Item & Field & More Info & Include Field? \\
\hline 1 & Pupil Number & Student's eSIS ID number & \\
\hline 2 & SSID & Student's state ID number & $\mathrm{x}$ \\
\hline 3 & Last Name & Preferred & $x$ \\
\hline 4 & First Name & Preferred & $x$ \\
\hline 5 & Ethnicity & Hispanic or Not Hispanic & $\bar{x}$ \\
\hline 6 & Race & Any of the six individual items, or "Multi" & $\mathrm{x}$ \\
\hline 7 & ODE E_R Code & 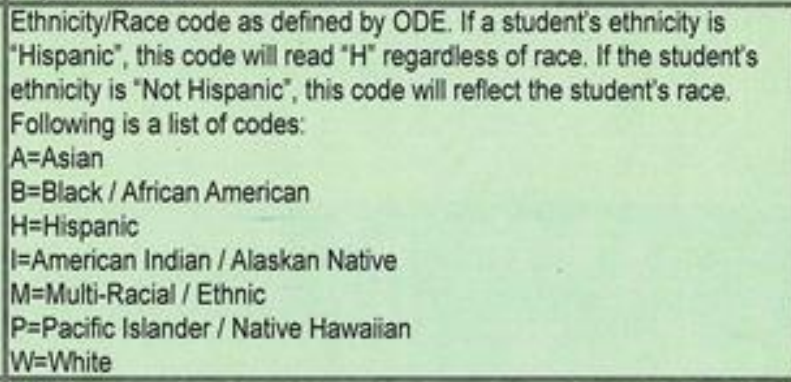 & $\mathrm{x}$ \\
\hline 8 & Gender & M/F & $\mathrm{x}$ \\
\hline 9 & Birth Date & & \\
\hline 10 & Current Grade & & $\mathrm{x}$ \\
\hline 11 & Current Registration Date & Date of most recent registration & \\
\hline 12 & Grade 9 Entry Date & If applicable & \\
\hline 13 & LEP Entry Date & & \\
\hline 14 & LEP Exit Date & & \\
\hline 15 & FARMs Base Year & $\begin{array}{l}\text { Only if user security allows, otherwise null. This field will read " } Y \text { " } \\
\text { during the carry-over period if a student was eligible the following year. }\end{array}$ & \\
\hline 16 & Counselor & & \\
\hline 17 & Homeroom & Hrm1 Teacher Name & \\
\hline 18 & School ID & Currently Enrolled School ID & $\mathrm{X}$ \\
\hline 19 & School Name & Currently Enrolled School & $\mathrm{x}$ \\
\hline 20 & First Admit Date & First Admission date found on eSIS for the current district. & \\
\hline 21 & Num Schls & Count of school transitions recorded in the SIS (regardless of district). & $\mathrm{x}$ \\
\hline 22 & Zip Code & & $\mathrm{x}$ \\
\hline 23 & County & & $\mathrm{X}$ \\
\hline 24 & Catchment & & \\
\hline 25 & GPA & Current Cumulative GPA & $\bar{x}$ \\
\hline 26 & First Language & & $\mathrm{x}$ \\
\hline 27 & Language at Home & & $\mathrm{x}$ \\
\hline 28 & Diploma Earned & Type of diploma earned if any & $\mathrm{x}$ \\
\hline 29 & Diploma Name & Name of the diploma currently assigned to the student & \\
\hline
\end{tabular}


THE EFFECTS OF AN OVERNIGHT ENVIRONMENTAL PROGRAM

Appendix C - Example District Request for Study Participation (PPS)

\section{Data Elements}

\section{Advanced Evaluation Export Fields}

SS Demographics

Please place an " $\mathrm{X}$ " in the "Include Field?" column for each data element that is required for this data request. Behavior Dato NOTE: You must be able to justify each data element requested in terms of the purpose of the data request. Attendace Data

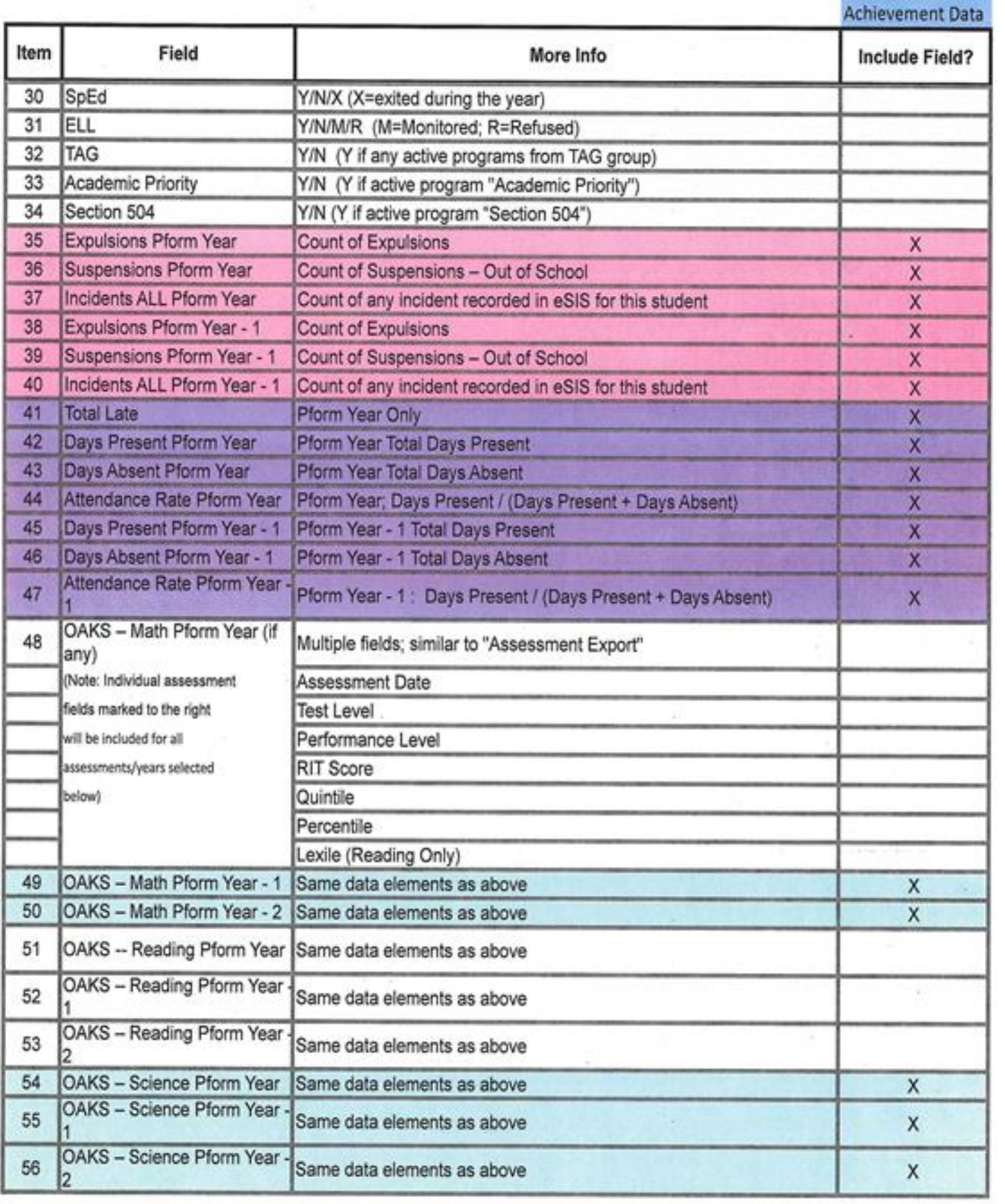




\section{THE EFFECTS OF AN OVERNIGHT ENVIRONMENTAL PROGRAM}

Appendix C - Example District Request for Study Participation (PPS)

\section{Data Elements}

\section{Advanced Evaluation Export Fields}

SS Demographics

School Info

Please place an " $X$ " in the "Include Field?" column for each data element that is required for this data request. Behavior Data

NOTE: You must be able to justify each data element requested in terms of the purpose of the data request. Attendace Data

\begin{tabular}{|c|c|c|c|}
\hline Item & Field & More Info & Include Field? \\
\hline 57 & OAKS - Writing Pform Year & Same data elements as above & \\
\hline 58 & $\begin{array}{l}\text { OAKS - Writing Pform Year - } \\
1\end{array}$ & Same data elements as above & \\
\hline 59 & $\begin{array}{l}\text { OAKS - Writing Pform Year - } \\
2\end{array}$ & Same data elements as above & \\
\hline 60 & CIM MA Date & Assessment Date & \\
\hline 61 & CIM MA PERF & Performance Level & \\
\hline 62 & CIM MA RIT & RIT Score & \\
\hline 63 & CIM MA Quintile & 5-Level Performance Level & \\
\hline 64 & CIM MA Percentile & Total Scale Score Percentile Rank & \\
\hline 65 & CIM MA Language & $\begin{array}{l}\text { Language of Test (if other than English) } \\
\mathrm{S}=\text { Spanish } \\
\mathrm{R}=\text { Russian }\end{array}$ & \\
\hline 66 & CIM RD Date & Assessment Date & \\
\hline 67 & CIM RD PERF & Performance Level & \\
\hline 68 & CIM RD RIT & RIT Score & \\
\hline 69 & CIM RD Quintile & 5-Level Performance Level & \\
\hline 70 & CIM RD Percentile & Total Scale Score Percentile Rank & \\
\hline 71 & CIM RD Language & $\begin{array}{l}\text { Language of Test (if other than English) } \\
\mathrm{S}=\text { Spanish } \\
\mathrm{R}=\text { Russian }\end{array}$ & 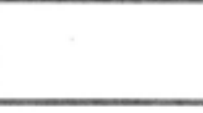 \\
\hline 72 & CIM RD Lexile & Lexile Score & \\
\hline 73 & CIM SC Date & Assessment Date & \\
\hline 74 & CIM SC PERF & Performance Level & \\
\hline 75 & CIM SC RIT & RIT Score & \\
\hline 76 & CIM SC Quintile & 5-Level Performance Level & \\
\hline 77 & CIM SC Percentile & Total Scale Score Percentile Rank & \\
\hline 78 & CIM SC Language & $\begin{array}{l}\text { Language of Test (if other than English) } \\
\mathrm{S}=\text { Spanish } \\
\mathrm{R}=\text { Russian }\end{array}$ & . \\
\hline 79 & CIM WR Date & Assessment Date & \\
\hline 80 & CIM WR PERF & Performance Level & \\
\hline 81 & CIM WR RIT & RIT Score & \\
\hline 82 & CIM WR Quintile & 5-Level Performance Level & \\
\hline 83 & CIM WR Strand & Strand & \\
\hline 84 & CIM WR Percentile & Total Scale Score Percentile Rank & \\
\hline 85 & CIM WR Language & $\begin{array}{l}\text { Language of Test (if other than English) } \\
\mathrm{S}=\text { Spanish } \\
\mathrm{R}=\text { Russian }\end{array}$ & 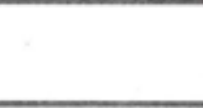 \\
\hline 86 & ELPA Level Pform Year & Performance level (1-5) & \\
\hline 87 & ELPA Level Pform Year - 1 & Performance level (1-5) & \\
\hline
\end{tabular}




\section{THE EFFECTS OF AN OVERNIGHT ENVIRONMENTAL PROGRAM}

Appendix C - Example District Request for Study Participation (PPS)

\section{Data Elements}

\section{Advanced Evaluation Export Fields}

SS Demographics

School Info

Please place an "X" in the "Include Field?" column for each data element that is required for this data request. Behavior Data NOTE: You must be able to justify each data element requested in terms of the purpose of the data request. Attendace Data

\begin{tabular}{|c|c|c|c|}
\hline & & & Achievement Data \\
\hline Item & Field & More Info & Include Field? \\
\hline 88 & ELPA Level Pform Year - 2 & Performance level (1-5) & \\
\hline 89 & $\begin{array}{l}\text { Cum HS Diploma Credits } \\
\text { Earned }\end{array}$ & $\begin{array}{l}\text { Total HS credits student has earned to date that fulfili diploma } \\
\text { requirements. }\end{array}$ & \\
\hline 90 & Cum HS Credits Attempted & Total HS credits student has attempted to date & $\mathrm{X}$ \\
\hline 91 & HS Credits Earned Base Yr & HS credits earned base year & $\mathrm{x}$ \\
\hline 92 & $\begin{array}{l}\text { HS Credits Attempted Base } \\
\text { Yr }\end{array}$ & HS credits attempted base year & $\mathrm{x}$ \\
\hline 93 & $\begin{array}{l}\text { Cumulative Math Credits } \\
\text { Earned }\end{array}$ & $\begin{array}{l}\text { Sum of credits earned for Math courses (Note: All credits summarized } \\
\text { below are based on course subject. This may or may not correspond to } \\
\text { the diploma subject area for HS classes.) }\end{array}$ & $\mathrm{x}$ \\
\hline 94 & $\begin{array}{l}\text { Cumulative Math Credits } \\
\text { Attempted }\end{array}$ & Sum of credits attempted for Math courses & $\mathrm{x}$ \\
\hline 95 & $\begin{array}{l}\text { Math Credits Earned Pform } \\
\text { Year }\end{array}$ & Sum of credits earned for Math courses & $\mathrm{x}$ \\
\hline 96 & $\begin{array}{l}\text { Math Credits Attempted } \\
\text { Pform Year }\end{array}$ & Sum of credits attempted for Math courses & $\mathrm{x}$ \\
\hline 97 & $\begin{array}{l}\text { Math Credits Earned Pform } \\
\text { Year - } 1\end{array}$ & Sum of credits earned for Math courses & $\mathrm{X}$ \\
\hline 98 & $\begin{array}{l}\text { Math Credits Attempted } \\
\text { Pform Year - } 1\end{array}$ & Sum of credits attempted for Math courses & $\mathrm{x}$ \\
\hline 99 & $\begin{array}{l}\text { Cumulative Language Arts } \\
\text { Credits Earned }\end{array}$ & Sum of credits earned for Language Arts courses & \\
\hline 100 & $\begin{array}{l}\text { Cumulative Language Arts } \\
\text { Credits Attempted }\end{array}$ & Sum of credits attempted for Language Arts courses & \\
\hline 101 & $\begin{array}{l}\text { Language Arts Credits } \\
\text { Earned Pform Year }\end{array}$ & Sum of credits earned for Language Arts courses & \\
\hline 102 & $\begin{array}{l}\text { Language Arts Credits } \\
\text { Attempted Pform Year }\end{array}$ & Sum of credits attempted for Language Arts courses & \\
\hline 103 & $\begin{array}{l}\text { Language Arts Credits } \\
\text { Earned Pform Year - } 1\end{array}$ & Sum of credits earned for Language Arts courses & \\
\hline 104 & $\begin{array}{l}\text { Language Arts Credits } \\
\text { Attempted Pform Year - } 1\end{array}$ & Sum of credits attempted for Language Arts courses & \\
\hline 105 & $\begin{array}{l}\text { Cumulative Science Credits } \\
\text { Earned }\end{array}$ & Sum of credits earned for Science courses & $x$ \\
\hline 106 & $\begin{array}{l}\text { Cumulative Science Credits } \\
\text { Attempted }\end{array}$ & Sum of credits attempted for Science courses & $\mathrm{x}$ \\
\hline 107 & $\begin{array}{l}\text { Science Credits Earned } \\
\text { Pform Year }\end{array}$ & Sum of credits earned for Science courses & $\mathrm{X}$ \\
\hline 108 & $\begin{array}{l}\text { Science Credits Attempted } \\
\text { Pform Year }\end{array}$ & Sum of credits attempted for Science courses & $x$ \\
\hline 109 & $\begin{array}{l}\text { Science Credits Earned } \\
\text { Pform Year - } 1\end{array}$ & Sum of credits earned for Science courses & $\mathrm{x}$ \\
\hline 110 & $\begin{array}{l}\text { Science Credits Attempted } \\
\text { Pform Year - } 1\end{array}$ & Sum of credits attempted for Science courses & $\mathrm{X}$ \\
\hline 111 & $\begin{array}{l}\text { Cumulative Social Studies } \\
\text { Credits Earned }\end{array}$ & Sum of credits earned for Social Studies courses & \\
\hline
\end{tabular}




\section{THE EFFECTS OF AN OVERNIGHT ENVIRONMENTAL PROGRAM}

Appendix C - Example District Request for Study Participation (PPS)

\section{Data Elements}

\section{Advanced Evaluation Export Fields}

SS Demographics

School Info

Please place an ' $\mathrm{X}$ ' in the "Include Field?' column for each data element that is required for this data request. Behavior Data NOTE: You must be able to justify each data element requested in terms of the purpose of the data request. Attendace Data

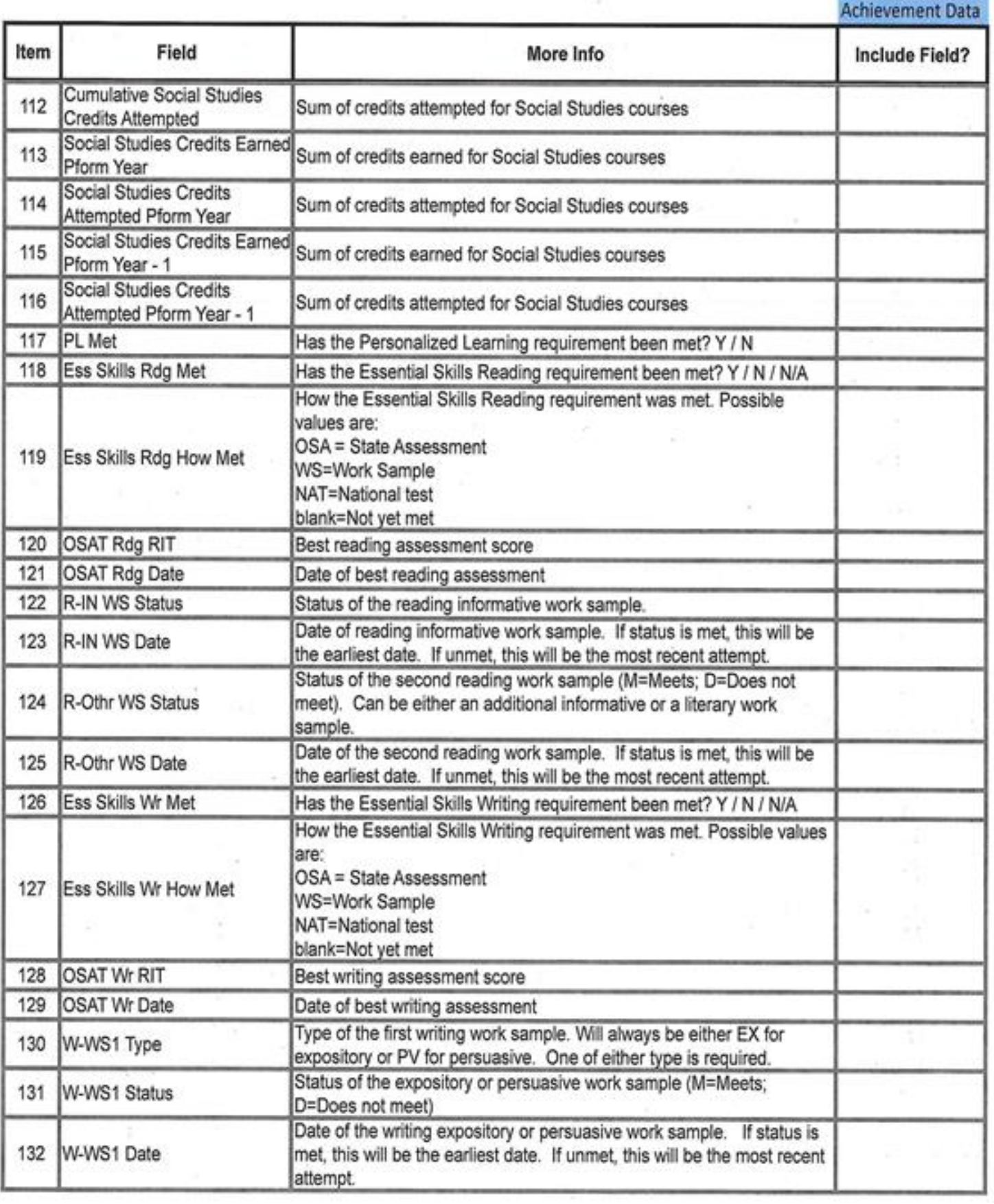




\section{THE EFFECTS OF AN OVERNIGHT ENVIRONMENTAL PROGRAM}

Appendix C - Example District Request for Study Participation (PPS)

\section{Data Elements}

\section{Advanced Evaluation Export Fields}

SS Demographics

School Info

Please place an " $X$ " in the "Include Field?" column for each data element that is required for this data request. Behavior Data NOTE: You must be able to justify each data element requested in terms of the purpose of the data request. Attendace Data

\begin{tabular}{|c|c|c|c|}
\hline Item & Field & More Info & Include Field? \\
\hline 133 & W-WS2 Type & $\begin{array}{l}\text { Type of the second writing work sample. This can be any of the } 3 \\
\text { types (expository, persuasive or narrative, which is NA) }\end{array}$ & \\
\hline 134 & W-WS2 Status & $\begin{array}{l}\text { Status of the second writing work sample (M=Meets; } D=\text { Does not } \\
\text { meet) }\end{array}$ & \\
\hline 135 & W-WS2 Date & $\begin{array}{l}\text { Date of the second writing work sample. If status is met, this will be } \\
\text { the earliest date. If unmet, this will be the most recent attempt. }\end{array}$ & \\
\hline 136 & Ess Skills Ma Met & Has the Essential Skills Math requirement been met? Y / N / N/A & \\
\hline 137 & Ess Skills Ma How Met & $\begin{array}{l}\text { How the Essential Skills Math requirement was met. Possible values } \\
\text { are: } \\
\text { OSA = State Assessment } \\
\text { WS=Work Sample } \\
\text { NAT=National test } \\
\text { blank=Not yet met }\end{array}$ & \\
\hline 138 & OSAT Ma RIT & Best math assessment score & \\
\hline 139 & OSAT MA Date & Date of best math assessment & \\
\hline 140 & M-Alg WS Status & $\begin{array}{l}\text { Status of the algebra work sample (M=Meets; } D=\text { Does not meet). } \\
\text { Note that } 2 \text { math work samples are required, one each from any two } \\
\text { areas (algebra, geometry or statistics) }\end{array}$ & \\
\hline 141 & M-Alg WS Date & $\begin{array}{l}\text { Date of the algebra work sample. If status is met, this will be the } \\
\text { earliest date. If unmet, this will be the most recent attempt. }\end{array}$ & \\
\hline 142 & M-Geom WS Status & Status of the geometry work sample (M=Meets; $D=$ Does not meet). & \\
\hline 143 & M-Geom WS Date & $\begin{array}{l}\text { Date of the geometry work sample. If status is met, this will be the } \\
\text { earliest date. If unmet, this will be the most recent attempt. }\end{array}$ & \\
\hline 144 & M-Stat WS Status & Status of the statistics work sample (M=Meets; $D=$ Does not meet). & \\
\hline 145 & M-Stat WS Date & $\begin{array}{l}\text { Date of the statistics work sample. If status is met, this will be the } \\
\text { earliest date. If unmet, this will be the most recent attempt. }\end{array}$ & \\
\hline 146 & ACT - Eng Score & Highest ACT English Score & \\
\hline 147 & ACT - Math Score & Highest ACT Math Score & \\
\hline 148 & ACT - Reading Score & Highest ACT Reading Score & \\
\hline 149 & ACT - Science Score & Highest ACT Science Score & \\
\hline 150 & ACT - Composite Score & Highest ACT Composite Score & \\
\hline 151 & $\begin{array}{l}\text { ACT - Combined } \\
\text { English/Writing Score }\end{array}$ & Highest ACT Combined English/Writing Score & \\
\hline 152 & PSAT - Math Score & Highest PSAT Math Score & \\
\hline 153 & PSAT - Reading Score & Highest PSAT Reading Score & \\
\hline 154 & PSAT - Writing Score & Highest PSAT Writing Score & \\
\hline 155 & SAT - Math Score & Highest SAT Math Score & \\
\hline 156 & SAT - Verbal Score & Highest SAT Verbal Score & \\
\hline 157 & SAT - Writing Score & Highest SAT Writing Score & \\
\hline
\end{tabular}


THE EFFECTS OF AN OVERNIGHT ENVIRONMENTAL PROGRAM

Appendix C - Example District Request for Study Participation (PPS)

Portland State and Multnomah Education Service District MOU 


\title{
THE EFFECTS OF AN OVERNIGHT ENVIRONMENTAL PROGRAM
}

\author{
Appendix C - Example District Request for Study Participation (PPS)
}

MESD Contract \# - C01676

HSR Application

\author{
MEMORANDUM OF UNDERSTANDING \\ Portland State University \\ and \\ Multnomah Education Service District
}

\section{Partnership}

Portland State University (PSU) and the Multnomah Education Service District (MESD) Outdoor School program are conducting a collaborative research study on the effects of the MESD Outdoor School program. This investigation seeks to address the following questions:

- Does the Outdoor School program have an impact on students' academic achievement? If so, where are the largest gains?

- Does the impact of Outdoor School differ depending on a student's background characteristics? If so, how?

As a partner in the Outdoor School research project, Portland State University (PSU) and Multnomah Education Service District (MESD) will contribute the following resources:

\section{Multnomah Education Service District}

- Multnomah Education Service District Outdoor School will provide technology (i.e. computer, access to a secure server, Internet access, and printing capabilities), office space, and supplies.

- Multnomah Education Service District will provide access to technology service staff members who will assist in compiling, merging, and de-identifying data sets, authorized through component school district protocols.

- Provide support, guidance, and help research team gain access to school district representatives, advisory committee members, and Multnomah Education Service District employees as needed.

\section{Portland State University}

- Portland State University research team members will provide support, guidance, and access to school district representatives and Portland State University resources as needed.

- Portland State University will provide access to relevant computer programs and secure technology services to assist with data analysis.

- Portland State University research team members will provide knowledge and expertise with advanced quantitative research methods and practices to analyze data and findings.

Kelley, Hara, Basham, Prince -1/24/14 


\title{
THE EFFECTS OF AN OVERNIGHT ENVIRONMENTAL PROGRAM
}

\author{
Appendix C - Example District Request for Study Participation (PPS)
}

MESD Contract \# - C01676

HSR Application

- Portland State University will supervise the research process to ensure that it is conducted in a professional and ethical manor in-line with the highest research standards.

- Portland State University will make data requests to school districts, store data, and share results with Multnomah Education Service District and Friends of Outdoor School Foundation.

\section{Benefits}

Through their participation in this partnership, Portland State University (PSU) and Multnomah Education Service District (MESD) will receive the following benefits and recognition:

- This knowledge will further our understanding of how the Multnomah Education Service District Outdoor School program supports students within traditional educational settings.

- This research may provide documentation of the variable effects related to the length of program participation.

- Research findings will provide opportunities to inform Outdoor School program improvement.

- Research team will disseminate findings to a broad audience of education professionals, non-profits, foundations, academia, and state and local policy makers to support the case for implementation of the Outdoor School program.

- The collaborative effort of the four researchers involved in the study will be recognized in all artifacts of the study, thus benefiting the professional growth of all involved.

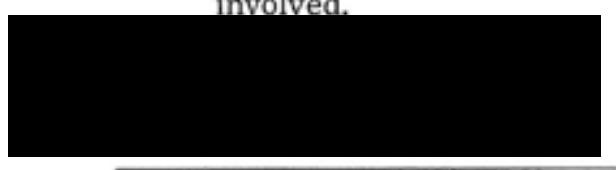

Barbara Jorgensen, Superintendent, Multnomah Education Service District

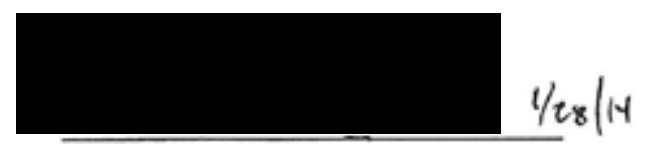

Dan Prince, Outdoor School Coordinator, Multnomah Education Service District

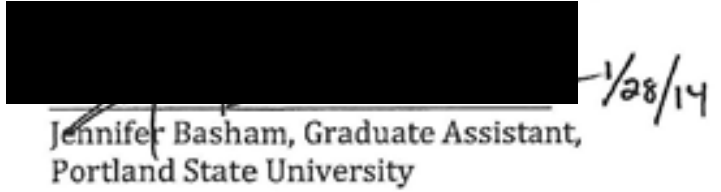

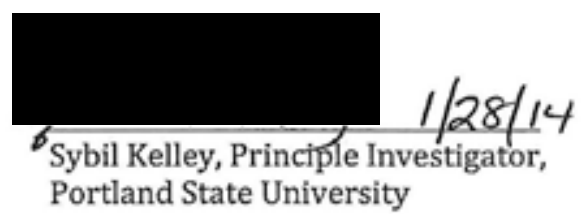

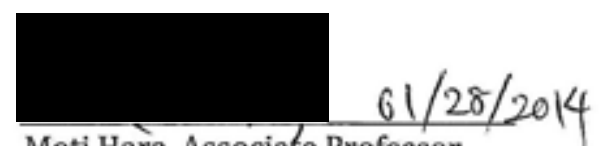

Moti Hara, Associate Professor, Portland State University 
THE EFFECTS OF AN OVERNIGHT ENVIRONMENTAL PROGRAM

Appendix C - Example District Request for Study Participation (PPS)

$\underline{\text { Researcher Training and Experience }}$

\author{
Portland State University \\ and \\ Multnomah Education Service District
}

Principal Investigator, Sybil Kelley, Assistant Professor in the Educational Leadership \& Policy Department at Portland State University has been engaged in educational research since 2000, and completed the NIH training module for research with human participants in 2004. Her research has included an in-depth study of engagement, critical thinking, and learning of $6^{\text {th }}$ grade participants, as well as research with adult participants. Additionally, PI Kelley is mid-way through the CITI training modules for researchers and IRB members, and anticipates completion by January 1, 2014.

Jennifer Basham is a graduate student within the Educational Leadership and Policy program working towards her master's thesis project. She will be working under the guidance and supervision of Drs. Sybil Kelley and Moti Hara. Jennifer has worked with the Multnomah Education Service District Outdoor School in a variety of roles from high school volunteer to Site Supervisor helping improve curriculum, support teachers, and continue building support of the program through targeted outreach.

Moti Hara, Assistant Professor within the Educational Leadership and Policy Department at Portland State University. Dr. Hara, Co-Principal Investigator, has conducted research with large-scale longitudinal data-files in educational research and public health, and was a recipient of the NIH/NIDA Pre-doctoral Research Fellowship while at the Semel Institute for Neuroscience and Human Behavior, UCLA David Geffen School of Medicine.

Daniel Prince, MS, is the Coordinator of Outdoor School Programs at Multnomah Education Service District in Portland, Oregon. His Masters degree is in Education Administration is from Portland State University, and his B.A. in Philosophy is from Whitman College. His twenty-five years in experiential, environmental education has generated a strong interest in understanding how non-formal, cocurricular learning experiences support student learning in STEM and other disciplines. 


\section{THE EFFECTS OF AN OVERNIGHT ENVIRONMENTAL PROGRAM}

Appendix C - Example District Request for Study Participation (PPS)

MESD Request for release of Attendance Records, Approval Letter, and Example Class List Form 


\title{
THE EFFECTS OF AN OVERNIGHT ENVIRONMENTAL PROGRAM
}

\section{Appendix C - Example District Request for Study Participation (PPS)}

\author{
Graduate School of Education \\ Educational Leadership \& Policy \\ Leadership for Sustainability Education \\ Post Office Box 751 \\ $503-725-8475$ fax \\ sybilkel@pdx.edu
}

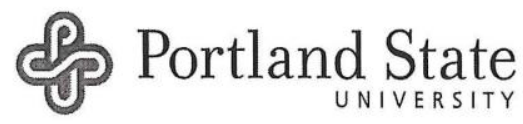

October 22, 2013

Dear Dan Prince,

This letter is to formally request the attendance records for students attending the Multnomah Education Service District Outdoor School program. The purpose of this request is to conduct a research study to understand how Outdoor School impacts students, related to the goals outlined by OEIB with a specific focus on student success, high school completion, career and college readiness, and the Essential Skills defined by the Oregon Department of Education.

We request that this data be supplied in the form of Outdoor School schedules and class lists denoting students in attendance, school, teacher, site and dates attended. Every effort will be made to ensure confidentiality and abide by the highest standard of research integrity.

Additionally, research methods in this study will be subject to successful acceptance by the PSU Human Subjects Review Committee, the governing body that ensures research conducted at PSU is ethical, neutral, and as low-risk as possible.

The requested data will be used to conduct a research study using quantitative research methods and seek to understand the impact of Outdoor School on various populations with regards to program length, how the program supports student success, and high school completion.

Thank you in advance for your anticipated cooperation in this matter. I look forward to receiving your response to this request at your earliest convenience.

Sincerely,

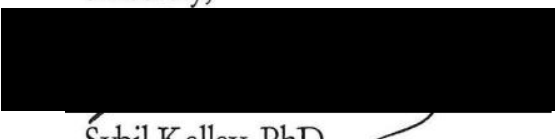

Sybil Kelley, $\mathrm{PhD}$.

Associate Professor

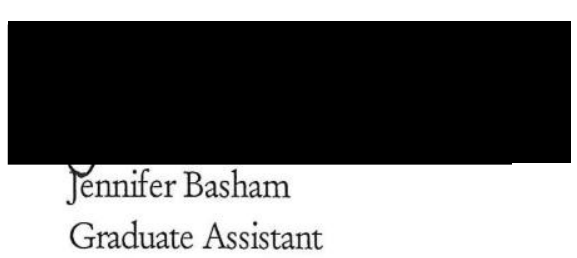


THE EFFECTS OF AN OVERNIGHT ENVIRONMENTAL PROGRAM

Appendix C - Example District Request for Study Participation (PPS)

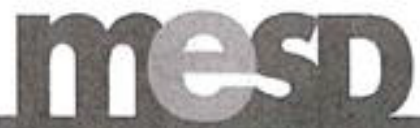

Multinomch Fducation Service District

A Regional Cooperative Opening Doors to Education

October 31,2013

Dear Sybil Kelley, $\mathrm{PhD}$. and Jennifer Basham,

MESD Outdoor School is happy to partner with Portland State University in researching how Outdoor School impacts students. Please consider this letter approval for your request of attendance records for students attending MESD Outdoor School.

Yours truly,

Daniel Prince

Coordinator, Outdoor School

Multnomah Education Service District. 


\section{THE EFFECTS OF AN OVERNIGHT ENVIRONMENTAL PROGRAM}

Appendix C - Example District Request for Study Participation (PPS)

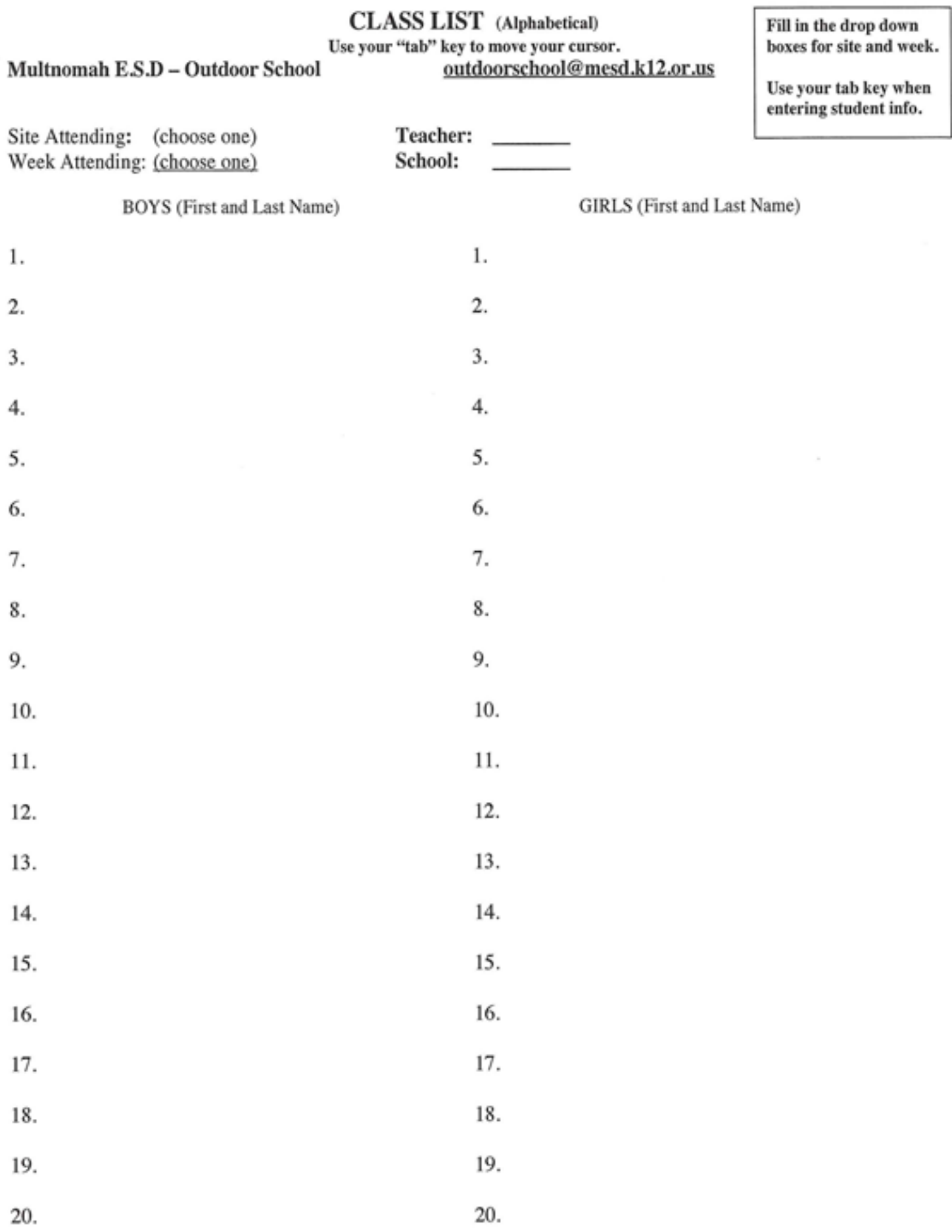


THE EFFECTS OF AN OVERNIGHT ENVIRONMENTAL PROGRAM

Appendix C - Example District Request for Study Participation (PPS)

Portland State University Human Subjects Review Approval Letter 


\title{
THE EFFECTS OF AN OVERNIGHT ENVIRONMENTAL PROGRAM
}

\author{
Appendix C - Example District Request for Study Participation (PPS)
}

\author{
Post Office Box 751 \\ Portland, Oregon 97207-0751 \\ Human Subjects Research Review Committee \\ 503-725-2227 tel \\ 503-725-8170 fax \\ hsrrc@lists.pdx.edu
}

Date: February 27, 2014

To: Sybil Kelley

From: Karen Cellarius, HSRRC Chair

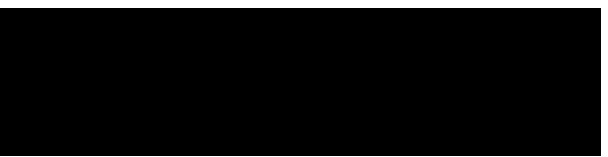

Re: $\quad$ HSRRC approval for your project titled, "The Effects of the MESD Outdoor School Program on Students' Academic Achievement, Behavior, and Attendance” HSRRC Proposal \# 142973

Review Type: Exempt, Categories 1, 4

In accordance with your request, the Human Subjects Research Review Committee has reviewed your proposal referenced above for compliance with PSU and DHHS policies and regulations covering the protection of human subjects. The Committee is satisfied that your provisions for protecting the rights and welfare of all subjects participating in the research are adequate, and your project is approved. Please note the following requirements:

Approval: You are approved to conduct this research study after receipt of this approval letter; and the research must be conducted according to the plans and protocol submitted (approved copy enclosed).

Consent: Signed consent is required from all participating school districts in this study. Consent is waived for students.

Changes to Protocol: Any changes in the proposed study, whether to procedures, survey instruments, consent forms or cover letters, must be outlined and submitted to the Committee immediately. The proposed changes cannot be implemented before they have been reviewed and approved by the Committee.

Adverse Reactions and/or Unanticipated Problems: If any adverse reactions or unanticipated problems occur as a result of this study, you are required to notify the Committee immediately. If the issue is serious, approval may be withdrawn pending an investigation by the Committee.

Completion of Study: Please notify the Committee as soon as your research has been completed. Study records, including protocols and signed consent forms for each participant, must be kept by the investigator in a secure location for three years following completion of the study (or per any requirements specified by the project's funding agency).

If you have questions or concerns, please contact the Office of Research Integrity in the PSU RSP at 503-725-2227, 1600 SW 4th Ave., Market Center Building, Suite 620. 
THE EFFECTS OF AN OVERNIGHT ENVIRONMENTAL PROGRAM

Appendix D - Portland Public School District Informed Consent 
THE EFFECTS OF AN OVERNIGHT ENVIRONMENTAL PROGRAM

Appendix D - Portland Public School District Informed Consent

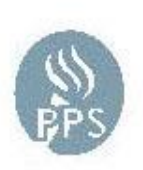

PORTLAND PUBLIC SCHOOLS

Research, Evaluation \& Assessment Department

$501 \mathrm{~N}$ Dixon Street P Portland, OR 97227

503-916-3341 Fax: 503-916-3106

wWW.pps.net.

May 12, 2014

Sybil Kelley; $\mathrm{PhD}$

Asst. Professor of Science Education \& Sustainable Systems

Leadership for Sustainability Education

Graduate Teacher Education Program

Portland State University

PO Box 715

Portland, OR 97207

Re: \#2013-14-024 The effects of the MESD Outdoor School program on student's academic achievement, behavior, and attendance

Dear Dr. Kelley:

The Portland Public Schools (PPS) Research, Evaluation \& Assessment Department has reviewed and approved your request for de-identified data in order to conduct your research entitled, The effects of the MESD Outdoor School program on student's academic achievement, behavior, and attendance. The study is consistent with Board policy and professional research practices. This project is approved for the 2013-14 school year.

I have communicated our approval of this research to Karen Finch at the MESD. This approval provides you with clearance to submit your data request to Karen. Please note that PPS will have final review of the data before releasing it and that participation in the study by the school district is voluntary. District staff and students are not obligated to participate in outside research, regardless of approval by the Research, Evaluation and Assessment Department.

Should you need to make changes to your research after this approval is granted, you must submit any changes in writing (e-mail is fine) to this department and receive additional approval for requested changes. PPS reserves the right to retract permission to continue your research at any time.

The District is interested in receiving information on the results of this study when they become available. Please submit a copy of the final report to this office. We wish you every success in this study.

Sincerely,

Karin Brown, Senior Analyst

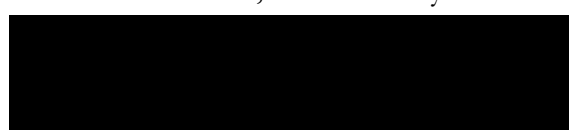

Research, Evaluation \& Assessment

Portland Public Schools

c: Karen Finch, Application Developer / Student Data Coordinator

Cascade Technology Alliance (CTA North - Multnomah ESD) 
THE EFFECTS OF AN OVERNIGHT ENVIRONMENTAL PROGRAM

Appendix E - Reynolds School District Informed Consent 
THE EFFECTS OF AN OVERNIGHT ENVIRONMENTAL PROGRAM

Appendix E - Reynolds School District Informed Consent

Graduate School of Education

Educational Leadership \& Policy

Leadership for Sustainability Education

Post Office Box $751 \quad 503-725-5976$ tel

Portland, Oregon 97207-0751 503-725-8475 fax

\section{The Portland State University Consent to Participate in Research}

Understanding the effects of the MESD Outdoor School program on student's academic achievement, behavior, and attendance.

$3 / 3 / 14$

\section{Introduction}

A collaborative research team from MESD Outdoor School and Portland State University are conducting a research study impact of the Outdoor School program on student's academic achievement, behavior, and attendance. As a representative of Reynolds School District, you are being asked to participate in the research study that is being done by Sybil Kelley who is the Principal Investigator, Moti Hara, Jennifer Basham, from the Department of Educational Leadership \& Policy, at Portland State University in Portland, Oregon and Dan Prince from the Multnomah Education Service District Outdoor School program. You are being asked to participate in this study because sixth graders in your school district have attended a partial or full week experience at Outdoor School with the Multnomah Education Service District.

This form will explain the research study, and will also explain the possible risks as well as the possible benefits to you. We encourage you to talk with your district representatives before you decide to take part in this research study. If you have any questions, please ask one of the study investigators. 
Appendix E - Reynolds School District Informed Consent

\section{What will happen if Reynolds School District agrees to participate?}

If your district approves this research, the following things will happen:

1. Your district will grant access to archival data such as Student ID numbers, state test scores, attendance, and behavior records through the MESD technology staff members for the years ranging 2006-2013. (See Appendix 2 for specific data request form)

2. MESD technology staff members will merge school district records with Multnomah Education School District Outdoor School attendance records.

3. MESD technology staff members will expunge student ID numbers and personal identifiers.

4. Researchers will receive the data sources.

5. Researchers will then analyze the unidentified data. No analysis will be conducted when student subgroups result in 10 or fewer participants to further protect the confidentiality of the participants.

6. Researchers will report the findings, and then all data will be deleted 3 years after the completion of the study. Because this research study is a secondary data analysis, there will be no direct contact with participants.

\section{Study Duration and Time Commitments}

Beyond review of the application, there will be no time commitment from your school district employees.

\section{What are the potential risks of this study? What safeguards are in place?}

The potential risks to students are minimal and would not exceed what a student within a traditional education setting would endure. The data collected for the purpose of this study will be garnered through existing data sources and all personally identifiable information will be removed prior to the data being made available to researchers. In some cases, the researchers will aggregate data within a larger demographic population if sub-groups of race or ethnicity result in a group of 10 students or less. The greatest risk to participants would be the accidental loss of confidentiality. Safeguards for this risk will be implemented by ensuring that all documents and raw data will be stored in password-protected files and servers. Furthermore, the transfer of data will be minimized by utilizing secure servers as the main storage system for electronic files, and locked cabinets for paper copies. Data accumulated and compiled for this research 
Appendix E - Reynolds School District Informed Consent

project will be protected with access given only to the principle investigators, Sybil Kelley, Moti Hara, Jennifer Basham, and Dan Prince.

For more information about risks and discomforts, ask the investigator.

\section{What are the potential benefits of this study?}

The benefits of this research will be to understand the impact of the Outdoor School program on student's academics, attendance, and behavior. This knowledge will further our understanding of how the Multnomah Education Service District Outdoor School program supports students within the traditional education settings.

Understanding how the program impacts students will provide validation for program implementation and provide valuable data to drive program improvement. There will be no direct benefit to the school districts participating in this study.

\section{How will student information be kept confidential?}

Researchers will ensure the confidentiality of all participants by adhering to various protocols for maintaining confidentiality. Digital student attendance records will be stored in secure password protected servers, to which only the researchers will hold access. Paper confidential records will be stored in locked cabinets within the Multnomah Education Service District building. Coding scripts will be stored in a password protected excel file within the secure server. All student names will be expunged from the data source prior to researchers having access to maintain the highest level of confidentiality possible. Data collected and utilized in this study will be purged 3 years after the completion of the research project.

\section{Will I be paid for taking part in this study?}

No. Your school district will not be financially compensated for participating in this study.

\section{Can I stop being in the study once I begin?}

Your school district participation in this study is completely voluntary. You have the right to choose not to participate or to withdraw your participation at any point in this study without penalty or loss of benefits to which you are otherwise entitled. 
THE EFFECTS OF AN OVERNIGHT ENVIRONMENTAL PROGRAM

Appendix E - Reynolds School District Informed Consent

\section{Whom can I call with questions or complaints about this study?}

If you have any questions, concerns or complaints at any time about the research study, Sybil Kelley, or her associates will be glad to answer them.

Sybil Kelley, Principle Investigator, Email: sybilkel@pdx.edu, Phone: 503-725-5976

Moti Hara, Assistant Professor, Email: mhara@pdx.edu, Phone: 503-725-9903

Jennifer Basham, Graduate Assistant, Email: jbasham@pdx.edu, Phone: 971-275-6269

Dan Prince, ODS Coordinator, Email: dprince@mesd.k12.or.us, Phone: 503-257-1600

\section{Whom can I call with questions about my rights as a research participant?}

If you have questions regarding your rights as a research participant, you may call the PSU Office for Research Integrity at (503) 725-2227 or 1(877) 480-4400. The ORI is the office that supports the PSU Institutional Review Board (IRB). The IRB is a group of people from PSU and the community who provide independent oversight of safety and ethical issues related to research involving human participants. For more information, you may also access the IRB website at https://sites.google.com/a/pdx.edu/research/integrity. 


\title{
THE EFFECTS OF AN OVERNIGHT ENVIRONMENTAL PROGRAM
}

\author{
Appendix E - Reynolds School District Informed Consent
}

\section{CONSENT}

You are making a decision whether to participate in this study. Your signature below indicates that you have read the information provided (or the information was read to you). By signing this consent form, you are not waiving any of your legal rights as a research participant.

You have had an opportunity to ask questions and all questions have been answered to your satisfaction. By signing this consent form, you agree to participate in this study. A copy of this consent form will be provided to you.

\section{LINOA FLORENCE}

Name of District Representative (print) Signature of District Representative

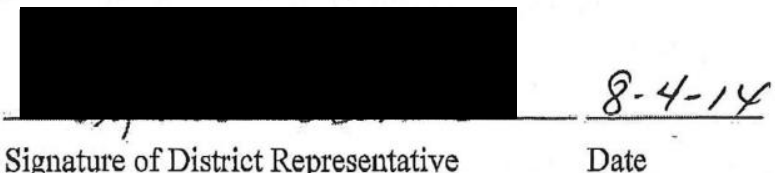
Reynolas

School District

\section{INVESTIGATOR SIGNATURE}

This research study has been explained to the participating district representative and all of his/her questions have been answered. The district representative understands the information described in this consent form and freely consents to participate.

$$
\text { Sybil Kelley }
$$

Name of Investigator/ Resedrch Team Member (type or print)

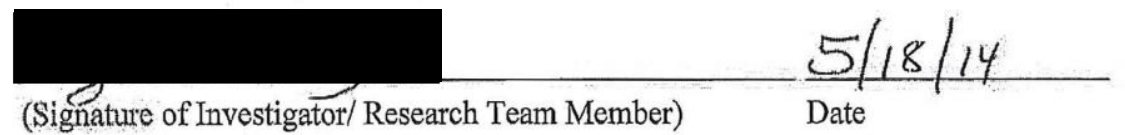


THE EFFECTS OF AN OVERNIGHT ENVIRONMENTAL PROGRAM

Appendix F - David Douglas School District Informed Consent 
THE EFFECTS OF AN OVERNIGHT ENVIRONMENTAL PROGRAM

Appendix F - David Douglas School District Informed Consent

Graduate School of Education

Educational Leadership \& Policy

Leadership for Sustainability Education

Post Office Box $751 \quad 503-725-5976$ tel

Portland, Oregon 97207-0751 503-725-8475 fax

\title{
Portland State \\ UNIVERSITY
}

\section{The Portland State University Consent to Participate in Research}

\begin{abstract}
Understanding the effects of the MESD Outdoor School program on student's academic achievement, behavior, and attendance.
\end{abstract}

$3 / 3 / 14$

\section{Introduction}

A collaborative research team from MESD Outdoor School and Portland State University are conducting a research study impact of the Outdoor School program on student's academic achievement, behavior, and attendance. As a representative of David Douglas School District, you are being asked to participate in the research study that is being done by Sybil Kelley who is the Principal Investigator, Moti Hara, Jennifer Basham, from the Department of Educational Leadership \& Policy, at Portland State University in Portland, Oregon and Dan Prince from the Multnomah Education Service District Outdoor School program. You are being asked to participate in this study because six th graders in your school district have attended a partial or full week experience at Outdoor School with the Multnomah Education Service District.

This form will explain the research study, and will also explain the possible risks as well as the possible benefits to you. We encourage you to talk with your district representatives before you decide to take part in this research study. If you have any questions, please ask one of the study investigators. 
Appendix F - David Douglas School District Informed Consent

\section{What will happen if David Douglas School District agrees to participate?}

If your district approves this research, the following things will happen:

1. Your district will grant access to archival data such as Student ID numbers, state test scores, attendance, and behavior records through the MESD technology staff members for the years ranging 2006-2013. (See Appendix 2 for specific data request form)

2. MESD technology staff members will merge school district records with Multnomah Education School District Outdoor School attendance records.

3. MESD technology staff members will expunge student ID numbers and personal identifiers.

4. Researchers will receive the data sources.

5. Researchers will then analyze the unidentified data. No analysis will be conducted when student subgroups result in 10 or fewer participants to further protect the confidentiality of the participants.

6. Researchers will report the findings, and then all data will be deleted 3 years after the completion of the study. Because this research study is a secondary data analysis, there will be no direct contact with participants.

\section{Study Duration and Time Commitments}

Beyond review of the application, there will be no time commitment from your school district employees.

\section{What are the potential risks of this study? What safeguards are in place?}

The potential risks to students are minimal and would not exceed what a student within a traditional education setting would endure. The data collected for the purpose of this study will be garnered through existing data sources and all personally identifiable information will be removed prior to the data being made available to researchers. In some cases, the researchers will aggregate data within a larger demographic population if sub-groups of race or ethnicity result in a group of 10 students or less. The greatest risk to participants would be the accidental loss of confidentiality. Safeguards for this risk will be implemented by ensuring that all documents and raw data will be stored in password-protected files and servers. Furthermore, the transfer of data will be minimized by utilizing secure servers as the main storage system for electronic files, and locked cabinets for paper copies. Data accumulated and compiled for this research 
Appendix F - David Douglas School District Informed Consent

project will be protected with access given only to the principle investigators, Sybil Kelley, Moti Hara, Jennifer Basham, and Dan Prince.

For more information about risks and discomforts, ask the investigator.

\section{What are the potential benefits of this study?}

The benefits of this research will be to understand the impact of the Outdoor School program on student's academics, attendance, and behavior. This knowledge will further our understanding of how the Multnomah Education Service District Outdoor School program supports students within the traditional education settings.

Understanding how the program impacts students will provide validation for program implementation and provide valuable data to drive program improvement. There will be no direct benefit to the school districts participating in this study.

\section{How will student information be kept confidential?}

Researchers will ensure the confidentiality of all participants by adhering to various protocols for maintaining confidentiality. Digital student attendance records will be stored in secure password protected servers, to which only the researchers will hold access. Paper confidential records will be stored in locked cabinets within the Multnomah Education Service District building. Coding scripts will be stored in a password protected excel file within the secure server. All student names will be expunged from the data source prior to researchers having access to maintain the highest level of confidentiality possible. Data collected and utilized in this study will be purged 3 years after the completion of the research project.

\section{Will I be paid for taking part in this study?}

No. Your school district will not be financially compensated for participating in this study.

\section{Can I stop being in the study once I begin?}

Your school district participation in this study is completely voluntary. You have the right to choose not to participate or to withdraw your participation at any point in this study without penalty or loss of benefits to which you are otherwise entitled. 
THE EFFECTS OF AN OVERNIGHT ENVIRONMENTAL PROGRAM

Appendix F - David Douglas School District Informed Consent

\section{Whom can I call with questions or complaints about this study?}

If you have any questions, concerns or complaints at any time about the research study, Sybil Kelley, or her associates will be glad to answer them.

Sybil Kelley, Principle Investigator, Email: sybilkel@pdx.edu, Phone: 503-725-5976

Moti Hara, Assistant Professor, Email: mhara@pdx.edu, Phone: 503-725-9903

Jennifer Basham, Graduate Assistant, Email: jbasham@pdx.edu, Phone: 971-275-6269

Dan Prince, ODS Coordinator, Email: dprince@mesd.k12.or.us, Phone: 503-257-1600

\section{Whom can I call with questions about my rights as a research participant?}

If you have questions regarding your rights as a research participant, you may call the PSU Office for Research Integrity at (503) 725-2227 or 1(877) 480-4400. The ORI is the office that supports the PSU Institutional Review Board (IRB). The IRB is a group of people from PSU and the community who provide independent oversight of safety and ethical issues related to research involving human participants. For more information, you may also access the IRB website at https://sites.google.com/a/pdx.edu/research/integrity. 


\section{THE EFFECTS OF AN OVERNIGHT ENVIRONMENTAL PROGRAM}

Appendix F - David Douglas School District Informed Consent

\section{CONSENT}

You are making a decision whether to participate in this study. Your signature below indicates that you have read the information provided (or the information was read to you). By signing this consent form, you are not waiving any of your legal rights as a research participant.

You have had an opportunity to ask questions and all questions have been answered to your satisfaction. By signing this consent form, you agree to participate in this study. A copy of this consent form will be provided to you.

Don Grotting

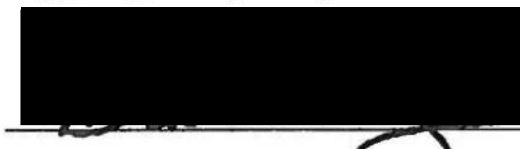

Signature of District Representat ve
May 29, 2014

Date

Name of District Representative (print)

David Douglas School District

School District

\section{INVESTIGATOR SIGNATURE}

This research study has been explained to the participating district representative and all of his/her questions have been answered. The district representative understands the information described in this consent form and freely consents to participate.

\section{Sybilkelley}

Name of Ihvestigator/ Research Team Member (type or print)

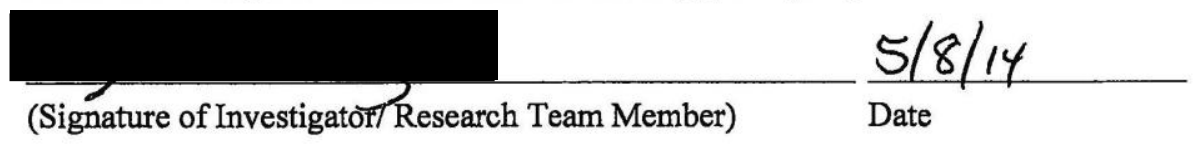


THE EFFECTS OF AN OVERNIGHT ENVIRONMENTAL PROGRAM

Appendix G - Parkrose School District Informed Consent 
Appendix G - Parkrose School District Informed Consent

Graduate School of Education

Educational Leadership \& Policy

Leadership for Sustainability Education

Post Office Box $751 \quad 503-725-5976$ tel

Portland, Oregon 97207-0751 503-725-8475 fax

\section{The Portland State University Consent to Participate in Research}

Understanding the effects of the MESD Outdoor School program on student's academic achievement, behavior, and attendance.

$3 / 3 / 14$

\section{Introduction}

A collaborative research team from MESD Outdoor School and Portland State University are conducting a research study impact of the Outdoor School program on student's academic achievement, behavior, and attendance. As a representative of Parkrose School District, you are being asked to participate in the research study that is being done by Sybil Kelley who is the Principal Investigator, Moti Hara, Jennifer Basham, from the Department of Educational Leadership \& Policy, at Portland State University in Portland, Oregon and Dan Prince from the Multnomah Education Service District Outdoor School program. You are being asked to participate in this study because sixth graders in your school district have attended a partial or full week experience at Outdoor School with the Multnomah Education Service District.

This form will explain the research study, and will also explain the possible risks as well as the possible benefits to you. We encourage you to talk with your district representatives before you decide to take part in this research study. If you have any questions, please ask one of the study investigators. 
Appendix G - Parkrose School District Informed Consent

\section{What will happen if Parkrose School District agrees to participate?}

If your district approves this research, the following things will happen:

1. Your district will grant access to archival data such as Student ID numbers, state test scores, attendance, and behavior records through the MESD technology staff members for the years ranging 2006-2013. (See Appendix 2 for specific data request form)

2. MESD technology staff members will merge school district records with Multnomah Education School District Outdoor School attendance records.

3. MESD technology staff members will expunge student ID numbers and personal identifiers.

4. Researchers will receive the data sources.

5. Researchers will then analyze the unidentified data. No analysis will be conducted when student subgroups result in 10 or fewer participants to further protect the confidentiality of the participants.

6. Researchers will report the findings, and then all data will be deleted 3 years after the completion of the study. Because this research study is a secondary data analysis, there will be no direct contact with participants.

\section{Study Duration and Time Commitments}

Beyond review of the application, there will be no time commitment from your school district employees.

\section{What are the potential risks of this study? What safeguards are in place?}

The potential risks to students are minimal and would not exceed what a student within a traditional education setting would endure. The data collected for the purpose of this study will be garnered through existing data sources and all personally identifiable information will be removed prior to the data being made available to researchers. In some cases, the researchers will aggregate data within a larger demographic population if sub-groups of race or ethnicity result in a group of 10 students or less. The greatest risk to participants would be the accidental loss of confidentiality. Safeguards for this risk will be implemented by ensuring that all documents and raw data will be stored in password-protected files and servers. Furthermore, the transfer of data will be minimized by utilizing secure servers as the main storage system for electronic files, and locked cabinets for paper copies. Data accumulated and compiled for this research 
Appendix G - Parkrose School District Informed Consent

project will be protected with access given only to the principle investigators, Sybil Kelley, Moti Hara, Jennifer Basham, and Dan Prince.

For more information about risks and discomforts, ask the investigator.

\section{What are the potential benefits of this study?}

The benefits of this research will be to understand the impact of the Outdoor School program on student's academics, attendance, and behavior. This knowledge will further our understanding of how the Multnomah Education Service District Outdoor School program supports students within the traditional education settings.

Understanding how the program impacts students will provide validation for program implementation and provide valuable data to drive program improvement. There will be no direct benefit to the school districts participating in this study.

\section{How will student information be kept confidential?}

Researchers will ensure the confidentiality of all participants by adhering to various protocols for maintaining confidentiality. Digital student attendance records will be stored in secure password protected servers, to which only the researchers will hold access. Paper confidential records will be stored in locked cabinets within the Multnomah Education Service District building. Coding scripts will be stored in a password protected excel file within the secure server. All student names will be expunged from the data source prior to researchers having access to maintain the highest level of confidentiality possible. Data collected and utilized in this study will be purged 3 years after the completion of the research project.

\section{Will I be paid for taking part in this study?}

No. Your school district will not be financially compensated for participating in this study.

\section{Can I stop being in the study once I begin?}

Your school district participation in this study is completely voluntary. You have the right to choose not to participate or to withdraw your participation at any point in this study without penalty or loss of benefits to which you are otherwise entitled. 
THE EFFECTS OF AN OVERNIGHT ENVIRONMENTAL PROGRAM

Appendix G - Parkrose School District Informed Consent

\section{Whom can I call with questions or complaints about this study?}

If you have any questions, concerns or complaints at any time about the research study, Sybil Kelley, or her associates will be glad to answer them.

Sybil Kelley, Principle Investigator, Email: sybilkel@pdx.edu, Phone: 503-725-5976

Moti Hara, Assistant Professor, Email: mhara@pdx.edu, Phone: 503-725-9903

Jennifer Basham, Graduate Assistant, Email: jbasham@pdx.edu, Phone: 971-275-6269

Dan Prince, ODS Coordinator, Email: dprince@mesd.k12.or.us, Phone: 503-257-1600

\section{Whom can I call with questions about my rights as a research participant?}

If you have questions regarding your rights as a research participant, you may call the PSU Office for Research Integrity at (503) 725-2227 or 1(877) 480-4400. The ORI is the office that supports the PSU Institutional Review Board (IRB). The IRB is a group of people from PSU and the community who provide independent oversight of safety and ethical issues related to research involving human participants. For more information, you may also access the IRB website at https://sites.google.com/a/pdx.edu/research/integrity. 


\title{
THE EFFECTS OF AN OVERNIGHT ENVIRONMENTAL PROGRAM
}

\author{
Appendix G - Parkrose School District Informed Consent
}

\section{CONSENT}

You are making a decision whether to participate in this study. Your signature below indicates that you have read the information provided (or the information was read to you). By signing this consent form, you are not waiving any of your legal rights as a research participant.

You have had an opportunity to ask questions and all questions have been answered to your satisfaction. By signing this consent form, you agree to participate in this study. A copy of this consent form will be provided to you.

\section{Christine Blouke}

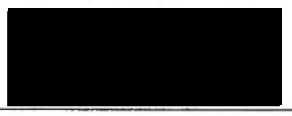

May 12, 2014

Name of District Representative (print) Signature of District Representative Parkrose

School District

\section{INVESTIGATOR SIGNATURE}

This research study has been explained to the participating district representative and all of his/her questions have been answered. The district representative understands the information described in this consent form and freely consents to participate.

\section{Sybil Kelley}

Name of Investigator/ Research Team Member (type or print)

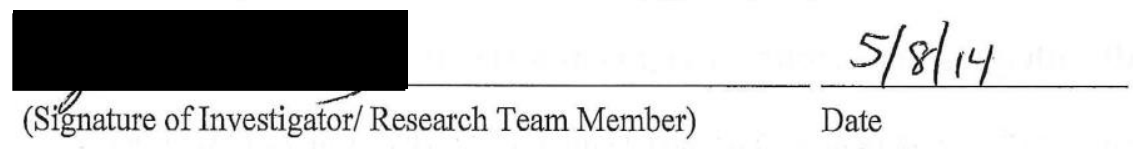

